\title{
Oligomer formation during gas-phase ozonolysis of small alkenes and enol ethers: new evidence for the central role of the Criegee Intermediate as oligomer chain unit
}

\author{
A. Sadezky ${ }^{1,2}$, R. Winterhalter ${ }^{1}$, B. Kanawati ${ }^{1}$, A. Römpp ${ }^{3}$, B. Spengler ${ }^{3}$, A. Mellouki ${ }^{2}$, G. Le Bras ${ }^{2}$, P. Chaimbault ${ }^{4}$, \\ and G. K. Moortgat ${ }^{1}$ \\ ${ }^{1}$ Max-Planck-Institute for Chemistry, Atmospheric Chemistry Department, P.O. Box 3060, 55020 Mainz, Germany \\ ${ }^{2}$ Institut de Combustion Aérothermique Réactivité et Environnement, CNRS, 1C Avenue de la Recherche Scientifique, 45071 \\ Orléans Cedex 2, France \\ ${ }^{3}$ Institut für Anorganische und Analytische Chemie, Justus-Liebig-Universität, 35392 Giessen, Germany \\ ${ }^{4}$ Institut de Chimie Organique et Analytique (ICOA), CNRS FR 2708, UMR 6005, Université d'Orléans, BP 6759, 45067 \\ Orléans Cédex 2, France
}

Received: 6 August 2007 - Published in Atmos. Chem. Phys. Discuss.: 4 October 2007

Revised: 26 March 2008 - Accepted: 9 April 2008 - Published: 21 May 2008

\begin{abstract}
An important fraction of secondary organic aerosol (SOA) formed by atmospheric oxidation of diverse volatile organic compounds (VOC) has recently been shown to consist of high-molecular weight oligomeric species. In our previous study (Sadezky et al., 2006), we reported the identification and characterization of oligomers as main constituents of SOA from gas-phase ozonolysis of small enol ethers. These oligomers contained repeated chain units of the same chemical composition as the main Criegee Intermediates $(\mathrm{CI})$ formed during the ozonolysis reaction, which were $\mathrm{CH}_{2} \mathrm{O}_{2}$ (mass 46) for alkyl vinyl ethers (AVE) and $\mathrm{C}_{2} \mathrm{H}_{4} \mathrm{O}_{2}$ (mass 60) for ethyl propenyl ether (EPE). In the present work, we extend our previous study to another enol ether (ethyl butenyl ether EBE) and a variety of structurally related small alkenes (trans-3-hexene, trans-4-octene and 2,3dimethyl-2-butene).

Experiments have been carried out in a 5701 spherical glass reactor at atmospheric conditions in the absence of seed aerosol. SOA formation was measured by a scanning mobility particle sizer (SMPS). SOA filter samples were collected and chemically characterized off-line by ESI(+)/TOF MS and ESI(+)/TOF MS/MS, and elemental compositions were determined by ESI(+)/FTICR MS and ESI(+)/FTICR MS/MS. The results for all investigated unsaturated compounds are in excellent agreement with the observations of
\end{abstract}

Correspondence to: G. K. Moortgat (moo@mpch-mainz.mpg.de) our previous study. Analysis of the collected SOA filter samples reveal the presence of oligomeric compounds in the mass range 200 to $800 \mathrm{u}$ as major constituents. The repeated chain units of these oligomers are shown to systematically have the same chemical composition as the respective main Criegee Intermediate (CI) formed during ozonolysis of the unsaturated compounds, which is $\mathrm{C}_{3} \mathrm{H}_{6} \mathrm{O}_{2}$ (mass 74) for ethyl butenyl ether (EBE), trans-3-hexene, and 2,3-dimethyl2-butene, and $\mathrm{C}_{4} \mathrm{H}_{8} \mathrm{O}_{2}$ (mass 88 ) for trans-4-octene. Analogous fragmentation pathways among the oligomers formed by gas-phase ozonolysis of the different alkenes and enol ethers in our present and previous study, characterized by successive losses of the respective CI-like chain unit as a neutral fragment, indicate a similar principal structure. In this work, we confirm the basic structure of a linear oligoperoxide $-[\mathrm{CH}(\mathrm{R})-\mathrm{O}-\mathrm{O}]_{n}$ - for all detected oligomers, with the repeated chain unit $\mathrm{CH}(\mathrm{R}) \mathrm{OO}$ corresponding to the respective major CI. The elemental compositions of parent ions, fragment ions and fragmented neutrals determined by accurate mass measurements with the FTICR technique allow us to assign a complete structure to the oligomer molecules. We suggest that the formation of the oligoperoxidic chain units occurs through a new gas-phase reaction mechanism observed for the first time in our present work, which involves the addition of stabilized CI to organic peroxy radicals. Furthermore, copolymerization of CI simultaneously formed in the gas phase from two different unsaturated compounds is shown to occur during the ozonolysis of a mixture

Published by Copernicus Publications on behalf of the European Geosciences Union. 
of trans-3-hexene and ethyl vinyl ether (EVE), leading to formation of oligomers with mixed chain units $\mathrm{C}_{3} \mathrm{H}_{6} \mathrm{O}_{2}$ (mass 74) and $\mathrm{CH}_{2} \mathrm{O}_{2}$ (mass 46). We therefore suggest oligoperoxide formation by repeated peroxy radical-stabilized CI addition to be a general reaction pathway of small stabilized CI in the gas phase, which represents an alternative way to highmolecular products and thus contributes to SOA formation.

\section{Introduction}

Organic material accounts for a substantial fraction of atmospheric fine particular matter that affects the global climate by direct and indirect effects as well as human health (Pöschl, 2005, and references therein). Secondary organic aerosol (SOA) is formed by gas-to-particle conversion of products of the tropospheric oxidation of volatile organic compounds (VOC), and its global formation is estimated to range from 12 to $70 \mathrm{Tg}^{-1}$ (Kanakidou et al., 2005, and references therein). Understanding the chemical composition and formation processes of SOA is required for a quantitative assessment of its production, properties and environmental effects (Fuzzi et al., 2006).

An important fraction of organic aerosol consists of highmolecular weight organic species, as have shown several studies of a wide range of VOC oxidation reactions. Most studies suggest that oligomerization takes place through heterogeneous condensation reactions of more volatile reaction products on the surface and within the bulk of aerosol particles, producing stable oligomeric compounds. Such reactions are aldol condensation and gem-diol formation (Gao et al., 2004; Tolocka et al., 2004), acid dehydration (Hamilton et al., 2006; Gao et al., 2004) and esterification (Hamilton et al., 2006; Surratt et al., 2006). Identified monomers were typical low-volatile reaction products formed during gasphase ozonolysis of cycloalkenes, such as multifunctional acids and diacids (Hamilton et al., 2006; Gao et al., 2004) and 2-methylglyceric acid formed during photooxidation of isoprene in the presence of high $\mathrm{NO}_{\mathrm{x}}$-concentrations (Surratt et al., 2006). Aldol and gem-diol condensation reactions have been reported to be significantly enhanced by acidic seed particles providing acid catalysis (Gao et al., 2004; Tolocka et al., 2004). Moreover, oligomer formation was detected during dark ozonolysis of $\alpha$-pinene by high-resolution FTICR MS (Reinhardt et al., 2007), and during photooxidation of 1,3,5-trimethylbenzene and $\alpha$-pinene by on-line aerosol time-of-flight (ATOF) mass spectrometry (Gross et al., 2006) and off-line matrix-assisted laser desorption mass spectrometry (Gross et al., 2006; Kalberer et al., 2004). Kalberer et al. (2004) attributed the oligomers observed during photooxidation of 1,3,5-trimethylbenzene to hydration-condensation reactions involving the main reaction products of aromatic photooxidation, glyoxal and methylglyoxal. These conden- sation processes are described as part of SOA aging processes taking place over several hours after SOA formation.

Furthermore, a variety of high-molecular peroxidic compounds mainly formed as reaction products of stabilized Criegee Intermediates have been identified as important SOA constituents. Among those products are secondary ozonides, $\alpha$-acyloxyalkyl hydroperoxides, cyclic geminal diperoxides, peroxyhemiacetals and diacyl peroxides (Zahardis and Petrucci, 2007; Mochida et al., 2006; Reynolds et al., 2006; Tolocka et al., 2006; Zahardis et al., 2006, 2005; Docherty et al., 2005; Dreyfus et al., 2005; Ziemann, 2003, 2002). Initial unsaturated compounds are either monoterpenes and cyclic alkenes consisting of six to ten carbon atoms (Tolocka et al., 2006; Docherty et al., 2005; Ziemann, 2003, 2002), cholesterol (Dreyfus et al., 2005) or the linear C18 oleic acid and methyl oleate (Zahardis and Petrucci, 2007; Mochida et al., 2006; Reynolds et al., 2006; Zahardis et al., 2006, 2005). Formation reactions leading to those highmolecular peroxidic compounds were partly suggested to take place in the liquid phase within the aerosol particles or heterogeneously. Furthermore, formation of oligomers from peroxidic reactions products of oleic acid and cholesterol ozonolysis was reported to proceed via their additional free carboxylic acid and carbonyl functionalities, which react with other, eventually multifunctional Criegee Intermediates (Zahardis and Petrucci, 2007; Zahardis et al., 2006; Reynolds et al., 2006; Dreyfus et al., 2005).

Other suggested pathways leading to oligomer formation in organic atmospheric aerosol involve aqueous-phase reactions of pyruvic acid, a product of the atmospheric oxidation of isoprene, initiated by $\mathrm{OH}$ radicals (Altieri et al., 2006) or photolysis (Guzman et al., 2006) within cloud droplets. Recently, formation of higher-molecular weight species was also observed for photooxidation and ozonolysis of tertiary alkylamines (Murphy et al., 2007).

In our recent study (Sadezky et al., 2006) we reported the discovery of oligomeric compounds by chemical analysis of secondary organic aerosol formed during ozonolysis of enol ethers using the off-line ESI/MS-TOF technique. These oligomers were found to consist of repetitive chain units, which have the same elementary compositions as the main Criegee Intermediates (CI) formed from these ozonolysis reactions: $\mathrm{CH}_{2} \mathrm{O}_{2}\left(=\mathrm{CH}_{2} \mathrm{OO}\right.$ for $\left.\mathrm{C}_{1}-\mathrm{CI}\right)$ of mass 46 for the alkyl vinyl ethers (AVE) and $\mathrm{C}_{2} \mathrm{H}_{4} \mathrm{O}_{2}\left(=\mathrm{CH}_{3} \mathrm{CHOO}\right.$ for $\mathrm{C}_{2}-$ $\mathrm{CI})$ of mass 60 for ethyl propenyl ether (EPE). It is proposed that these oligomers have the following basic structure of an oligoperoxide, $-[\mathrm{CH}(\mathrm{R})-\mathrm{O}-\mathrm{O}]_{n}-$, where $\mathrm{R}=\mathrm{H}$ for the AVE and $\mathrm{R}=\mathrm{CH}_{3}$ for the EPE. We suggested a new pathway for secondary organic aerosol and oligomer formation involving gas-phase reactions involving stabilized CI, which lead to formation of oligoperoxidic chains carrying mostly three to four CI-like chain units.

Our present work is aimed at investigating the possibility that the correlation between the structure of the main Criegee Intermediate formed during alkene ozonolysis and the 


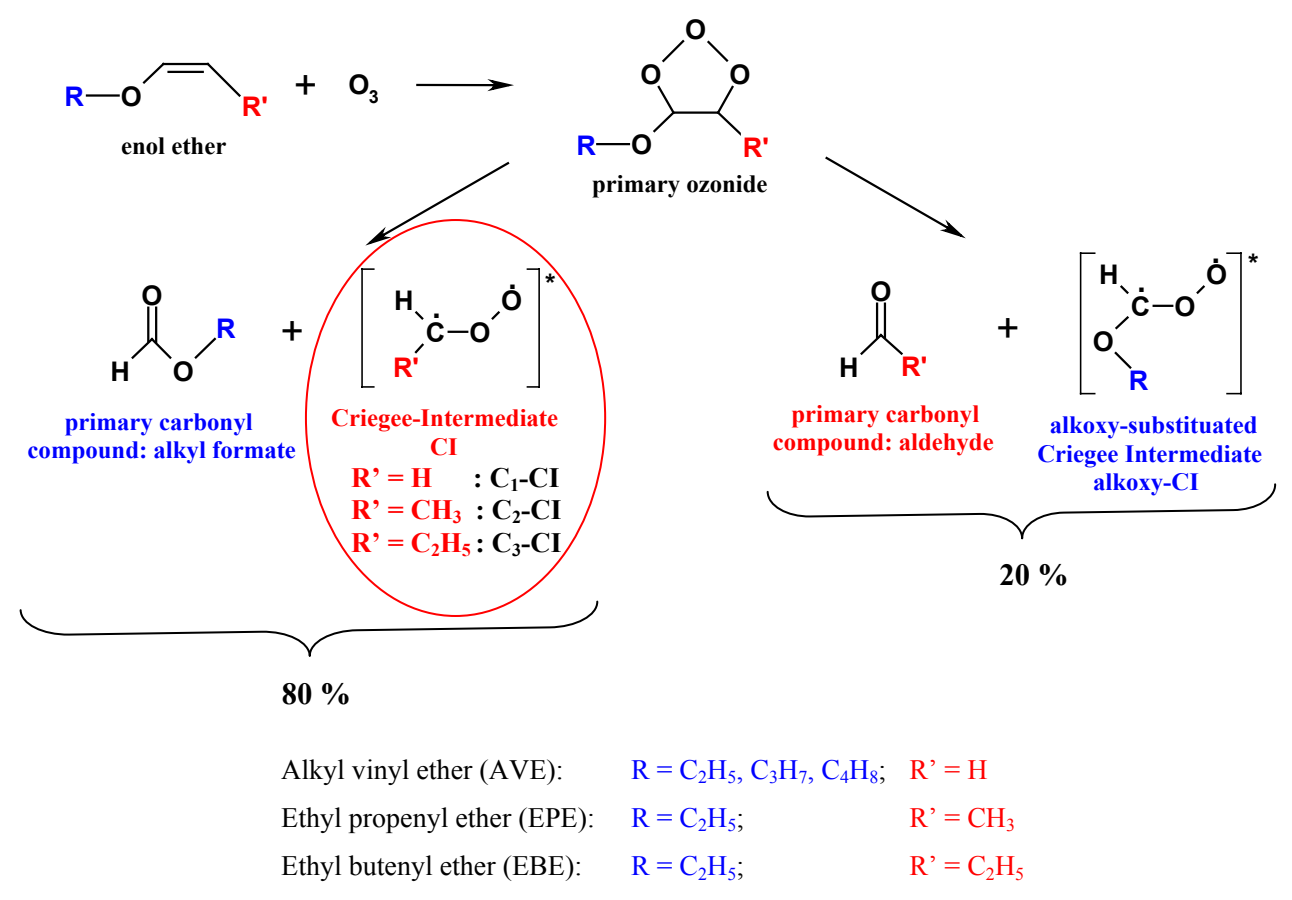

(a)

Fig. 1. General mechanism of the gas-phase ozonolysis of enol ethers and symmetric alkenes (a) Enol ethers.

composition of formed SOA and oligomers described in our previous work (Sadezky et al., 2006) might apply to a wider range of unsaturated compounds. We therefore extend our previous study to a wider variety of small unsaturated compounds, among which are another enol ether, ethyl butenyl ether $\left(\mathrm{EBE}, \mathrm{C}_{2} \mathrm{H}_{5} \mathrm{OCH}=\mathrm{CHC}_{2} \mathrm{H}_{5}\right)$, and three symmetric hydrocarbon alkenes, trans-3-hexene $\left(\mathrm{C}_{2} \mathrm{H}_{5} \mathrm{CH}=\mathrm{CHC}_{2} \mathrm{H}_{5}\right)$, 2,3-dimethyl-2-butene $\left(\left(\mathrm{CH}_{3}\right)_{2} \mathrm{C}=\mathrm{C}\left(\mathrm{CH}_{3}\right)_{2}\right)$, and trans-4octene $\left(\mathrm{C}_{3} \mathrm{H}_{7} \mathrm{CH}=\mathrm{CHC}_{3} \mathrm{H}_{7}\right)$. A gas-phase ozonolysis experiment of a mixture of ethyl vinyl ether $\left(\mathrm{EVE}, \mathrm{C}_{2} \mathrm{H}_{5} \mathrm{O}\right.$ $\left.\mathrm{CH}=\mathrm{CH}_{2}\right)$ and trans-3-hexene $\left(\mathrm{C}_{2} \mathrm{H}_{5} \mathrm{CH}=\mathrm{CHC}_{2} \mathrm{H}_{5}\right)$ was also performed in order to investigate a possible formation of mixed oligomers that might contain combinations of chain units corresponding to the main CI formed during both reactions. Gas-phase ozonolysis experiments have been performed in a laboratory-reaction chamber under experimental conditions similar to those of Sadezky et al. (2006). SOA formed during the reactions have been observed by a SMPS system and chemically characterized by a hybrid ESI(+)/QTOF and chemical composition was confirmed by accurate mass measurements with an ESI Fourier Transform Ion cyclotron resonance (FTICR) mass spectrometer. FTICR MS offers ultrahigh resolution and high sensitivity for the characterization of complex samples (e.g. Römpp et al., 2005).

\section{Experimental}

Experiments in the laboratory were performed in a 570-1 spherical glass reactor at room temperature in synthetic air at a total pressure of 730 Torr. A detailed description of this setup has been described in earlier publications (Neeb et al., 1998; Winterhalter et al., 2000). Ozone was produced by a mercury pen-ray lamp inside the reactor, prior to the addition of the mixture of the unsaturated compound and synthetic air (reaction start). The concentrations of reactants and reaction products were followed by Fourier Transform infrared spectroscopy (FTIR). The aerosol concentration and size distribution was monitored with a scanning mobility particle sizer (SMPS, TSI 3936) and provides information of the total SOA mass $\mathrm{M}_{0}$. The SMPS consists of an electrostatic classifier (TSI 3080) with a long differential mobility analyzer, (LDMA; TSI 3081) and an ultrafine condensation particle counter (CPC; TSI 3025A) as detector.

Experiments were performed with initial ozone mixing ratios of $8 \mathrm{ppm}$, and enol ether and alkene mixing ratios of $15 \mathrm{ppm}$. For simultaneous ozonolysis of EVE and trans-3hexene, initial mixing ratios were $8 \mathrm{ppm}$ of ozone, $8 \mathrm{ppm}$ of EVE and 12 ppm of trans-3-hexene. In order to prevent reactions of vinyl ethers with $\mathrm{OH}$ radicals, which are known to be generated during the ozonolysis of alkenes (Finlayson et al., 1972), cyclohexane (excess, 300 ppm) was added in 


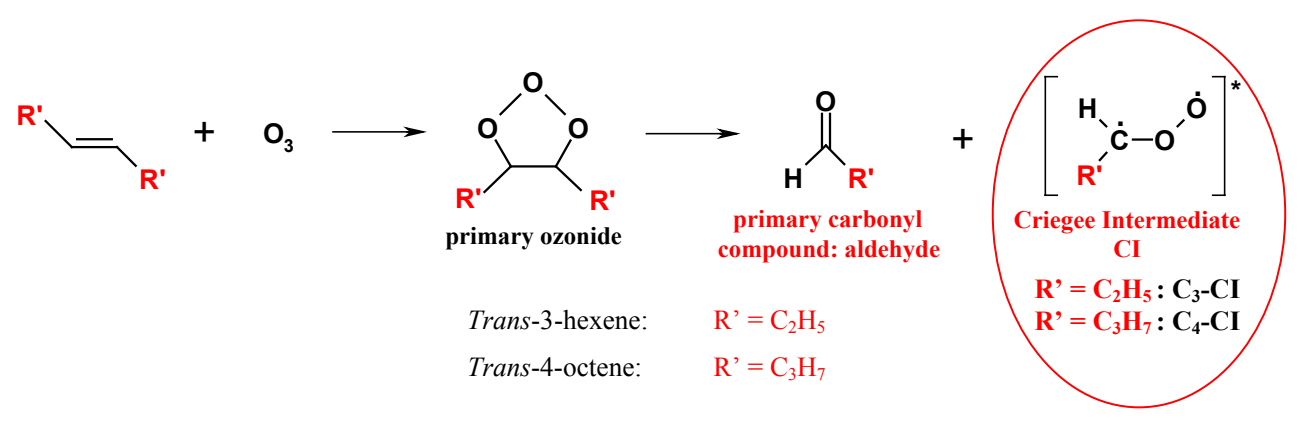

(b)

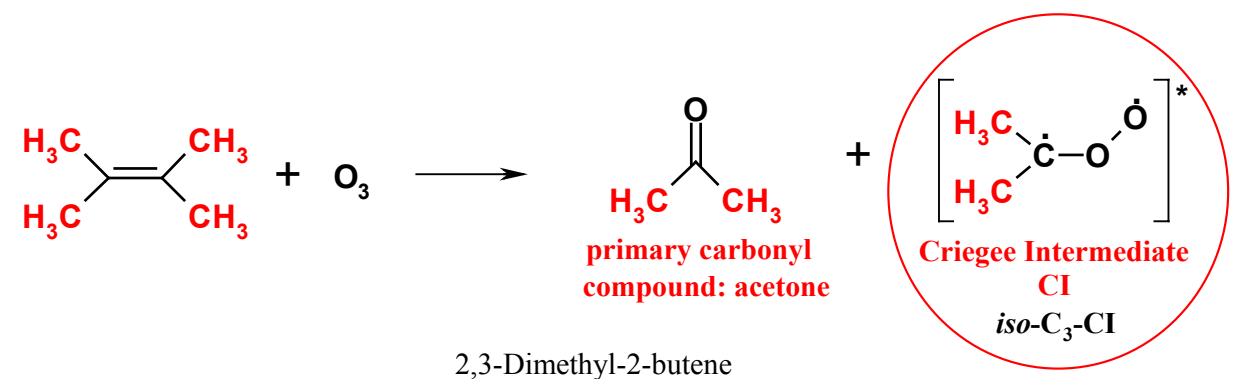

(c)

Fig. 1. General mechanism of the gas-phase ozonolysis of enol ethers and symmetric alkenes (b) Trans-3-hexene and trans-4-octene. (c) 2,3-Dimethyl-2-butene.

some experiments. All chemicals were commercially available (purity $>95 \%$ ) and used without further purification.

The aerosol formed in the laboratory experiments was collected during 20-25 min on Teflon (PTFE) filters ( $45 \mathrm{~mm}$ diameter, $0.45 \mu \mathrm{m}$ pore size), using a flow rate of $141 \mathrm{~min}^{-1}$. After collection the filters were extracted in a $7 \mathrm{~cm}^{3}$ glass flask with $3 \mathrm{ml}$ pure methanol (HPLC grade), and stored at $-20^{\circ} \mathrm{C}$ until analysis. $\mathrm{LiCl}$ solution was added to selected samples in order to study the formation of metal cation adducts. The resulting $\mathrm{Li}^{+}$ion concentration in these samples was about $0.1 \mathrm{mg} / \mathrm{ml}$.

Chemical constituents were detected by a hybrid mass spectrometer (quadrupole and time-of-flight) QSTAR (Applied Biosystems MDS SCIEX) with an electrospray ion source. The extraction solution was directly injected (30 $\mu 1 / \mathrm{min})$. The electrospray ion source (TurboIonSpray) was operated in the positive mode at $400^{\circ} \mathrm{C}$ and an ionization voltage of $+3.4 \mathrm{kV}$. The declustering potential was 0 to $+30 \mathrm{~V}$, and the focussing potential (focus ring) was $+100 \mathrm{~V}$. For tandem Q-TOF experiments, the collision energy was between 10 and $30 \mathrm{eV}$ with $\mathrm{CAD}$ (collision gas) set to 2 . Instrument control, spectra treatment and calculations of elemental compositions were done with the software Analyst (Applied Biosystems MDS SCIEX). Moreover, the elemental composition of the analytes was determined by nanoelectrospray
Fourier transform ion cyclotron resonance (FTICR) mass spectrometery. The instrument used was a combined linear ion trap and FTICR mass spectrometer (LTQ FT, Thermo Fisher Scientific, Bremen, Germany). The sample was introduced by a nanospray source using gold-coated fused-silica emitters (New Objective, Woburn, MA, USA) at an ionization potential of $+1 \mathrm{kV}$. Data analysis was done with the Xcalibur 2.0 software (Thermo Electron, Bremen, Germany). The mass deviation of the FTICR measurements are usually well below $2 \mathrm{ppm}$.

\section{Results and discussion}

\subsection{Gas phase reaction mechanisms}

\subsubsection{Enol ethers}

The general mechanism of the ozonolysis of enol ethers is displayed in Fig. 1a. The initial product formed is the primary ozonide (1,2,3-trioxolane), which is unstable and decomposes into a carbonyl oxide, called the Criegee intermediate (CI), and a primary carbonyl compound. The ozonolysis of enol ether molecules produces CIs of the type $\mathrm{CH}_{2} \mathrm{OO}\left(\mathrm{C}_{1}\right.$-CI, R'=H) for the alkyl vinyl ethers (AVE), $\mathrm{CH}_{3} \mathrm{CHOO}\left(\mathrm{C}_{2}-\mathrm{CI}, \mathrm{R}^{\prime}=\mathrm{CH}_{3}\right)$ for ethyl propenyl ether $(\mathrm{EPE})$, 


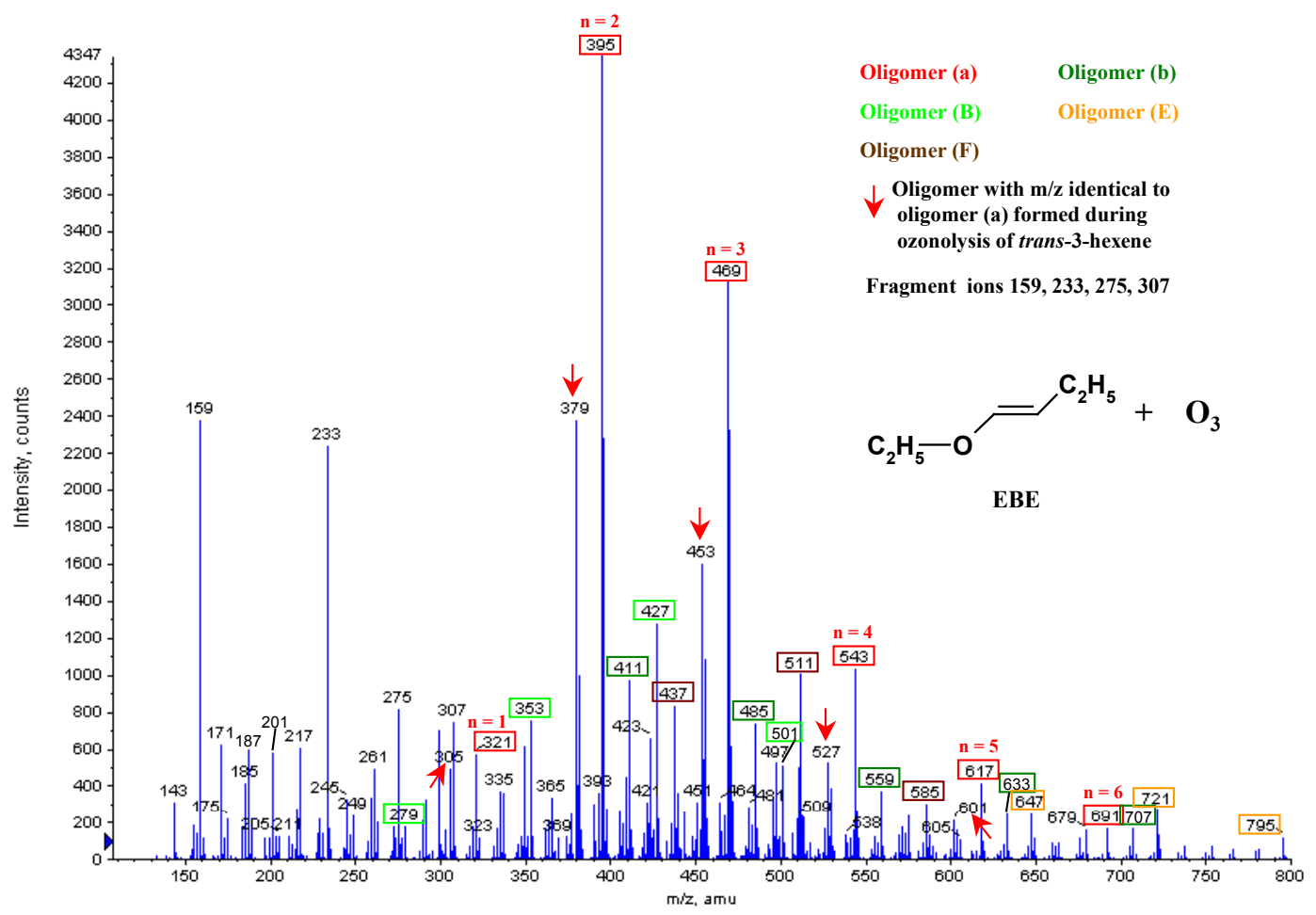

Fig. 2a. ESI(+)/TOF MS mass spectrum of SOA formed during the gas phase ozonolysis of EBE (initial mixing ratios: 8 ppm ozone, 15 ppm EBE).

and $\mathrm{C}_{2} \mathrm{H}_{5} \mathrm{CHOO}\left(\mathrm{C}_{3}-\mathrm{CI}, \mathrm{R}^{\prime}=\mathrm{C}_{2} \mathrm{H}_{5}\right)$ for ethyl butenyl ether, together with ROCHOO (alkoxy-substituted CI).

The corresponding primary carbonyl compounds consist of an alkyl formate $\mathrm{ROC}(\mathrm{O}) \mathrm{H}$ and formaldehyde (AVE, $\left.\mathrm{R}^{\prime}=\mathrm{H}\right)$, acetaldehyde $\left(\mathrm{EPE}, \mathrm{R}^{\prime}=\mathrm{CH}_{3}\right)$ or propanal $(\mathrm{EBE}$, $\mathrm{R}^{\prime}=\mathrm{C}_{2} \mathrm{H}_{5}$ ).

Previous studies of the gas-phase ozonolyses of ethyl vinyl ether $\left(\mathrm{EVE}, \mathrm{C}_{2} \mathrm{H}_{5} \mathrm{O}-\mathrm{CH}=\mathrm{CH}_{2}\right)$ and ethyl propenyl ether (EPE, $\mathrm{C}_{2} \mathrm{H}_{5} \mathrm{O}-\mathrm{CH}=\mathrm{CHCH}_{3}$ ) by FTIR spectroscopy showed that the branching ratios of the splitting of the primary ozonide into both pathways was $(71 \pm 13) \%$ for the "ethyl formate $+\mathrm{C}_{1}$-CI" channel for EVE, and $(83 \pm 13) \%$ for the "ethyl formate $+\mathrm{C}_{2}$-CI" channel for EPE (Sadezky, 2005). In this work, the branching ratio for the "ethyl formate $+\mathrm{C}_{3}$ CI" channel during ozonolysis of EBE was also determined to be close to $80 \%$.

\subsubsection{Symmetric alkenes}

Symmetric alkenes form only one type of primary carbonyl compound and Criegee Intermediate upon their reaction with ozone (Fig. 1b). The symmetric alkene trans-3-hexene therefore produces only $\mathrm{CIs}$ of the type $\mathrm{C}_{2} \mathrm{H}_{5} \mathrm{CHOO}\left(\mathrm{C}_{3}-\mathrm{CI}\right.$, $\mathrm{R}^{\prime}=\mathrm{C}_{2} \mathrm{H}_{5}$ ), which is also the major CI formed during ozonolysis of ethyl butenyl ether (EBE). Trans-4-octene forms the analogous $\mathrm{CIs}$ of the type $\mathrm{C}_{3} \mathrm{H}_{7} \mathrm{CHOO}\left(\mathrm{C}_{4}-\mathrm{CI}, \mathrm{R}^{\prime}=\mathrm{C}_{3} \mathrm{H}_{7}\right)$.
The primary carbonyl compounds simultaneously formed are the corresponding aldehydes propanal (trans-3-hexene, $\mathrm{R}^{\prime}=\mathrm{C}_{2} \mathrm{H}_{5}$ ) and butanal (trans-4-octene, $\mathrm{R}^{\prime}=\mathrm{C}_{3} \mathrm{H}_{7}$ ).

2,3-Dimethyl-2-butene produces $\mathrm{CIs}$ of the type $\left(\mathrm{CH}_{3}\right)_{2} \mathrm{COO}$ (iso- $\mathrm{C}_{3}-\mathrm{CI}$ ), which is an isomer of the $\mathrm{C}_{3}$-CI formed from the ozonolyses of trans-3-hexene and EBE. The corresponding primary carbonyl compound is acetone (Fig. 1c).

The CI formed from the decomposition of the primary ozonide are formed in excited states, which then either decompose into various products or become collisionally stabilized.

About $50-60 \%$ of the excited $\mathrm{C}_{1}$-CI are stabilized, while the yields of stabilized $\mathrm{C}_{2}$-CI and $\mathrm{C}_{3}$-CI are estimated to be between 20 and $40 \%$ per reacted alkene or enol ether (Sadezky, 2005; Kroll et al., 2002). The stabilization rate of the excited iso-C $_{3}$-CI, however, is very low, as this type of CI decomposes by nearly $100 \%$ via the hydroperoxide channel (e.g. Rickard et al., 1999).

\subsection{Formation of secondary organic aerosol (SOA)}

Total SOA masses $\mathrm{M}_{0}\left(\mu \mathrm{g} / \mathrm{m}^{3}\right)$ measured by SMPS after completion of the reaction, before the beginning of the filter sampling, are given in Table 1. Initial mixing ratios of reactants and of cyclohexane $\left(\mathrm{C}_{6} \mathrm{H}_{12}\right)$ added as $\mathrm{OH}$ scavenger, 


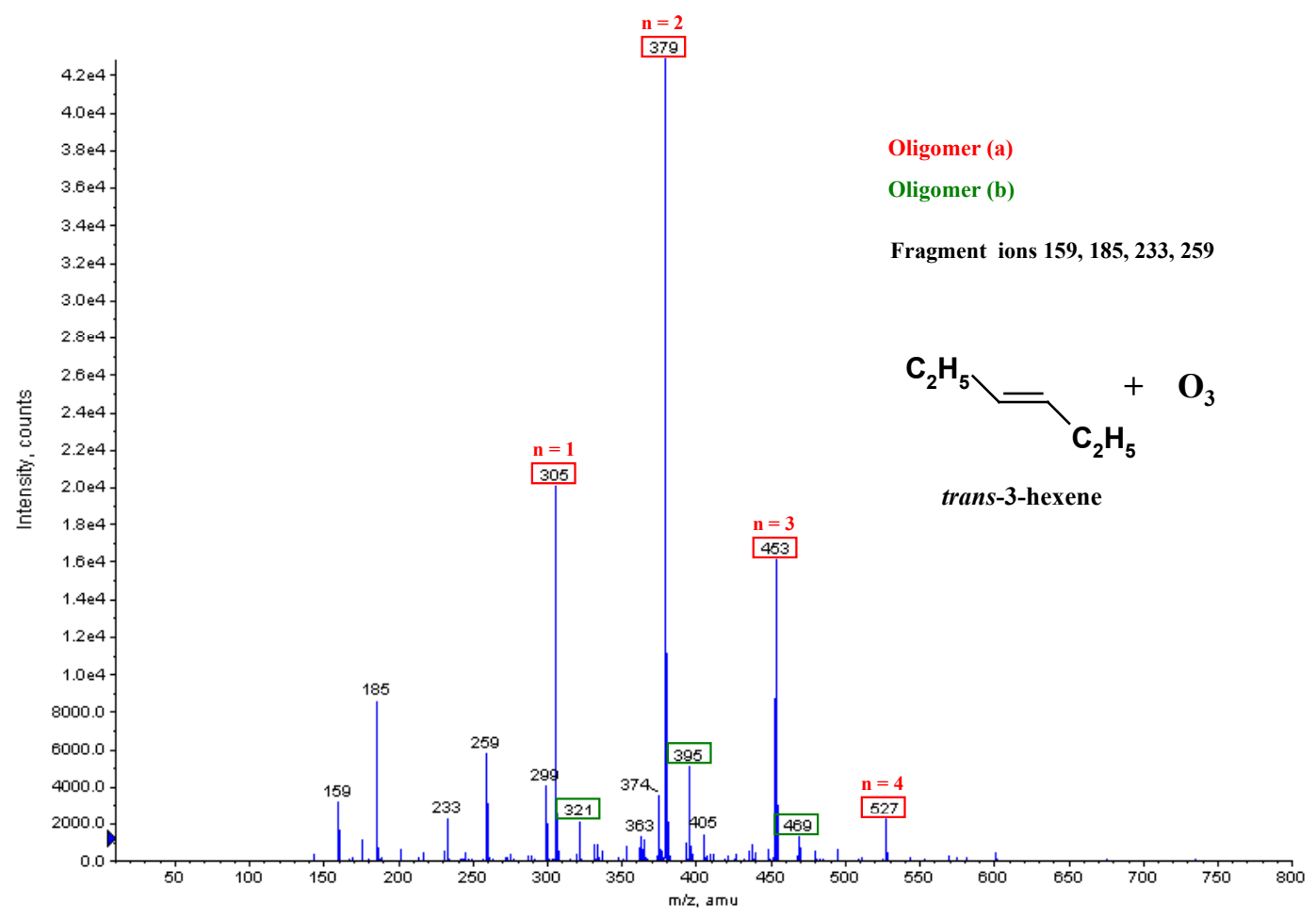

Fig. 2b. ESI(+)/TOF MS mass spectrum of SOA formed during the gas phase ozonolysis of trans-3-hexene (initial mixing ratios: 8 ppm ozone, 15 ppm trans-3-hexene).

Table 1. Total SOA masses $\mathrm{M}_{0}\left(\mu \mathrm{g} / \mathrm{m}^{3}\right)$ formed, initial mixing ratios of reactants and cyclohexane $\left(\mathrm{C}_{6} \mathrm{H}_{12}\right)$, and types of major $\mathrm{CI}$ formed in the gas-phase ozonolysis reactions of the unsaturated compounds studied in this work.

\begin{tabular}{|c|c|c|c|c|c|}
\hline Alkene & $\begin{array}{l}{[\text { alkene }]_{0}} \\
{[\mathrm{ppm}]}\end{array}$ & $\begin{array}{l}\text { [ozone }]_{0} \\
{[\mathrm{ppm}]}\end{array}$ & $\begin{array}{l}{\left[\mathrm{C}_{6} \mathrm{H}_{12}\right]_{0}} \\
{[\mathrm{ppm}]}\end{array}$ & $\begin{array}{l}\text { Type of } \\
\text { CI }\end{array}$ & $\begin{array}{l}\mathrm{M}_{0}(\mathrm{SOA}) \\
{\left[\mu \mathrm{g} / \mathrm{m}^{3}\right]}\end{array}$ \\
\hline $\mathrm{EBE}\left(\mathrm{C}_{2} \mathrm{H}_{5} \mathrm{O}-\mathrm{CH}=\mathrm{CHC}_{2} \mathrm{H}_{5}\right)$ & 15 & 8 & - & $\mathrm{C}_{3}-\mathrm{CI}$ & 250 \\
\hline trans-3-hexene $\left(\mathrm{C}_{2} \mathrm{H}_{5} \mathrm{CH}=\mathrm{CHC}_{2} \mathrm{H}_{5}\right)$ & 15 & 8 & - & $\mathrm{C}_{3}-\mathrm{CI}$ & 160 \\
\hline " $"$ & 15 & 8 & 300 & $\mathrm{C}_{3}-\mathrm{CI}$ & 400 \\
\hline trans-4-octene $\left(\mathrm{C}_{3} \mathrm{H}_{7} \mathrm{CH}=\mathrm{CHC}_{3} \mathrm{H}_{7}\right)$ & 15 & 8 & - & $\mathrm{C}_{4}-\mathrm{CI}$ & 300 \\
\hline 2,3-dimethyl-2-butene $\left(\left(\mathrm{CH}_{3}\right)_{2} \mathrm{C}=\mathrm{C}\left(\mathrm{CH}_{3}\right)_{2}\right)$ & 15 & 8 & 300 & iso- $\mathrm{C}_{3}-\mathrm{CI}$ & 40 \\
\hline " & 15 & 8 & - & iso- $\mathrm{C}_{3}-\mathrm{CI}$ & 3 \\
\hline $\mathrm{EVE}\left(\mathrm{C}_{2} \mathrm{H}_{5} \mathrm{O}-\mathrm{CH}=\mathrm{CH}_{2}\right)$ & 6 & 8 & - & $\mathrm{C}_{1}$-CI & $* *$ \\
\hline+ & + & & & + & \\
\hline trans-3-hexene $\left(\mathrm{C}_{2} \mathrm{H}_{5} \mathrm{CH}=\mathrm{CHC}_{2} \mathrm{H}_{5}\right)$ & 8 & & & $\mathrm{C}_{3}-\mathrm{CI}$ & \\
\hline
\end{tabular}

** not measured

and the main types of CI formed from these ozonolysis reactions, as discussed in the previous section, are also given.

Measured total SOA masses $\mathrm{M}_{0}$ formed during gas phase ozonolysis amount to several hundreds of $\mu \mathrm{g} / \mathrm{m}^{3}$ for most unsaturated compounds, except the 2,3-dimethyl-2-butene, which forms much lower amounts of SOA. The reason for this difference might be the very low stabilization rate (less than $1 \%$ of stabilized $\mathrm{CI}$ ) of the disubstituted iso- $_{-} \mathrm{C}_{3}-\mathrm{CI}$ in comparison with the monosubstituted $\mathrm{C}_{3}-\mathrm{CI}$ and $\mathrm{C}_{4}-\mathrm{CI}(20 \%$ to $40 \%$ of stabilized CI) (Kroll et al., 2002; Rickard et al., 1999). A correlation between the amount of SOA formed and the stabilization rate of the CI, independently of their number of carbon atoms - as the disubstituted $\mathrm{C}_{3}-\mathrm{CI}$ and the monosubstituted iso- $\mathrm{C}_{3}$ - $\mathrm{CI}$ are isomers -, might indicate a key role of stabilized CI in SOA formation. 


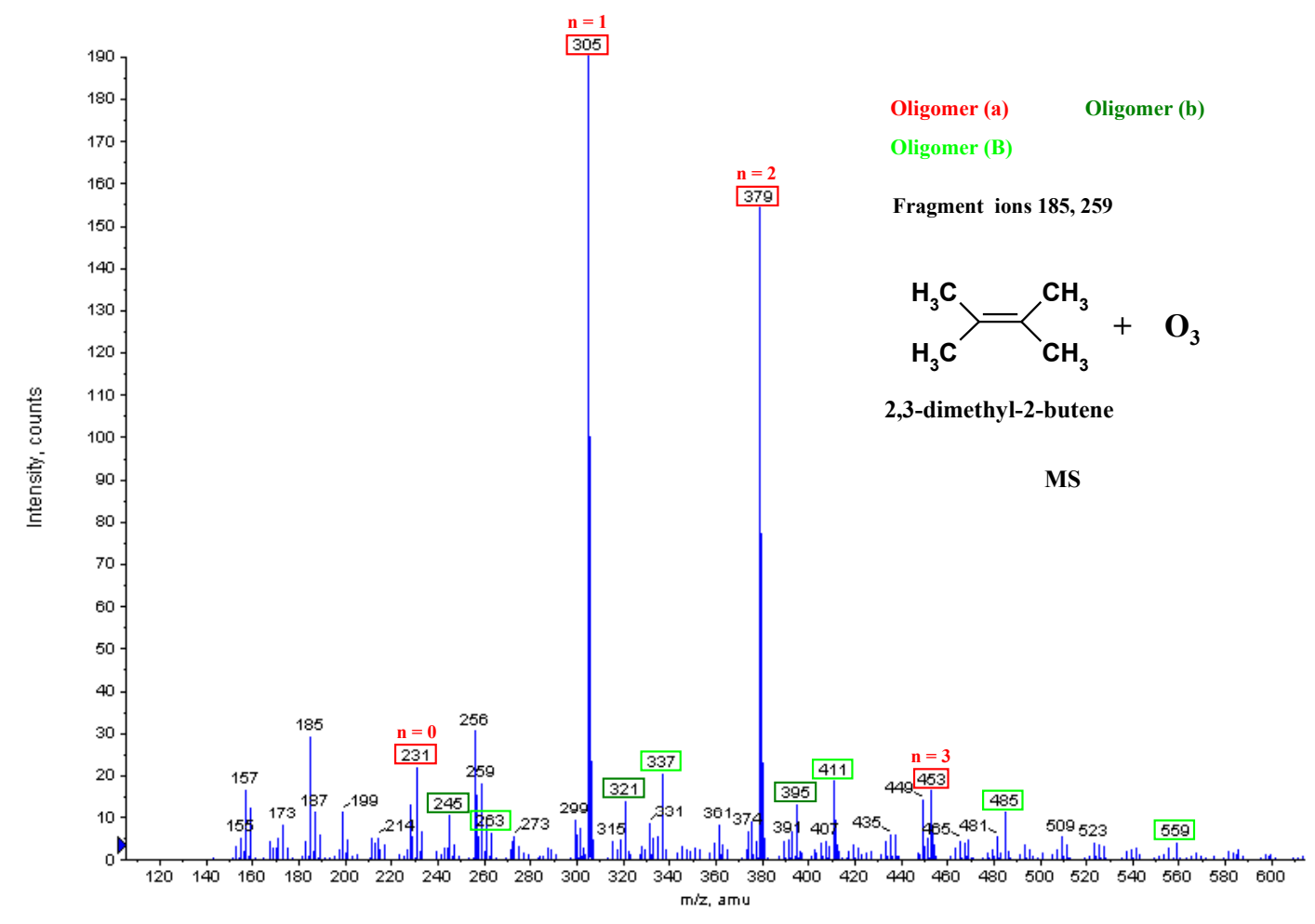

Fig. 2c. ESI(+)/TOF MS mass spectrum of SOA formed during the gas phase ozonolysis of 2,3-dimethyl-2-butene (initial mixing ratios: 8 ppm ozone, 15 ppm 2,3-dimethyl-2-butene, 300 ppm cyclohexane).

A significant increase of the total SOA mass $\mathrm{M}_{0}$ upon addition of an excess of cyclohexane $\left(\mathrm{C}_{6} \mathrm{H}_{12}\right)$ as an $\mathrm{OH}$ radical scavenger is observed for the two alkenes trans-3hexene and 2,3-dimethyl-2-butene. A similar influence of $\mathrm{C}_{6} \mathrm{H}_{12}$ on SOA yields has been observed by Docherty and Ziemann (2003) for the ozonolysis of $\beta$-pinene, while the reverse effect was found for the ozonolysis of alkyl vinyl ethers (Sadezky et al., 2006). In all cases, however, the qualitative results obtained from chemical analysis of the SOA by mass spectrometry do not change in the presence of an $\mathrm{OH}$ scavenger.

3.3 Chemical analysis of the SOA: identification and characterization of oligomers

\subsubsection{Identification of oligomers in the SOA}

Deploying the smooth ionisation of the electrospray technique, oligomeric products were detected in the SOA filter samples for all compounds studied. Figure $2 \mathrm{a}-\mathrm{d}$ show the mass spectra of the aerosol samples obtained.

The spectra show the presence of ions in the mass range between $\mathrm{m} / \mathrm{z} 200$ and 800 for the enol ether EBE and between $\mathrm{m} / \mathrm{z}, 200$ and 600 for the three alkenes with the typical regular structures of oligomers. The ion peaks could be grouped in series whose ions display regular differences of $\Delta m / z=74$ for ethyl butenyl ether (EBE), trans-3-hexene and 2,3-dimethyl2-butene (Fig. 2a-c), and of $\Delta m / z=88$ for trans-4-octene (Fig. 2d). The results are consistent with those from analogous studies (Sadezky et al., 2006; Sadezky, 2005), revealing oligomer ions with regular mass differences of $\Delta m / z=46$ for alkyl vinyl ethers (AVE) and $\Delta m / z=60$ for the ethyl propenyl ether (EPE). The pseudomolecular ions carry a single positive charge.

The different ion series for the various unsaturated ethers are presented in Table 2 and correspond to different types of oligomers designated (a), (b), (B), (C), (D), (E), (F), (G). In order to better distinguish the series, the peaks of the series are identified by different colours, corresponding to the colours of the peaks of Fig. 2a-d. Ion series observed for ethyl vinyl ether (EVE) and ethyl propenyl ether (EPE) are also given for comparison (Sadezky et al., 2006).

The most intense series observed for each ether is coloured in red, and is assigned as oligomer of type (a). The other observed oligomer series usually appear with much lower intensities and differ from the major oligomer series of type (a) by multiples and sums of $\Delta m / z=16$ and $\Delta m / z=14$. Oligomer series with similar differences of $\Delta \mathrm{m} / \mathrm{z}$ towards the main oligomer series of type (a) are labelled with similar letters and colours in Table 2 and in Fig. 2a-d for the different alkenes and enol ethers. For example, for most enol ethers 


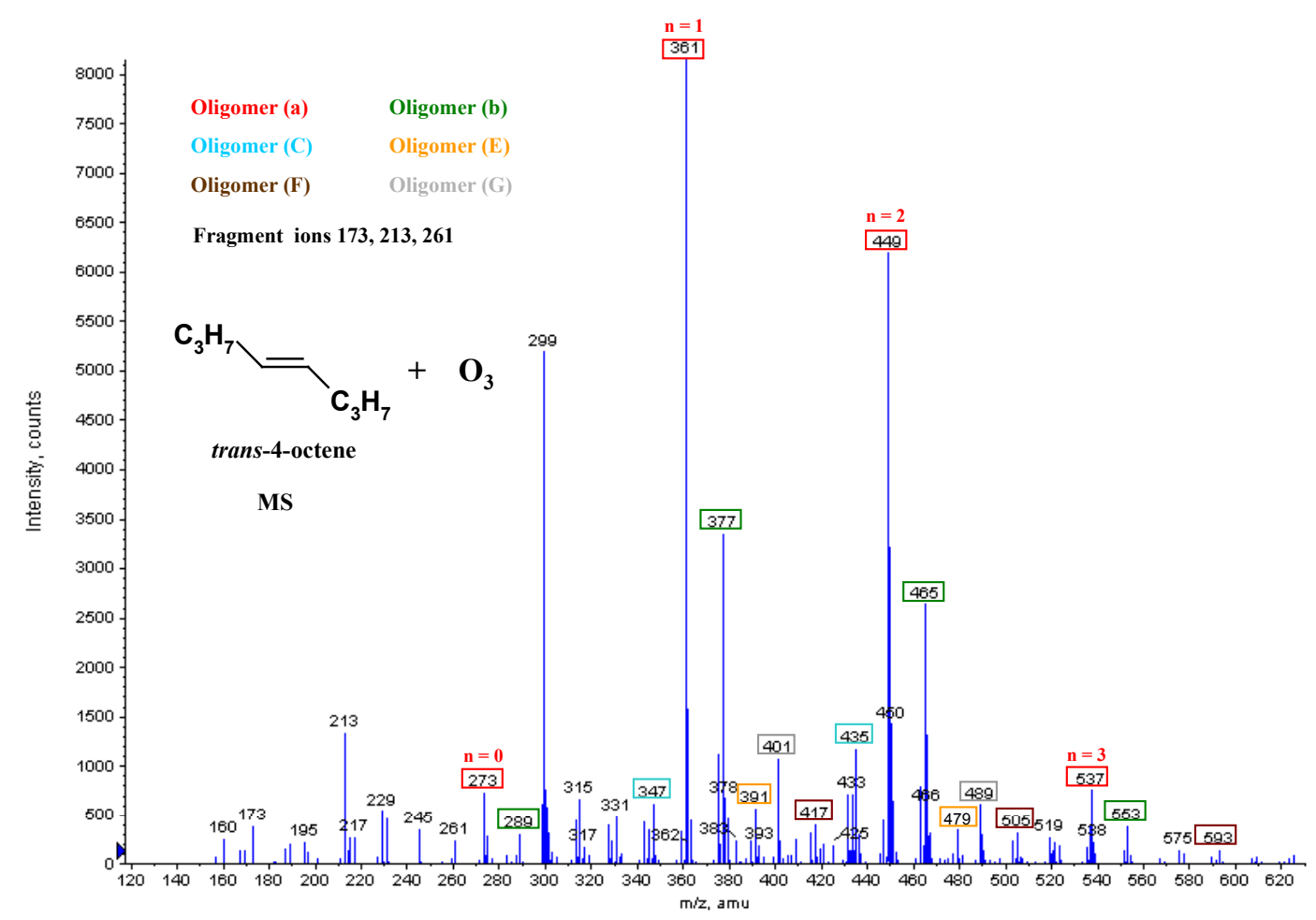

Fig. 2d. ESI(+)/TOF MS mass spectrum of SOA formed during the gas phase ozonolysis of trans-4-octene (initial mixing ratios: 8 ppm ozone, 15 ppm trans-4-octene).

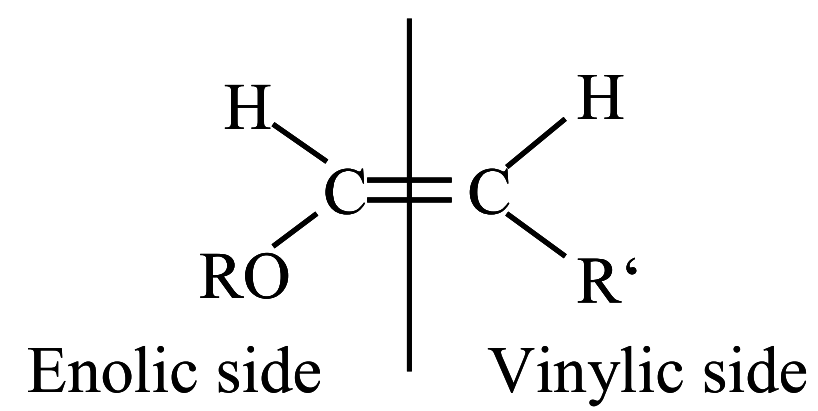

Fig. 3. Schematic structure of an enol ether.

and alkenes, oligomer ions of type (b) are observed, coloured in green in Table 2 and Fig. 2a-d. They differ from the series of type (a) ions by an additional $\Delta m / z=16$. Exact mass measurements by FTICR have revealed in our present work (Sect. 3.3.3.) that the ions of type (a) and type (b) respectively represent the $\mathrm{Na}^{+}$and $\mathrm{K}^{+}$adducts of the same oligomer molecule. The difference $\Delta m / z=16$ between the type (a) and (b) oligomer ions thus corresponds to the difference between $\mathrm{Na}^{+}$and $\mathrm{K}^{+}$rather than to an additional oxygen atom, as suggested by Sadezky et al. (2006). While for trans-3-hexene and ethyl vinyl ether (EVE), only oligomers of type (a) and (b) are observed, a variety of other ions series appear for ethyl butenyl ether (EBE), trans-4-octene, 2,3- dimethyl-2-butene and ethyl propenyl ether (EPE). Mass differences of these oligomer series towards the oligomers of type (a) are, for example, $\Delta m / z=14$ for oligomers (C) and (D) (with $\Delta m / z, 14$ possibly corresponding to a $\mathrm{CH}_{2}$ group), $\Delta m / z=42$ for oligomer (B) $(\Delta m / z, 42=3 \times \Delta m / z, 14$, possibly corresponding to three $\mathrm{CH}_{2}$ groups), and $\Delta m / z=30$ for oligomer (E) $(\Delta \mathrm{m} / \mathrm{z}, 30=\Delta \mathrm{m} / \mathrm{z}, 14+\Delta \mathrm{m} / \mathrm{z}, 16$, eventually accounting in total for a formaldehyde-like unit $\mathrm{CH}_{2} \mathrm{O}$ ).

As described in a later section of this work and in our previous study (Sadezky et al., 2006), MS/MS experiments allowed to fragment the pseudomolecular ions and thus to determine the minimum number $\mathrm{n}$ of fragmented repetitive chain units $46,60,74$ or 88 contained in the molecular species. In Fig. $2 \mathrm{a}-\mathrm{d}, \mathrm{n}$ are given for the pseudomolecular ions of the most intensive oligomer series designated as type (a). Ions of type (a) and ions of weaker oligomer series suggested to carry similar numbers of chain units, are arranged in vertical columns in Table 2.

Some ions between $\mathrm{m} / \mathrm{z}, 150$ and 300, which are also observed as fragment ions in the MS/MS spectra (Sect. 3.3.3.) of parent oligomer ions, are listed separately on Figs. 2a-d.

Oligomer ions observed for EBE in the present work corroborate the dependence of their chain unit on the vinylic side $=$ CHR' of the double bond of the initial enol ether derived from the analogous study of AVE and EPE (Sadezky et al., 2006). The schematic structure of an enol ether shown in 
Table 2. Oligomer pseudomolecular ion series detected by ESI(+)/TOF MS in the SOA formed during ozonolysis of enol ethers and alkenes (n: minimum number of repetitive chain units which are directly identified as neutral fragments in the MS/MS spectra) (MW: molar weight $[\mathrm{g} / \mathrm{mol}])$.

\begin{tabular}{|c|c|c|c|c|c|c|c|c|c|c|c|}
\hline \multirow{2}{*}{$\begin{array}{l}\text { Ether/Alkene } \\
\text { n }\end{array}$} & \multicolumn{11}{|c|}{ Ion Series $(\mathrm{m} / \mathrm{z})$} \\
\hline & $\mathbf{n}=\mathbf{0}$ & $\mathrm{n}=1$ & $\mathrm{n}=\mathbf{2}$ & $\mathbf{n}=\mathbf{3}$ & $n=4$ & $\mathbf{n}=\mathbf{5}$ & $n=6$ & $n=7$ & $\mathrm{n}=\mathbf{8}$ & $\mathrm{n}=\mathbf{9}$ & \\
\hline Ethyl propenyl ether & & & 339 & 399 & 459 & 519 & 579 & 639 & 699 & 759 & (a) $[\mathrm{M}+\mathrm{Na}]^{+}$ \\
\hline (MW 86 g/mol) & & & & 357 & 417 & 477 & & & & & (B) \\
\hline $\mathrm{EPE}, \mathrm{C}_{2} \mathrm{H}_{5} \mathrm{OCH}=\mathrm{CHCH}_{3}$ & & 265 & 325 & 385 & 445 & & & & & & (C) \\
\hline \multirow[t]{2}{*}{ (Sadezky et al., 2006) } & & 293 & 353 & 413 & 473 & 533 & & & & & (D) \\
\hline & & & & & 489 & 549 & 609 & 669 & 729 & 789 & (E) \\
\hline Ethyl vinyl ether & & & 283 & 329 & 375 & 421 & 467 & 513 & & & (a) $[\mathrm{M}+\mathrm{Na}]^{+}$ \\
\hline (MW 72g/mol) & & & & 345 & 391 & 437 & 483 & & & & (b) $[\mathrm{M}+\mathrm{K}]^{+}$ \\
\hline \multicolumn{12}{|l|}{$\begin{array}{l}\text { EVE, } \mathrm{C}_{2} \mathrm{H}_{5} \mathrm{OCH}=\mathrm{CH}_{2} \\
\text { (Sadezky et al., 2006) }\end{array}$} \\
\hline Ethyl butenyl ether & & 321 & 395 & 469 & 543 & 617 & 691 & & & & (a) $[\mathrm{M}+\mathrm{Na}]^{+}$ \\
\hline (MW $100 \mathrm{~g} / \mathrm{mol}$ ) & & & 411 & 485 & 559 & 633 & 707 & & & & (b) $[\mathbf{M}+\mathbf{K}]^{+}$ \\
\hline EBE, $\mathrm{C}_{2} \mathrm{H}_{5} \mathrm{OCH}=\mathrm{CHC}_{2} \mathrm{H}_{5}$ & & 279 & 353 & 427 & 501 & & & & & & (B) \\
\hline \multirow[t]{3}{*}{ (this work) } & & & & & & 647 & 721 & 795 & & & (E) \\
\hline & & & & 437 & 511 & 585 & & & & & (F) \\
\hline & & 305 & 379 & 453 & 527 & 601 & & & & & $* \downarrow$ \\
\hline trans-3-hexene & & 305 & 379 & 453 & 527 & & & & & & (a) $[\mathrm{M}+\mathrm{Na}]^{+}$ \\
\hline (MW 84 g/mol) & & 321 & 395 & 469 & & & & & & & (b) $[\mathrm{M}+\mathrm{K}]^{+}$ \\
\hline \multicolumn{12}{|l|}{$\begin{array}{l}\mathrm{C}_{2} \mathrm{H}_{5} \mathrm{CH}=\mathrm{CHC}_{2} \mathrm{H}_{5} \\
\text { (this work) }\end{array}$} \\
\hline 2,3-dimethyl-2-butene & 231 & 305 & 379 & 453 & & & & & & & (a) $[\mathrm{M}+\mathrm{Na}]^{+}$ \\
\hline (MW $84 \mathrm{~g} / \mathrm{mol})$ & 245 & 321 & 395 & & & & & & & & (b) $[\mathbf{M}+\mathbf{K}]^{+}$ \\
\hline \multicolumn{11}{|l|}{ (this work) } & (B) \\
\hline trans-4-octene & 273 & 361 & 449 & 537 & & & & & & & (a) $[\mathrm{M}+\mathrm{Na}]^{+}$ \\
\hline (MW $112 \mathrm{~g} / \mathrm{mol}$ ) & 289 & 377 & 465 & 553 & & & & & & & (b) $[\mathrm{M}+\mathrm{K}]^{+}$ \\
\hline $\mathrm{C}_{3} \mathrm{H}_{7} \mathrm{CH}=\mathrm{CHC}_{3} \mathrm{H}_{7}$ & & 347 & 435 & & & & & & & & (C) \\
\hline \multirow[t]{3}{*}{ (this work) } & & 391 & 479 & & & & & & & & (E) \\
\hline & & & 417 & 505 & 593 & & & & & & (F) \\
\hline & & & 401 & 489 & & & & & & & (G) \\
\hline
\end{tabular}

* Oligomer with $\mathrm{m} / \mathrm{z}$ identical to the oligomer ion (a) formed during ozonolysis of trans-3-hexene

Fig. 3 displays the two alkyl substituents, R' on the vinylic side $=\mathrm{CHR}$ ' of the double bond and $\mathrm{R}$ on its enolic side $=\mathrm{CHOR}$.

$\mathrm{R}^{\prime}=\mathrm{C}_{2} \mathrm{H}_{5}$ for $\mathrm{EBE} \quad\left(\mathrm{C}_{2} \mathrm{H}_{5} \mathrm{OCH}=\mathrm{CHC}_{2} \mathrm{H}_{5}\right)$, while $\mathrm{R}^{\prime}=\mathrm{H}$ for $\mathrm{AVE}\left(\mathrm{ROCH}=\mathrm{CH}_{2}\right)$ and $\mathrm{R}^{\prime}=\mathrm{CH}_{3}$ for $\mathrm{EPE}$ $\left(\mathrm{C}_{2} \mathrm{H}_{5} \mathrm{OCH}=\mathrm{CHCH}_{3}\right)$. R' differs thus by mass $14\left(\mathrm{CH}_{2}\right)$ between the AVE and EPE as well as between EPE and EBE, a difference that is reflected in the masses of the observed oligomer chain units, which are of $\Delta m / z=46$ for the AVE, $\Delta$ $m / z=60=46+14$ for EPE and $\Delta m / z=74=60+14$ for EBE.
As discussed in the Sect. 3.1.1, the major Criegee Intermediate (CI) formed with yields around $80 \%$ during enol ether ozonolysis originates from the vinylic side of the enol ethers, thus carrying $\mathrm{R}^{\prime}$ as substituent. The major CI produced from EBE is therefore the $\mathrm{C}_{3}$-CI with $\mathrm{R}^{\prime}=\mathrm{C}_{2} \mathrm{H}_{5}$, which is identical to the $\mathrm{C}_{3}$-CI formed during ozonolysis of trans3-hexene (Sect. 3.1.2). The results given in Fig. 2a and $\mathrm{b}$ and in Table 2 show that the oligomers obtained from ozonolysis of EBE and trans-3-hexene consist of chain units with identical mass 74. Moreover, chain units with similar mass 
Table 3a. ESI(+)/FTICR MS/MS measurements:

Calculated elemental compositions of parent ions, fragment ions and fragmented neutral molecules for the red-marked fragmentation pathway of the pseudomolecular oligomer ion 379 formed from trans-3- hexene*.

\begin{tabular}{|c|c|c|c|c|}
\hline $\begin{array}{l}\text { Accurate mass } \\
\text { (u) }\end{array}$ & $\begin{array}{l}\text { Elemental com- } \\
\text { position }\end{array}$ & $\begin{array}{l}\text { Exact mass } \\
\text { (u) }\end{array}$ & $\begin{array}{l}\text { Absolute mass er- } \\
\text { ror }(\mathrm{mDa})\end{array}$ & $\begin{array}{l}\text { Relative mass er- } \\
\text { ror (ppm) }\end{array}$ \\
\hline \multicolumn{5}{|l|}{$\begin{array}{l}\text { parent ion } \\
379.19384\end{array}$} \\
\hline $\begin{array}{l}{\left[\mathrm{X}-[74]_{2}-\mathrm{Y}+\mathrm{H}\right]^{+}} \\
{\left[\mathrm{X}-[\mathrm{74}]_{2}-\mathrm{Y}+\mathrm{Na}\right]^{+}}\end{array}$ & $\begin{array}{l}\mathrm{C}_{17} \mathrm{H}_{31} \mathrm{O}_{9} \\
\mathbf{C}_{15} \mathbf{H}_{32} \mathbf{O}_{9} \mathbf{N a}^{+}\end{array}$ & $\begin{array}{l}379.1962 \\
\mathbf{3 7 9 . 1 9 3 8}\end{array}$ & $\begin{array}{l}-2.4194 \\
-\mathbf{0 . 0 1 4 1}\end{array}$ & $\begin{array}{l}-6.3804 \\
-\mathbf{0 . 0 3 7 3}\end{array}$ \\
\hline $\begin{array}{l}\text { initially fragmented } \\
\text { neutral } X \\
146.13063\end{array}$ & $\boldsymbol{C}_{8} \mathrm{H}_{18} \boldsymbol{O}_{2}$ & 146.1306 & -0.0499 & -0.3421 \\
\hline \multicolumn{5}{|l|}{ fragment ion } \\
\hline $\begin{array}{l}{\left[\mathrm{Y}-[74]_{2}+\mathrm{H}\right]^{+}} \\
{\left[\mathrm{Y}-[74]_{2}+\mathrm{Na}\right]^{+}}\end{array}$ & $\begin{array}{l}\mathrm{C}_{9} \mathrm{H}_{13} \mathrm{O}_{7} \\
\mathbf{C}_{7} \mathbf{H}_{14} \mathbf{O}_{7} \mathbf{N a}^{+}\end{array}$ & $\begin{array}{l}233.0655 \\
\mathbf{2 3 3 . 0 6 3 1}\end{array}$ & $\begin{array}{l}-2.3694 \\
\mathbf{0 . 0 3 5 8}\end{array}$ & $\begin{array}{l}-10.1664 \\
\mathbf{0 . 1 5 3 7}\end{array}$ \\
\hline $\begin{array}{l}\text { neutral } \\
\text { chain unit CI } \\
74.03684\end{array}$ & $\boldsymbol{C}_{3} \boldsymbol{H}_{6} \boldsymbol{O}_{2}$ & 74.0367 & 0.0604 & 0.8168 \\
\hline $\begin{array}{l}\text { fragment ion } \\
159.02637\end{array}$ & & & & \\
\hline $\begin{array}{l}{[\mathrm{Y}-[74]+\mathrm{H}]^{+}} \\
{[\mathrm{Y}-[\mathbf{7 4}]+\mathrm{Na}]^{+}}\end{array}$ & $\begin{array}{l}\mathrm{C}_{6} \mathrm{H}_{7} \mathrm{O}_{5} \\
\mathbf{C}_{4} \mathbf{H}_{8} \mathbf{O}_{5} \mathbf{N a}^{+}\end{array}$ & $\begin{array}{l}159.0287 \\
\mathbf{1 5 9 . 0 2 6 3}\end{array}$ & $\begin{array}{l}-2.4299 \\
-\mathbf{0 . 0 2 4 6}\end{array}$ & $\begin{array}{l}-15.2798 \\
\mathbf{- 0 . 1 5 4 9}\end{array}$ \\
\hline
\end{tabular}

* The ion 85 appearing in the ESI(+)/TOF MS/MS spectra in Fig. 4a is not visible in the ESI(+)/FTICR MS/MS spectra due to the strong decrease in sensitivity of the FTICR analyzer for ions with $\mathrm{m} / \mathrm{z}$, below $100 \mathrm{u}$.

74 are also found for oligomers formed from 2,3-dimethyl2-butene (Fig. 2c and Table 2), which produce the iso- $\mathrm{C}_{3}$ $\mathrm{CI}$, an isomer of the $\mathrm{C}_{3}$-CI. Finally, trans-4-octene forms the $\mathrm{C}_{4}$-CI, which differs by a $\mathrm{CH}_{2}$ group of mass 14 from the $\mathrm{C}_{3}$-CI produced by EBE and trans-3-hexene. The chain units of the oligomers obtained from ozonolysis of trans-4octene (Fig. 2d and Table 2) reflect this difference by their $\Delta$ $m / z=88=74+14$. These results point towards a decisive role of the $\mathrm{CI}$ in the formation of the oligomers observed as chemical constituents of the SOA from the different unsaturated compounds.

In our previous study (Sadezky et al., 2006), we suggested furthermore that the alkoxy group OR on the enolic side of the initial ether is contained once in each oligomer ion. A comparison of the initial structures of EBE and trans-3hexene shows that each symmetric side of the double bond of trans-3-hexene is identical to the vinylic side of EBE. The enolic side of EBE differs from the vinylic side only by the enolic $\mathrm{O}$ atom directly linked to the double bond. Indeed, the $\mathrm{Na}^{+}$and $\mathrm{K}^{+}$adducts of the oligomers (oligomer ion types a and b) from ozonolysis of EBE carry an additional $\Delta \mathrm{m} / \mathrm{z}$ 16 in comparison with those formed from trans-3-hexene
(Table 2 and Figs. 2a and b), which might account for the enolic $\mathrm{O}$ atom of EBE. Moreover, Table 2 and Fig. $2 b$ and c show that trans-3-hexene and 2,3-dimethyl-2-butene form oligomer ions of type (a) and (b) with identical $\mathrm{m} / \mathrm{z}$. Both alkenes, like their CI, are isomers, carrying the same number of carbon and hydrogen atoms as alkyl substituents on each side of their double bonds.

The results presented in Table 2 and in Fig. 2a-d furthermore show that the degree of oligomerization decreases with increasing size of the chain unit. For the most abundant oligomers, $n$ is 3 with the chain units of mass 46 (AVE) and mass 60 (EPE) (Sadezky et al., 2006), while $n$ is 2 with the chain unit of mass 74 (EBE and trans-3-hexene, Fig. 2a and b), and $\mathrm{n}$ is 1 with the largest chain unit of mass 88 (trans-4octene, Fig. 2d).

Although the chain units are of similar mass 74, lower degrees of oligomerization are observed for oligomers formed from 2,3-dimethyl-2-butene, with $\mathrm{n}=1$ for the most abundant oligomer molecule (Fig. 2c), than for those produced from EBE and trans-3-hexene. This observation is consistent with the low total SOA masses formed during ozonolysis of this compound, and might be correlated with the low stabilization 
Table 3b. ESI(+)/FTICR MS/MS measurements:

Calculated elemental compositions of parent ions, fragment ions and fragmented neutral molecules for the violet-marked fragmentation pathway of the pseudomolecular oligomer ion 395 formed from EBE

\begin{tabular}{|c|c|c|c|c|}
\hline $\begin{array}{l}\text { Accurate mass } \\
\text { (u) }\end{array}$ & $\begin{array}{l}\text { Elemental com- } \\
\text { position }\end{array}$ & $\begin{array}{l}\text { Exact mass } \\
\text { (u) }\end{array}$ & $\begin{array}{l}\text { Absolute mass er- } \\
\text { ror }(\mathrm{mDa})\end{array}$ & $\begin{array}{l}\text { Relative mass er- } \\
\text { ror }(\mathrm{ppm})\end{array}$ \\
\hline \multicolumn{5}{|l|}{$\begin{array}{l}\text { parent ion } \\
\mathbf{3 9 5 . 1 8 8 5 7}\end{array}$} \\
\hline $\begin{array}{l}{\left[\mathrm{X}-[74]_{2}-\mathrm{Y}+\mathrm{H}\right]^{+}} \\
{\left[\mathrm{X}-[\mathbf{7 4}]_{2}-\mathrm{Y}+\mathrm{Na}\right]^{+}}\end{array}$ & $\begin{array}{l}\mathrm{C}_{17} \mathrm{H}_{31} \mathrm{O}_{10} \\
\mathbf{C}_{15} \mathbf{H}_{32} \mathbf{O}_{10} \mathbf{N a}^{+}\end{array}$ & $\begin{array}{l}395.1911 \\
\mathbf{3 9 5 . 1 8 8 7}\end{array}$ & $\begin{array}{l}-2.604 \\
\mathbf{- 0 . 1 9 8 8}\end{array}$ & $\begin{array}{l}-6.5894 \\
\mathbf{- 0 . 5 0 3}\end{array}$ \\
\hline $\begin{array}{l}\text { initially fragmented } \\
\text { neutral } Y \\
120.07855\end{array}$ & $\mathrm{C}_{5} \mathrm{H}_{12} \mathrm{O}_{3}$ & 120.0786 & -0.0943 & -0.7861 \\
\hline $\begin{array}{l}\text { fragment ion } \\
275.11002\end{array}$ & & & & \\
\hline $\begin{array}{l}{\left[\mathrm{X}-[74]_{2}+\mathrm{H}\right]^{+}} \\
{\left[\mathrm{X}-[\mathbf{7 4 4}]_{2}+\mathrm{Na}\right]^{+}}\end{array}$ & $\begin{array}{l}\mathrm{C}_{12} \mathrm{H}_{19} \mathrm{O}_{7} \\
\mathbf{C}_{10} \mathbf{H}_{20} \mathbf{O}_{7} \mathbf{N a}^{+}\end{array}$ & $\begin{array}{l}275.1125 \\
\mathbf{2 7 5 . 1 1 0 1}\end{array}$ & $\begin{array}{l}-2.5096 \\
\mathbf{- 0 . 1 0 4 3}\end{array}$ & $\begin{array}{l}-9.1223 \\
\mathbf{- 0 . 3 7 9 4}\end{array}$ \\
\hline $\begin{array}{l}\text { neutral } \\
\text { chain unit CI } \\
74.03667\end{array}$ & $\boldsymbol{C}_{3} \mathrm{H}_{6} \mathrm{O}_{2}$ & 74.0367 & -0.1095 & -1.4792 \\
\hline $\begin{array}{l}\text { fragment ion } \\
201.07335\end{array}$ & & & & \\
\hline $\begin{array}{l}{[\mathrm{X}-[74]+\mathrm{H}]^{+}} \\
{[\mathrm{X}-[\mathbf{7 4}]+\mathbf{N a}]^{+}}\end{array}$ & $\begin{array}{l}\mathrm{C}_{9} \mathrm{H}_{13} \mathrm{O}_{5} \\
\mathbf{C}_{7} \mathbf{H}_{14} \mathbf{O}_{5} \mathbf{N a}^{+}\end{array}$ & $\begin{array}{l}201.0757 \\
\mathbf{2 0 1 . 0 7 3 3}\end{array}$ & $\begin{array}{l}-2.4001 \\
\mathbf{0 . 0 0 5 1}\end{array}$ & $\begin{array}{l}-11.9366 \\
\mathbf{0 . 0 2 5 4}\end{array}$ \\
\hline
\end{tabular}

rate of the iso- $\mathrm{C}_{3}-\mathrm{CI}$ in comparison with the $\mathrm{C}_{3}-\mathrm{CI}$, eventually leading to a lower fraction of $\mathrm{CI}$ undergoing oligomerization reactions.

\subsubsection{Oligomer ion fragmentations and elemental compo- sitions}

The fragmentation of the pseudomolecular ions using the ESI(+)/TOF MS/MS mode confirms that they consist of an oligomeric structure with the chain unit of $\Delta m / z=74$ (ozonolysis of EBE, trans-3-hexene and 2,3-dimethyl-2butene) and $\Delta m / z=88$ (ozonolysis of trans-4-octene). Examples of the MS/MS spectra are displayed in Figs. 4a-d, which show the fragmentation of a selected specific pseudomolecular ion of the type (a) oligomer from each of the four unsaturated compounds studied. The elemental compositions given for the ions and neutrals in Figs. 4a-d were confirmed by accurate ESI(+)/FTICR MS/MS measurements.

The main fragment ions observed in the MS/MS spectra can be classified as being part of fragmentation pathways, formed by successive losses of the chain unit as neutral mass 74 or 88 , respectively. Fragmentation pathways of oligomers from different enol ethers and alkenes, which show apparent analogies among each other, are marked by similar colours. Two fragmentation pathways, marked in violet and red colour in Fig. 4a-d, can be identified for the type (a) oligomers from all unsaturated compounds. Two more pathways, marked in dark and light green colour, are observed for 2,3-dimethyl-2-butene (Fig. 4c) only.

The results are consistent with MS/MS spectra of oligomer ions produced from gas phase ozonolysis of AVE and of EPE, which are presented in our previous study (Sadezky et al., 2006). They show similar fragmentation pathways consisting of successive losses of the chain units 46 for AVE and 60 for EPE, corresponding to the respective oligomer chain unit. In particular, the two fragmentation pathways, marked in violet and red colours, are also identified for type (a) oligomers from all enol ethers studied in our previous work (Sadezky et al., 2006). However, in comparison with oligomers formed from the unsaturated compounds investigated in the present work, fragmentation spectra of oligomers formed from AVE or EPE are much more rich and complex, with up to nine fragmentation pathways being simultaneously observed for a parent oligomer ion of type (a) (Sadezky et al., 2006). 
Table 3c. ESI(+)/FTICR MS/MS measurements:

Calculated elemental compositions of parent ions, fragment ions and fragmented neutral molecules for the violet-marked fragmentation pathway of the pseudomolecular oligomer ion 379 formed from 2,3-dimethyl-2-butene.

\begin{tabular}{|c|c|c|c|c|}
\hline $\begin{array}{l}\text { Accurate mass } \\
\text { (u) }\end{array}$ & $\begin{array}{l}\text { Elemental com- } \\
\text { position }\end{array}$ & $\begin{array}{l}\text { Exact mass } \\
\text { (u) }\end{array}$ & $\begin{array}{l}\text { Absolute mass er- } \\
\text { ror }(\mathrm{mDa})\end{array}$ & $\begin{array}{l}\text { Relative mass er- } \\
\text { ror (ppm) }\end{array}$ \\
\hline \multicolumn{5}{|l|}{$\begin{array}{l}\text { parent ion } \\
379.19371\end{array}$} \\
\hline $\begin{array}{l}{\left[\mathrm{X}-[74]_{2}-\mathrm{Y}+\mathrm{H}\right]^{+}} \\
{\left[\mathrm{X}-[\mathbf{7 4}]_{2}-\mathrm{Y}+\mathrm{Na}\right]^{+}}\end{array}$ & $\begin{array}{l}\mathrm{C}_{17} \mathrm{H}_{31} \mathrm{O}_{9} \\
\mathbf{C}_{15} \mathbf{H}_{32} \mathbf{O}_{9} \mathbf{N a}^{+}\end{array}$ & $\begin{array}{l}379.1962 \\
\mathbf{3 7 9 . 1 9 3 8}\end{array}$ & $\begin{array}{l}-2.5494 \\
\mathbf{- 0 . 1 4 4 1}\end{array}$ & $\begin{array}{l}-6.7232 \\
-\mathbf{0 . 3 8 0 1}\end{array}$ \\
\hline $\begin{array}{l}\text { initially fragmented } \\
\text { neutral } Y \\
120.07863\end{array}$ & $\mathrm{C}_{5} \mathrm{H}_{12} \mathrm{O}_{3}$ & 120.0786 & -0.0344 & -0.2864 \\
\hline $\begin{array}{l}\text { fragment ion } \\
259.11510\end{array}$ & & & & \\
\hline $\begin{array}{l}{\left[\mathrm{X}-[74]_{2}+\mathrm{H}\right]^{+}} \\
{\left[\mathrm{X}-[\mathbf{7 4}]_{2}+\mathbf{N a}\right]^{+}}\end{array}$ & $\begin{array}{l}\mathrm{C}_{12} \mathrm{H}_{19} \mathrm{O}_{6} \\
\mathbf{C}_{10} \mathbf{H}_{20} \mathbf{O}_{6} \mathbf{N a}^{+}\end{array}$ & $\begin{array}{l}259.1176 \\
\mathbf{2 5 9 . 1 1 5 2}\end{array}$ & $\begin{array}{l}-2.515 \\
\mathbf{- 0 . 1 0 9 7}\end{array}$ & $\begin{array}{l}-9.7061 \\
\mathbf{- 0 . 4 2 3 5}\end{array}$ \\
\hline $\begin{array}{l}\text { neutral } \\
\text { chain unit CI } \\
74.03673\end{array}$ & $\boldsymbol{C}_{3} \boldsymbol{H}_{6} \boldsymbol{O}_{2}$ & 74.0367 & -0.0495 & -0.6688 \\
\hline $\begin{array}{l}\text { fragment ion } \\
185.07837\end{array}$ & & & & \\
\hline $\begin{array}{l}{[\mathrm{X}-[74]+\mathrm{H}]^{+}} \\
{[\mathrm{X}-[\mathbf{7 4}]+\mathrm{Na}]^{+}}\end{array}$ & $\begin{array}{l}\mathrm{C}_{9} \mathrm{H}_{13} \mathrm{O}_{4} \\
\mathbf{C}_{7} \mathbf{H}_{14} \mathbf{O}_{4} \mathbf{N a}^{+}\end{array}$ & $\begin{array}{l}185.0808 \\
\mathbf{1 8 5 . 0 7 8 4}\end{array}$ & $\begin{array}{l}-2.4654 \\
\mathbf{- 0 . 0 6 0 2}\end{array}$ & $\begin{array}{l}-13.3213 \\
-\mathbf{0 . 3 2 5 4}\end{array}$ \\
\hline
\end{tabular}

\subsubsection{Elemental compositions}

Elemental compositions of parent ions, fragment ions and fragmented neutral molecules given in Figs. 4a-d, 5 and 6 are determined from the measured accurate $m / z$ values during ESI(+)/FTICR MS and ESI(+)/FTICR MS/MS experiments. The most likely candidates are selected by comparison of the measured accurate masses with the calculated exact masses of elemental formulas. The results are shown in Tables 3a-d and $4 \mathrm{a}$ and $\mathrm{b}$.

Table $3 \mathrm{a}$ shows the detailed calculation for the redcoloured fragmentation pathway of the parent ion 379 formed from trans-3-hexene, and Tables 3b-d show the calculations for the violet-coloured fragmentation pathway of the parent ions 395 formed from EBE, 379 formed from 2,3dimethyl-2-butene, and 449 formed from trans-4-octene.

The results first of all identify the elemental compositions of the chain units, which, as suggested earlier in the present work (Sect. 3.3.1.), correspond to those of the respective major Criegee Intermediates CI. They are determined as $\mathrm{C}_{3} \mathrm{H}_{6} \mathrm{O}_{2}$ for the chain unit of mass 74 (trans-3-hexene, EBE, and 2,3-dimethyl-2-butene, Tables 3a-c) and $\mathrm{C}_{4} \mathrm{H}_{8} \mathrm{O}_{2}$ for the chain unit of mass 88 (trans-4-octene, Table $3 \mathrm{~d}$ ) with relative mass errors lower than $2 \mathrm{ppm}$. Analogous elemental compo- sitions of $\mathrm{CH}_{2} \mathrm{O}_{2}$ for the chain unit 46 and $\mathrm{C}_{2} \mathrm{H}_{4} \mathrm{O}_{2}$ for the chain unit 60 were found for oligomers formed from AVE and EPE in our previous study (Sadezky et al., 2006).

Concerning the chemical compositions of the parent and fragment ions, in our previous study (Sadezky et al., 2006), we exclusively took into account those sum formulas which consist of the elements $\mathrm{C}, \mathrm{H}$, and $\mathrm{O}$ only. Due to the fact that good fragmentation spectra are generally obtained during MS/MS experiments under the low-energy conditions of collision-activated dissociation (CAD), we assumed ionization by protonation in the ESI(+) ion source. Sodium and potassium adduct ions of oxygenated oligomers are usually known to give very poor fragment ion spectra or not to fragment at all under CAD conditions (e. g. Chen et al., 2001). The much higher accuracy and resolution of the FTICR analyzer used in our present study in comparison with the TOF analyzer of our previous work (Sadezky et al., 2006), now allow us to distinguish the elemental compositions consisting of $\mathrm{C}, \mathrm{H}$, and $\mathrm{O}$ only, which are in analogy to those reported in our previous work (Sadezky et al., 2006), from another series of sum formulas with very close exact masses containing a sodium ion (Tables 3a-d) (Suggestion of the referee 1). The measured accurate $m / z$ values in Tables 3a-d systematically favour the elemental compositions containing a sodium 
Table 3d. ESI(+)/FTICR MS/MS measurements:

Calculated elemental compositions of parent ions, fragment ions and fragmented neutral molecules for the violet-marked fragmentation pathway of the pseudomolecular oligomer ion 449 formed from trans-4-octene.

\begin{tabular}{|c|c|c|c|c|}
\hline $\begin{array}{l}\text { Accurate mass } \\
\text { (u) }\end{array}$ & $\begin{array}{l}\text { Elemental com- } \\
\text { position }\end{array}$ & $\begin{array}{l}\text { Exact mass } \\
\text { (u) }\end{array}$ & $\begin{array}{l}\text { Absolute mass er- } \\
\text { ror }(\mathrm{mDa})\end{array}$ & $\begin{array}{l}\text { Relative mass er- } \\
\text { ror }(\mathrm{ppm})\end{array}$ \\
\hline \multicolumn{5}{|l|}{$\begin{array}{l}\text { parent ion } \\
449.27189\end{array}$} \\
\hline $\begin{array}{l}{\left[\mathrm{X}-[88]_{2}-\mathrm{Y}+\mathrm{H}\right]^{+}} \\
{\left[\mathrm{X}-[\mathbf{8 8}]_{2}-\mathbf{Y}+\mathbf{N a}\right]^{+}}\end{array}$ & $\begin{array}{l}\mathrm{C}_{22} \mathrm{H}_{41} \mathrm{O}_{9} \\
\mathbf{C}_{20} \mathbf{H}_{42} \mathbf{O}_{9} \mathbf{N a}^{+}\end{array}$ & $\begin{array}{l}449.2745 \\
\mathbf{4 4 9 . 2 7 2 1}\end{array}$ & $\begin{array}{l}-2.6198 \\
-\mathbf{0 . 2 1 4 5}\end{array}$ & $\begin{array}{l}-5.8312 \\
\mathbf{- 0 . 4 7 7 5}\end{array}$ \\
\hline $\begin{array}{l}\text { initially fragmented } \\
\text { neutral } Y \\
148.10988\end{array}$ & $\boldsymbol{C}_{7} \mathrm{H}_{16} \boldsymbol{O}_{3}$ & 148.1099 & -0.0645 & -0.4358 \\
\hline \multicolumn{5}{|l|}{ fragment ion } \\
\hline $\begin{array}{l}{\left[\mathrm{X}-[88]_{2}+\mathrm{H}\right]^{+}} \\
{\left[\mathbf{X}-[\mathbf{8 8}]_{2}+\mathbf{N a}\right]^{+}}\end{array}$ & $\begin{array}{l}\mathrm{C}_{15} \mathrm{H}_{25} \mathrm{O}_{6} \\
\mathbf{C}_{13} \mathbf{H}_{26} \mathbf{O}_{6} \mathbf{N a}^{+}\end{array}$ & $\begin{array}{l}301.1645 \\
\mathbf{3 0 1 . 1 6 2 1}\end{array}$ & $\begin{array}{l}-2.5552 \\
\mathbf{- 0 . 1 5}\end{array}$ & $\begin{array}{l}-8.4846 \\
\mathbf{- 0 . 4 9 8}\end{array}$ \\
\hline $\begin{array}{l}\text { neutral } \\
\text { chain unit CI } \\
88.05231\end{array}$ & $\boldsymbol{C}_{4} \boldsymbol{H}_{8} \boldsymbol{O}_{2}$ & 88.0524 & -0.1195 & -1.3582 \\
\hline $\begin{array}{l}\text { fragment ion } \\
213.10970\end{array}$ & & & & \\
\hline $\begin{array}{l}{[\mathrm{X}-[88]+\mathrm{H}]^{+}} \\
{[\mathbf{X}-[\mathbf{8 8}]+\mathbf{N a}]^{+}}\end{array}$ & $\begin{array}{l}\mathrm{C}_{11} \mathrm{H}_{17} \mathrm{O}_{4} \\
\mathbf{C}_{9} \mathbf{H}_{18} \mathbf{O}_{4} \mathbf{N a}^{+}\end{array}$ & $\begin{array}{l}213.1121 \\
\mathbf{2 1 3 . 1 0 9 7}\end{array}$ & $\begin{array}{l}-2.4356 \\
-\mathbf{0 . 0 3 0 4}\end{array}$ & $\begin{array}{l}-11.4291 \\
\mathbf{- 0 . 1 4 2 6}\end{array}$ \\
\hline
\end{tabular}

ion, with relative mass errors below $1 \mathrm{ppm}$, while those sum formulas consisting only of $\mathrm{C}, \mathrm{H}$ and $\mathrm{O}$ show considerably higher mass errors. The observation of good fragmentation spectra of $\mathrm{Na}^{+}$adducts in the case of the present oligomers might be in agreement with a high content of oxygen atoms working as electron pair donors.

The presence of the parent ions as $\mathrm{Na}^{+}$adducts after $\mathrm{ESI}(+)$ ionization is further confirmed by $\mathrm{ESI}(+) / \mathrm{FTICR}$ MS experiments. Tables $4 \mathrm{a}$ and $\mathrm{b}$ show the results of the $\mathrm{ESI}(+) / F T I C R$ MS measurements for the parent ions formed from EBE and trans-3-hexene. For the most intense oligomer ion series of type (a) (marked in red colour in Fig. 2a-d and in Tables 2 and 4), measured accurate $m / z$ values clearly support the elemental compositions containing a sodium ion, which confirms the results for type (a) parent and fragment ions obtained from ESI(+)/FTICR MS/MS measurements in Tables 3a-d. Furthermore, we examined the parent ions of a less intense oligomer series appearing for most alkenes and enol ethers, which is assigned as type (b) and marked with green colour in Fig. 2a-d and in Tables 2 and 4. The oligomer series of type (b) differs by an additional $\Delta m / z=16$ from the most intense, red-marked series of type (a), which might correspond to an additional oxygen atom in the oligomer molecule, as suggested in our previous work (Sadezky et al.,
2006), or to the exchange of the $\mathrm{Na}^{+}$by a $\mathrm{K}^{+}$during ionization in the $\mathrm{ESI}(+)$ ion source. Accurate $\mathrm{m} / z$ values measured by ESI(+)/FTICR MS show that the oligomer parent ions of type (b) consist of the same elemental composition as the sodiated type (a) oligomers with the $\mathrm{Na}^{+}$being replaced by a $\mathrm{K}^{+}$. Elemental compositions resulting from the addition of an oxygen atom to either the sodiated or the protonated parent ions of type (a) instead result in very high relative mass errors of 40 to $60 \mathrm{ppm}$ and are thus ruled out.

ESI(+)/FTICR MS measurements have also been performed for analyte solutions with added excess $\mathrm{Li}^{+}$. As $\mathrm{Li}^{+}$ions show a greater affinity to organic molecules than $\mathrm{Na}^{+}$and $\mathrm{K}^{+}$, the oligomer molecules are supposed to be ionized in the $\mathrm{ESI}(+)$ ion source rather through addition of $\mathrm{Li}^{+}$instead of $\mathrm{Na}^{+}$or $\mathrm{K}^{+}$. In the ESI(+)/FTICR MS spectra of these experiments, the type (a) parent ions are indeed replaced by a series of oligomer parent ions, whose nominal $\mathrm{m} / z$ are by $\Delta \mathrm{m} / \mathrm{z}=16$ lower than those of the type (a) oligomer parent ions. The observed mass shift of $\Delta m / z=16$ corresponds to the difference between a $\mathrm{Na}^{+}$and a $\mathrm{Li}^{+}$ion. The measured accurate $\mathrm{m} / \mathrm{z}$ values of these ions in Tables $4 \mathrm{a}$ and $\mathrm{b}$ confirm that the elemental compositions are identical to those of the sodiated type (a) and the potassiated type (b) oligmer ions, with the $\mathrm{Na}^{+}$and $\mathrm{K}^{+}$respectively being re- 


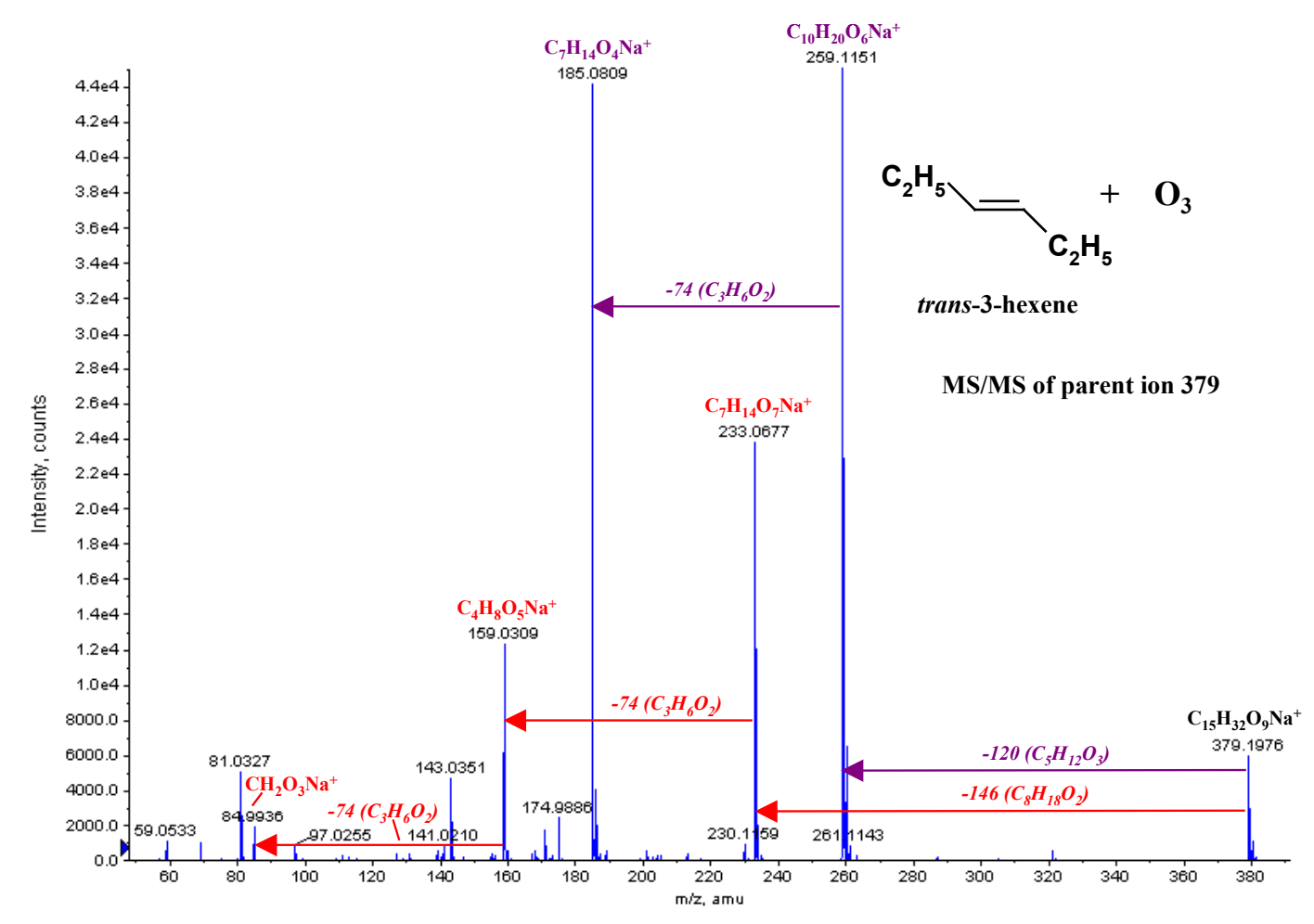

Fig. 4a. SOA formed during the gas phase ozonolysis of trans-3-hexene (initial mixing ratios: 8 ppm ozone, 15 ppm trans-3-hexene): ESI(+)/TOF MS/MS spectrum of the parent ion 379 of oligomer (a).

placed by a $\mathrm{Li}^{+}$. The exchange of $\mathrm{Na}^{+}$by $\mathrm{Li}^{+}$during ESI(+) ionization upon addition of $\mathrm{Li}^{+}$ions to the analyte solution ultimately proves the identity of the type (a) parent ions as $\mathrm{Na}^{+}$adducts and the correctness of the corresponding sum formulas of the ions.

\subsubsection{Principal structure of type (a) oligomers}

The fragmentation pathways characterized by the regular loss of the chain unit typically range from $m / z=300$ to 400 , the masses of the oligomer pseudo-molecular ions, down to $\mathrm{m} / \mathrm{z}$ about 100 for the smallest fragment ions. The regularity of these fragmentation pathways and their analogy observed for oligomers from different enol ethers and alkenes in our present and previous study (Sadezky et al., 2006) indicate that all type (a) oligomers follow the same structural principle. The observations made in our present study corroborate the general linear oligomeric structure that was suggested by Sadezky et al. (2006) for type (a) oligomers from the ozonolysis of AVE and EPE.

The suggested principal structure for the parent ions, and the two main fragmentation pathways marked in violet and red colour, are schematically displayed in Fig. 5 for enol ethers and in Fig. 6 for symmetric alkenes. Like in Sadezky et al. (2006), we represent the oligomeric structure of the parent ions by a chain having a starting group " $\mathrm{X}$ " and an end group "Y" linked by several chain units "CI" of mass 46 (AVE), 60 (EPE), 74 (EBE, trans-3-hexene and 2,3-dimethyl-2-butene), or 88 (trans-4-octene). Ionization of the type (a) oligomers by $\operatorname{ESI}(+)$ most probably takes place through addition of an ion $\mathrm{Na}^{+}$, leading to the formation of the pseudomolecular parent ion as a sodium adduct $\left[\mathrm{X}-(\mathrm{CI})_{n}-\mathrm{Y}+\mathrm{Na}\right]^{+}$. In contrast to Sadezky et al. (2006), where we suggested ion formation by protonation, evaluation of the elemental compositions with the improved mass accuracy of the FTICR MS rather points towards the presence of sodium and potassium adducts (Sect. 3.3.3.). This was confirmed by additional FTICR MS experiments with addition of excess $\mathrm{Li}^{+}$to the analyte solutions. Determination of the elemental compositions by accurate ESI(+)/FTICR MS and MS/MS measurements is discussed in detail in Sect. 3.3.3. of this work. The resulting elemental compositions of type (a) parent ions, fragment ions, and fragmented neutrals are given in the Figs. 4, 5, and 6. In the examples schematically given in Figs. 5 and 6, the number of chain units comprised by the oligomer parent ions $\mathrm{n}$ is 2 , thus leading to the parent ions with masses 283 (EVE), 339 (EPE), 395 (EBE), 379 (trans-3-hexene and 2,3-dimethyl-2-butene) and 449 (trans4-octene) (Table 2).

The fragmentation initiates with a loss of a neutral species $\mathrm{X}$ or $\mathrm{Y}$ from one side of the pseudomolecular 


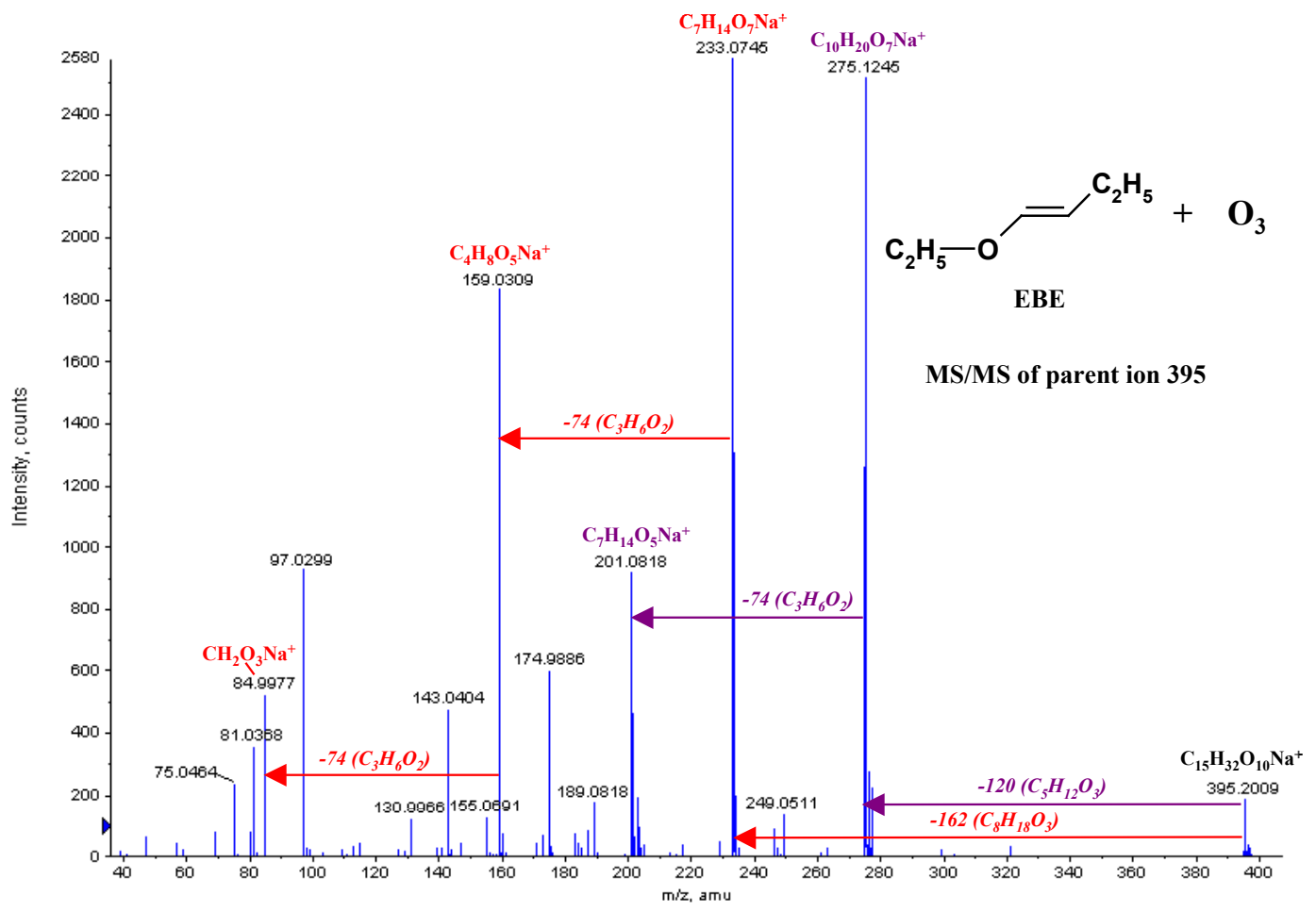

Fig. 4b. SOA formed during the gas phase ozonolysis of ethyl butenyl ether EBE (initial mixing ratios: 8 ppm ozone, 15 ppm EBE): ESI(+)/TOF MS/MS spectrum of the parent ion 395 of oligomer (a).

ion $\left[\mathrm{X}-(\mathrm{CI})_{n}-\mathrm{Y}+\mathrm{Na}\right]^{+}$, leading to the fragment ion $\left[\mathrm{X}-[\mathrm{CI}]_{n}+\mathrm{Na}\right]^{+}$(violet-marked fragmentation pathway) or $\left[\mathrm{Y}-[\mathrm{CI}]_{n}+\mathrm{Na}\right]^{+}$(red-marked fragmentation pathway). Fragmentation continues with $\mathrm{n}$ (red-marked fragmentation pathway) or n-1 (violet-marked fragmentation pathway) successive losses of a chain unit "CI", to finally terminate with a fragment ion $[\mathrm{X}+\mathrm{Na}]^{+}$(violet-marked fragmentation pathway) or $[\mathrm{Y}+\mathrm{Na}]^{+}$(red-marked fragmentation pathway) representing the opposite side of the oligomer molecule. The number of chain units $\mathrm{n}$ comprised in the oligomer molecule corresponds to the number of successive losses of the chain unit "CI" as a neutral fragment directly observed in the MS/MS spectra. Values of $\mathrm{n}$ are given in Table 2 and in Fig. 2a-d.

In the schematic Figs. 5 and 6, the oligomer end group "Y" is thus represented by the terminating fragment ion $[\mathrm{Y}+\mathrm{Na}]^{+}$of the red-coloured fragmentation pathway, and by the initially fragmented neutral $Y$ of the violet-coloured fragmentation pathway. The terminating fragment ion $[\mathrm{Y}+\mathrm{Na}]^{+}$ of the red-coloured fragmentation pathway is shown to be identical for all enol ethers and alkenes, corresponding to $\mathrm{CH}_{2} \mathrm{O}_{3} \mathrm{Na}^{+}(\mathrm{m} / \mathrm{z}, 85)$. The initially fragmented neutrals $\mathrm{Y}$ of the violet-coloured fragmentation pathway are generally composed of a basic unit of similar elemental composition as $[\mathrm{Y}+\mathrm{Na}]^{+}, \mathrm{CH}_{2} \mathrm{O}_{3}$, and additionally twice the vinylic group $\mathrm{R}$ ' of the initial unsaturated compound. This leads to the sum formulas $\mathrm{CH}_{4} \mathrm{O}_{3}$ (mass 64) for EVE ( $\left.\mathrm{R}^{\prime}=\mathrm{H}\right), \mathrm{C}_{3} \mathrm{H}_{8} \mathrm{O}_{3}$ (mass 92) for $\mathrm{EPE}\left(\mathrm{R}^{\prime}=\mathrm{CH}_{3}\right), \mathrm{C}_{5} \mathrm{H}_{12} \mathrm{O}_{3}$ (mass 120) for EBE, trans-3-hexene $\left(\mathrm{R}^{\prime}=\mathrm{C}_{2} \mathrm{H}_{5}\right)$, and 2,3-dimethyl-2-butene, and $\mathrm{C}_{7} \mathrm{H}_{16} \mathrm{O}_{3}$ (mass 148) for trans-4-octene $\left(\mathrm{R}^{\prime}=\mathrm{C}_{3} \mathrm{H}_{7}\right)$.

The opposite side of the oligomer molecule, the starting group " $\mathrm{X}$ " is consequently represented by the terminating fragment ion $[\mathrm{X}+\mathrm{Na}]^{+}$of the violet-coloured fragmentation pathway, and by the initially fragmented neutral $X$ of the red-coloured fragmentation pathway. In most fragmentation spectra, only n-1 successive losses of the chain unit "CI" are observed for the violet-coloured fragmentation pathway, in comparison with $\mathrm{n}$ successive losses of "Cl" observed for the red-coloured fragmentation pathway. Therefore, in Figs. 5 and 6 , the terminating fragment ions $[\mathrm{X}+\mathrm{Na}]^{+}$are deduced by subtraction of another chain unit from the next higher observed fragment ion attributed to $[\mathrm{X}-[\mathrm{CI}]+\mathrm{Na}]^{+}$. Sadezky et al. (2006) also directly observed the ions $[\mathrm{X}+\mathrm{Na}]^{+}$with $\mathrm{m} / \mathrm{z}$ 127 in the MS/MS spectra of the parent ions 329 and 399 formed from EVE and EPE (Table 2).

Figs. 5 and 6 show that, for all enol ethers and alkenes, the terminating fragment ion $[\mathrm{X}+\mathrm{Na}]^{+}$of the violet-coloured fragmentation pathway is based on a basic unit of the elemental composition $\mathrm{C}_{2} \mathrm{H}_{3} \mathrm{O}_{2} \mathrm{Na}^{+}$. For the three enol ethers (Fig. 5), the elemental composition of $[\mathrm{X}+\mathrm{Na}]^{+}$is identical, $\mathrm{C}_{4} \mathrm{H}_{8} \mathrm{O}_{3} \mathrm{Na}^{+}(\mathrm{m} / \mathrm{z}, 127)$, and corresponds to the sum of the alkoxy group $\mathrm{OR}\left(\mathrm{R}=\mathrm{C}_{2} \mathrm{H}_{5}\right)$ of the original enol ethers and 


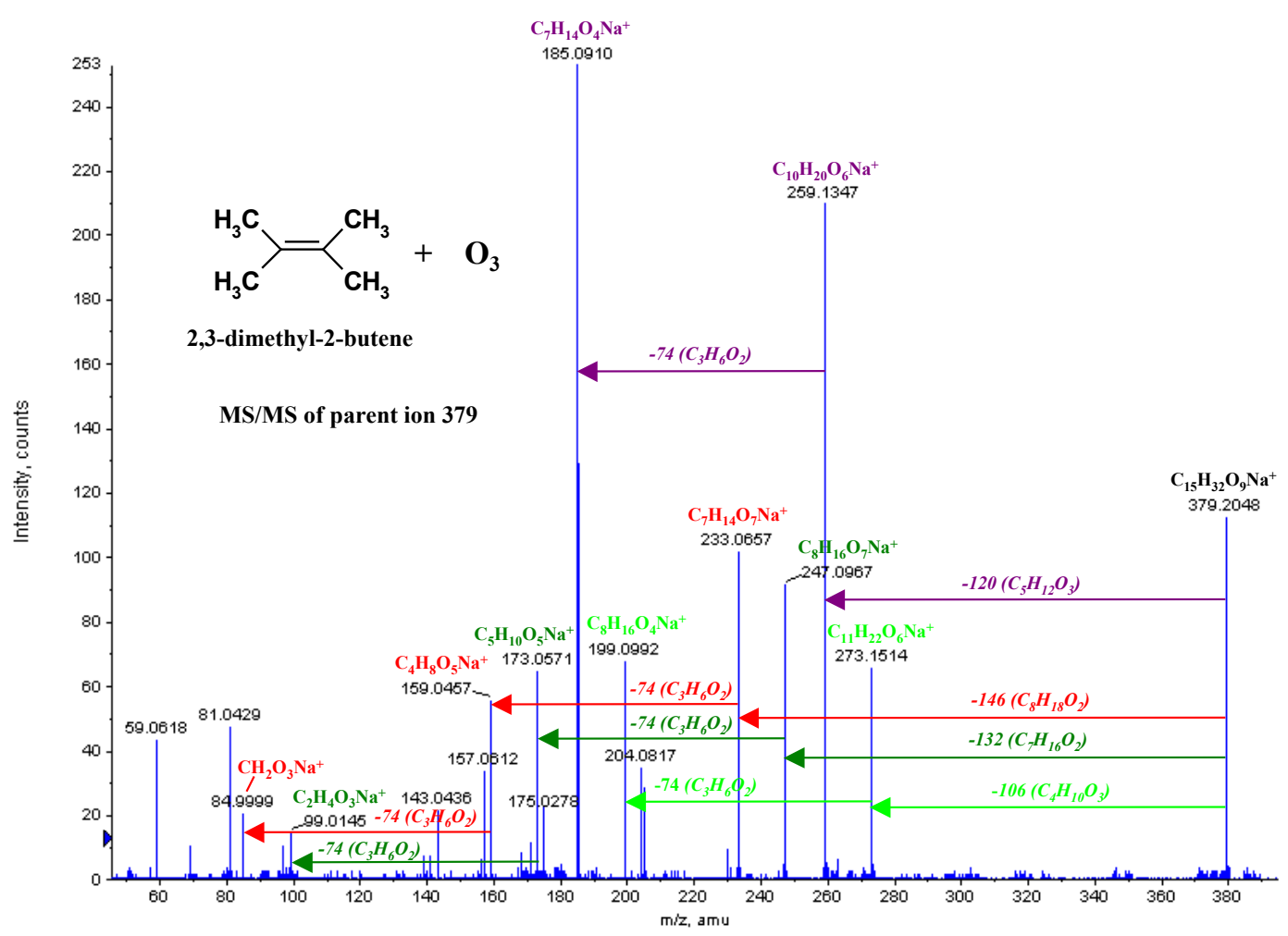

Fig. 4c. SOA formed during the gas phase ozonolysis of 2,3-dimethyl-2-butene (initial mixing ratios: 8 ppm ozone, 15 ppm 2,3-dimethyl-2butene, $300 \mathrm{ppm}$ cyclohexane): ESI(+)/TOF MS/MS spectrum of the parent ion 379 of oligomer (a).

the basic unit $\mathrm{C}_{2} \mathrm{H}_{3} \mathrm{O}_{2} \mathrm{Na}^{+}$. This indicates that the ion 127 , and all fragment ions of the violet-coloured fragmentation pathway, thus contain the alkoxy group OR from the enolic side of the enol ether generally comprised once in each oligomer parent ion (see Sect. 3.3.1. and Fig. 3).

For the symmetric alkenes, the elemental composition of $[\mathrm{X}+\mathrm{Na}]^{+}$corresponds to the sum of the basic unit $\mathrm{C}_{2} \mathrm{H}_{3} \mathrm{O}_{2} \mathrm{Na}^{+}$and the vinylic group R' (Fig. 6), leading to $\mathrm{C}_{4} \mathrm{H}_{8} \mathrm{O}_{2} \mathrm{Na}^{+}(\mathrm{m} / 2,111)$ for trans-3-hexene and 2,3 dimethyl2-butene, and to $\mathrm{C}_{5} \mathrm{H}_{10} \mathrm{O}_{2} \mathrm{Na}^{+}(\mathrm{m} / \mathrm{z}, 125)$ for trans-4-octene. The enolic group OR of the enol ethers is indeed replaced by a second vinylic group R' in the original unsaturated molecules of the symmetric alkenes (Sects. 3.1. and 3.3.1.). Thus, it is consistent that for symmetric alkenes, $[\mathrm{X}+\mathrm{Na}]^{+}$ and all fragment ions of the violet-coloured fragmentation pathway contain the R' group instead of the enolic group $\mathrm{OR}$ of the enol ethers. For example, the enol ether EBE contains the enolic group $\mathrm{OR}=\mathrm{OC}_{2} \mathrm{H}_{5}$, while the symmetric alkene trans-3-hexene contains the vinylic group $\mathrm{R}^{\prime}=\mathrm{C}_{2} \mathrm{H}_{5}$ instead. Both groups only differ by the enolic $\mathrm{O}$ atom. Indeed, $[\mathrm{X}+\mathrm{Na}]^{+}$and all fragment ions of the violet-coloured fragmentation pathways of oligomers from trans-3-hexene differ by an oxygen atom $(\Delta m / z=16)$ from those formed from EBE. The oligomer parent ions formed from trans-3hexene and EBE show the same difference of an $\mathrm{O}$ atom $(\Delta$ $m / z=16$ ) (Sect. 3.3.1.), which obviously corresponds to an exchange of an enolic and a vinylic group and is conserved in the fragment ions of their violet-coloured fragmentation pathways.

Figs. 5 and 6 illustrate that each of the initially fragmented neutrals $\mathrm{X}$ and $\mathrm{Y}$ of the violet- and red-coloured fragmentation pathway is composed of the elemental composition of the terminating fragment ion $[\mathrm{X}+\mathrm{Na}]^{+}$or $[\mathrm{Y}+\mathrm{Na}]^{+}$of the respective opposite fragmentation pathway, and additionally twice the vinylic group R'. Taking into account the composition of $[\mathrm{X}+\mathrm{Na}]^{+}$discussed before, the initially fragmented neutral $\mathrm{X}$ of the red-coloured fragmentation pathway thus comprises, besides the two additional vinylic groups $\mathrm{R}^{\prime}$, the basic unit $\mathrm{C}_{2} \mathrm{H}_{3} \mathrm{O}_{2}$ of the ion $[\mathrm{X}+\mathrm{Na}]^{+}$and either an enolic group $\mathrm{OR}\left(\mathrm{R}=\mathrm{C}_{2} \mathrm{H}_{5}\right)$ for the enol ethers (Fig. 5) or a third vinylic group R' for the symmetric alkenes (Fig. 6). The resulting sum formulas for $\mathrm{X}$ are the following: $\mathrm{C}_{4} \mathrm{H}_{10} \mathrm{O}_{3}$ (mass 106) for $\mathrm{EVE}\left(\mathrm{R}^{\prime}=\mathrm{H}\right), \mathrm{C}_{6} \mathrm{H}_{14} \mathrm{O}_{3}$ (mass 134) for EPE $\left(\mathrm{R}^{\prime}=\mathrm{CH}_{3}\right), \mathrm{C}_{8} \mathrm{H}_{18} \mathrm{O}_{3}$ (mass 162) for $\mathrm{EBE}$, $\mathrm{C}_{8} \mathrm{H}_{18} \mathrm{O}_{2}$ (mass 146) for trans-3-hexene $\left(\mathrm{R}^{\prime}=\mathrm{C}_{2} \mathrm{H}_{5}\right)$ and 2,3dimethyl-2-butene, and $\mathrm{C}_{11} \mathrm{H}_{24} \mathrm{O}_{2}$ (mass 188) for trans-4octene $\left(\mathrm{R}^{\prime}=\mathrm{C}_{3} \mathrm{H}_{7}\right)$. For EBE, $\mathrm{X}$ thus contains an additional oxygen atom $(\Delta m / z, 16)$ in comparison with trans-3-hexene, which corresponds to the difference between the enolic group $\mathrm{OC}_{2} \mathrm{H}_{5}$ and a vinylic group $\mathrm{C}_{2} \mathrm{H}_{5}$. As the location of the exchange of vinylic and enolic group, which differentiates the oligomer parent ions formed from trans-3-hexene and EBE, 


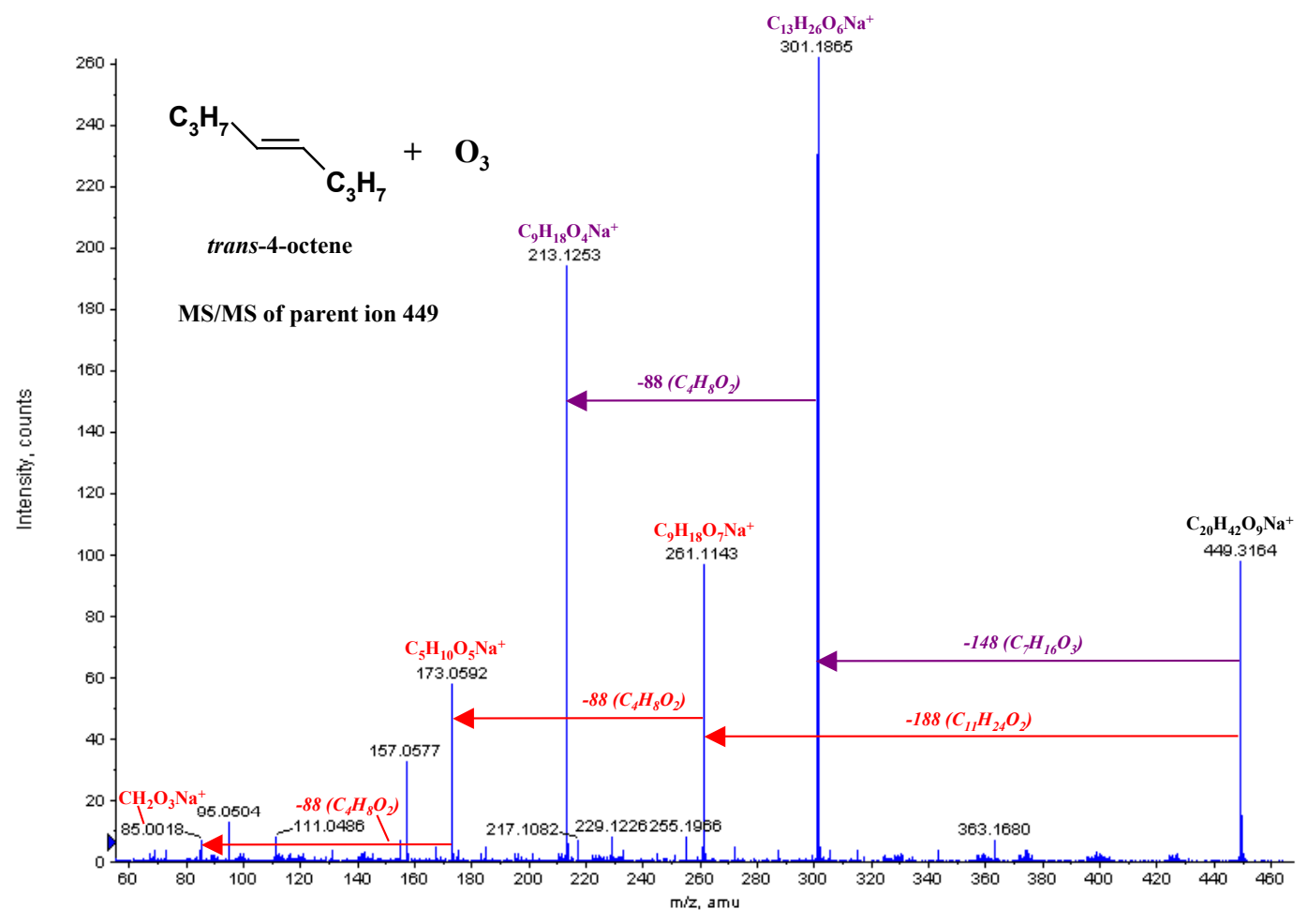

Fig. 4d. SOA formed during the gas phase ozonolysis of trans-4-octene (initial mixing ratios: 8 ppm ozone, $15 \mathrm{ppm}$ trans-4-octene): ESI(+)/TOF MS/MS spectrum of the parent ion 449 of oligomer (a).

is thus comprised in the initial neutral fragment $\mathrm{X}$, all subsequent fragment ions of the red-coloured fragmentation pathway following the loss of $\mathrm{X}$ are identical for both parent ions.

Oligomers formed from the symmetric alkene 2,3dimethyl-2-butene show the same chemical composition as those observed for trans-3-hexene (Sect. 3.3.1 and Table 2). Moreover, their main fragmentation pathways displayed in violet and red colour in Fig. 6 are identical to those of the oligomers from trans-3-hexene. Like the two initial alkenes, oligomers and their fragment ions originating from trans-3hexene and 2,3-dimethyl-2-butene are most likely isomers. A parent or fragment ion or a fragmented neutral for 2,3dimethyl-2-butene can be formally deduced from the analogous ion for trans-3-hexene by replacing a $\mathrm{C}_{2} \mathrm{H}_{5}$ group and an $\mathrm{H}$ atom substituent by two $\mathrm{CH}_{3}$ substituents. However, in comparison with type (a) oligomers formed from trans3-hexene, those for 2,3-dimethyl-2-butene show additional fragmentation pathways marked in dark and light green in the MS/MS spectrum in Fig. 4c. The fragmentation pathway marked in dark green colour is apparently analogous to a third fragmentation pathway identified for oligomers from the enol ethers EVE and EPE (Sadezky et al., 2006), and terminates for all three unsaturated compounds on a fragment ion of identical $\mathrm{m} / \mathrm{z}$ 99. The fragment ions of this pathway generally comprise an additional $\mathrm{CH}_{2}$ unit $(\Delta \mathrm{m} / \mathrm{z}$
14) in comparison to those of the red-marked fragmentation pathway of the same oligomer parent ion. The fourth pathway, marked in light green colour, is observed for the parent oligomer ions from 2,3-dimethyl-2-butene only. Its fragment ions contain an additional $\mathrm{CH}_{2}$ unit $(\Delta m / z$ 14) compared to those of the violet-marked fragmentation pathway.

The description of the oligomeric structure and its fragmentation pathways in Figs. 5 and 6 is consistent with Sadezky et al. (2006), in which we investigated oligomer formation from a variety of enol ethers. Figs. 5 and 6 illustrate that the oligomers shown to be formed from the enol ether EBE and the symmetric alkenes in our present work agree very well with the structural principles suggested in our previous study. As in our previous work (Sadezky et al., 2006), we define the starting group "X" of the oligomer structure by the presence of the enolic group OR of the original enol ethers in the respective fragment ions and initially fragmented neutrals. The new elemental compositions of parent and fragment ions determined by ESI(+)/FTICR in our present work demonstrates the analogy among initially fragmented neutrals $\mathrm{X}$ and $\mathrm{Y}$ and terminating fragment ions $[\mathrm{X}+\mathrm{Na}]^{+}$and $[\mathrm{Y}+\mathrm{Na}]^{+}$representing the two endings " $\mathrm{X}$ " and "Y" of a linear oligomeric chain. 
Table 4a. ESI(+)/FTICR MS measurements of oligomers formed from trans-3-hexene: Elemental compositions of type (a) and type (b) parent ions, and of parent ions after addition of $\mathrm{Li}^{+}$to the analyte solution.

\begin{tabular}{|c|c|c|c|c|}
\hline $\begin{array}{c}\text { Accurate mass } \\
\text { (u) }\end{array}$ & $\begin{array}{c}\text { Elemental } \\
\text { composition }\end{array}$ & $\begin{array}{c}\text { Exact mass } \\
\text { (u) }\end{array}$ & $\begin{array}{l}\text { Absolute mass } \\
\text { error (mDa) }\end{array}$ & $\begin{array}{c}\text { Relative mass } \\
\text { error (ppm) }\end{array}$ \\
\hline \multicolumn{5}{|l|}{$\begin{array}{c}379.19364 \\
\text { Type (a) parent ion }\end{array}$} \\
\hline$\left[\mathrm{X}-[74]_{2}-\mathrm{Y}+\mathrm{H}\right]^{+}$ & $\mathrm{C}_{17} \mathrm{H}_{31} \mathrm{O}_{9}$ & 379.1962 & -2.6194 & -6.9078 \\
\hline$\left[\mathrm{X}-[74]_{2}-\mathrm{Y}+\mathrm{Na}\right]^{+}$ & $\mathrm{C}_{15} \mathrm{H}_{32} \mathrm{O}_{9} \mathrm{Na}^{+}$ & 379.1938 & -0.2141 & -0.5647 \\
\hline \multicolumn{5}{|l|}{$\begin{array}{l}395.16762 \\
\text { Type (b) parent ion }\end{array}$} \\
\hline$\left.[\mathrm{X}-74]_{2}-\mathrm{Y}+\mathrm{K}\right]^{+}$ & $\mathrm{C}_{15} \mathrm{H}_{32} \mathrm{O}_{9} \mathrm{~K}^{+}$ & 395.1677 & -0.1723 & -0.4361 \\
\hline$\left[\mathrm{X}-[74]_{2}-\mathrm{Y}(\mathrm{O})+\mathrm{Na}\right]^{+}$ & $\mathrm{C}_{15} \mathrm{H}_{32} \mathrm{O}_{10} \mathrm{Na}^{+}$ & 395.1887 & -21.1488 & -53.5184 \\
\hline$\left[\mathrm{X}-[74]_{2}-\mathrm{Y}(\mathrm{O})+\mathrm{H}\right]^{+}$ & $\mathrm{C}_{17} \mathrm{H}_{31} \mathrm{O}_{10}$ & 395.1911 & -23.554 & -59.6051 \\
\hline \multicolumn{5}{|l|}{$\begin{array}{c}363.22029 \\
\text { parent ion with } \mathrm{Li}^{+} \\
\text {exchange }\end{array}$} \\
\hline$\left[\mathrm{X}-[\mathbf{7 4}]_{2}-\mathrm{Y}+\mathrm{Li}\right]^{+}$ & $\mathrm{C}_{15} \mathrm{H}_{32} \mathrm{O}_{9} \mathrm{Li}^{+}$ & 363.22 & 0.201 & 0.5534 \\
\hline \multicolumn{5}{|l|}{$\begin{array}{c}453.23031 \\
\text { Type (a) parent ion }\end{array}$} \\
\hline$\left[\mathrm{X}-[74]_{3}-\mathrm{Y}+\mathrm{H}\right]^{+}$ & $\mathrm{C}_{20} \mathrm{H}_{37} \mathrm{O}_{11}$ & 453.233 & -2.7289 & -6.021 \\
\hline$\left[\mathrm{X}-[74]_{3}-\mathrm{Y}+\mathrm{Na}\right]^{+}$ & $\mathrm{C}_{18} \mathrm{H}_{38} \mathrm{O}_{11} \mathrm{Na}^{+}$ & 453.2306 & -0.3236 & -0.7141 \\
\hline \multicolumn{5}{|l|}{$\begin{array}{c}469.20431 \\
\text { Type (b) parent ion }\end{array}$} \\
\hline$\left.[\mathrm{X}-74]_{3}-\mathrm{Y}+\mathrm{K}\right]^{+}$ & $\mathrm{C}_{18} \mathrm{H}_{38} \mathrm{O}_{11} \mathrm{~K}^{+}$ & 469.2045 & -0.2618 & -0.5581 \\
\hline$\left[\mathrm{X}-[74]_{3}-\mathrm{Y}(\mathrm{O})+\mathrm{Na}\right]^{+}$ & $\mathrm{C}_{18} \mathrm{H}_{38} \mathrm{O}_{12} \mathrm{Na}^{+}$ & 469.2255 & -21.2383 & -45.2644 \\
\hline$\left[\mathrm{X}-[74]_{3}-\mathrm{Y}(\mathrm{O})+\mathrm{H}\right]^{+}$ & $\mathrm{C}_{20} \mathrm{H}_{37} \mathrm{O}_{12}$ & 469.2279 & -23.6435 & -50.3907 \\
\hline \multicolumn{5}{|l|}{$\begin{array}{c}437.25712 \\
\text { parent ion with } \mathrm{Li}^{+} \\
\text {exchange }\end{array}$} \\
\hline$\left[\mathrm{X}-[\mathbf{7 4}]_{3}-\mathrm{Y}+\mathbf{L i}\right]^{+}$ & $\mathrm{C}_{18} \mathrm{H}_{38} \mathrm{O}_{11} \mathrm{Li}^{+}$ & 437.2568 & 0.2515 & 0.5752 \\
\hline \multicolumn{5}{|l|}{$\begin{array}{c}527.26708 \\
\text { Type (a) parent ion }\end{array}$} \\
\hline$\left[\mathrm{X}-[74]_{4}-\mathrm{Y}+\mathrm{H}\right]^{+}$ & $\mathrm{C}_{23} \mathrm{H}_{43} \mathrm{O}_{13}$ & 527.2698 & -2.7384 & -5.1936 \\
\hline$\left[\mathrm{X}-[74]_{4}-\mathrm{Y}+\mathrm{Na}\right]^{+}$ & $\mathrm{C}_{21} \mathrm{H}_{44} \mathrm{O}_{13} \mathrm{Na}^{+}$ & 527.2674 & -0.3332 & -0.6319 \\
\hline \multicolumn{5}{|l|}{$\begin{array}{l}543.24117 \\
\text { Type (b) parent ion }\end{array}$} \\
\hline$\left.[\mathrm{X}-74]_{4}-\mathrm{Y}+\mathrm{K}\right]^{+}$ & $\mathrm{C}_{21} \mathrm{H}_{44} \mathrm{O}_{13} \mathrm{~K}^{+}$ & 543.2413 & -0.1813 & -0.3339 \\
\hline$\left[X-[74]_{4}-\mathrm{Y}(\mathrm{O})+\mathrm{Na}\right]^{+}$ & $\mathrm{C}_{21} \mathrm{H}_{44} \mathrm{O}_{14} \mathrm{Na}^{+}$ & 543.2623 & -21.1578 & -38.9473 \\
\hline$\left[\mathrm{X}-[74]_{4}-\mathrm{Y}(\mathrm{O})+\mathrm{H}\right]^{+}$ & $\mathrm{C}_{23} \mathrm{H}_{43} \mathrm{O}_{14}$ & 543.2647 & -23.563 & -43.3749 \\
\hline \multicolumn{5}{|l|}{$\begin{array}{l}511.29410 \\
\text { parent ion with } \mathrm{Li}^{+} \\
\text {exchange }\end{array}$} \\
\hline$\left[\mathrm{X}-[\mathbf{7 4}]_{4}-\mathrm{Y}+\mathrm{Li}\right]^{+}$ & $\mathrm{C}_{21} \mathbf{H}_{44} \mathbf{O}_{13} \mathrm{Li}^{+}$ & 511.2936 & 0.452 & 0.884 \\
\hline
\end{tabular}

\subsubsection{Isomers}

The MS/MS spectra of the type (a) oligomer ions formed from the unsaturated compounds studied in the present work are much less complex than those described for the enol ethers AVE and EPE in our previous study (Sadezky et al., 2006). While between two and four fragmentation pathways are observed for each type (a) oligomer parent ion in the present work, up to nine fragmentation pathways were si- multaneously identified for each parent oligomer ion formed from AVE and EPE. In our previous study by Sadezky et al. (2006), we attributed the richness and complexity of the fragmentation spectra for AVE and EPE to the existence of several isomers of the linear type (a) oligomer parent ion. Therefore, in the MS/MS spectrum of a pseudomolecular ion of a certain $\mathrm{m} / \mathrm{z}$, the fragmentation pathways of all its isomers appear simultaneously, leading to the observed large number of different fragmentation pathways. 
Table 4b. ESI(+)/FTICR MS measurements of oligomers formed from EBE: Elemental compositions of type (a) and type (b) parent ions, and of parent ions after addition of $\mathrm{Li}^{+}$to the analyte solution.

\begin{tabular}{|c|c|c|c|c|}
\hline $\begin{array}{c}\text { Accurate mass } \\
(\text { u) }\end{array}$ & $\begin{array}{c}\text { Elemental } \\
\text { composition }\end{array}$ & $\begin{array}{c}\text { Exact mass } \\
\text { (u) }\end{array}$ & $\begin{array}{l}\text { Absolute mass } \\
\text { error (mDa) }\end{array}$ & $\begin{array}{l}\text { Relative mass } \\
\text { error (ppm) }\end{array}$ \\
\hline \multicolumn{5}{|l|}{$\begin{array}{c}395.18899 \\
\text { Type (a) parent ion }\end{array}$} \\
\hline$\left[\mathrm{X}-[74]_{2}-\mathrm{Y}+\mathrm{H}\right]^{+}$ & $\mathrm{C}_{17} \mathrm{H}_{31} \mathrm{O}_{10}$ & 395.1911 & -2.184 & -5.5266 \\
\hline$\left[\mathrm{X}-[74]_{2}-\mathrm{Y}+\mathrm{Na}\right]^{+}$ & $\mathrm{C}_{15} \mathrm{H}_{32} \mathrm{O}_{10} \mathrm{Na}^{+}$ & 395.1887 & 0.2211 & 0.5597 \\
\hline \multicolumn{5}{|l|}{$\begin{array}{c}411.16333 \\
\text { Type (b) parent ion }\end{array}$} \\
\hline$\left.[\mathrm{X}-74]_{2}-\mathrm{Y}+\mathrm{K}\right]^{+}$ & $\mathrm{C}_{15} \mathrm{H}_{32} \mathrm{O}_{10} \mathrm{~K}^{+}$ & 411.1627 & 0.6229 & 1.5152 \\
\hline$\left[\mathrm{X}-[74]_{2}-\mathrm{Y}(\mathrm{O})+\mathrm{Na}\right]^{+}$ & $\mathrm{C}_{15} \mathrm{H}_{32} \mathrm{O}_{11} \mathrm{Na}^{+}$ & 411.1836 & -20.3534 & -49.502 \\
\hline$\left[\mathrm{X}-[74]_{2}-\mathrm{Y}(\mathrm{O})+\mathrm{H}\right]^{+}$ & $\mathrm{C}_{17} \mathrm{H}_{31} \mathrm{O}_{11}$ & 411.186 & -22.7586 & -55.3518 \\
\hline \multicolumn{5}{|l|}{$\begin{array}{l}379.21525 \\
\text { parent ion with } \mathrm{Li}^{+} \\
\text {exchange }\end{array}$} \\
\hline$\left[\mathrm{X}-[74]_{2}-\mathrm{Y}+\mathrm{Li}\right]^{+}$ & $\mathrm{C}_{15} \mathrm{H}_{32} \mathrm{O}_{10} \mathrm{Li}^{+}$ & 379.215 & 0.2463 & 0.6497 \\
\hline \multicolumn{5}{|l|}{$\begin{array}{c}469.22592 \\
\text { Type (a) parent ion }\end{array}$} \\
\hline$\left[\mathrm{X}-[74]_{3}-\mathrm{Y}+\mathrm{H}\right]^{+}$ & $\mathrm{C}_{20} \mathrm{H}_{37} \mathrm{O}_{12}$ & 469.2279 & -2.0335 & -4.3338 \\
\hline$\left[\mathrm{X}-[74]_{3}-\mathrm{Y}+\mathrm{Na}\right]^{+}$ & $\mathrm{C}_{18} \mathrm{H}_{38} \mathrm{O}_{12} \mathrm{Na}^{+}$ & 469.2255 & 0.3716 & 0.7921 \\
\hline \multicolumn{5}{|l|}{$\begin{array}{l}485.20006 \\
\text { Type (b) parent ion }\end{array}$} \\
\hline$\left.[\mathrm{X}-74]_{3}-\mathrm{Y}+\mathrm{K}\right]^{+}$ & $\mathrm{C}_{18} \mathrm{H}_{38} \mathrm{O}_{12} \mathrm{~K}^{+}$ & 485.1994 & 0.5734 & 1.1819 \\
\hline$\left[\mathrm{X}-[74]_{3}-\mathrm{Y}(\mathrm{O})+\mathrm{Na}\right]^{+}$ & $\mathrm{C}_{18} \mathrm{H}_{38} \mathrm{O}_{13} \mathrm{Na}^{+}$ & 485.2204 & -20.4029 & -42.0505 \\
\hline$\left[\mathrm{X}-[74]_{3}-\mathrm{Y}(\mathrm{O})+\mathrm{H}\right]^{+}$ & $\mathrm{C}_{20} \mathrm{H}_{37} \mathrm{O}_{13}$ & 485.2228 & -22.8082 & -47.0078 \\
\hline \multicolumn{5}{|l|}{$\begin{array}{l}\mathbf{4 5 3 . 2 5 2 0 2} \\
\text { parent ion with } \mathrm{Li}^{+} \\
\quad \text { exchange }\end{array}$} \\
\hline$\left[\mathrm{X}-[74]_{3}-\mathrm{Y}+\mathrm{Li}\right]^{+}$ & $\mathrm{C}_{18} \mathrm{H}_{38} \mathrm{O}_{12} \mathrm{Li}^{+}$ & 453.2517 & 0.2368 & 0.5226 \\
\hline \multicolumn{5}{|l|}{$\begin{array}{c}543.26322 \\
\text { Type (a) parent ion }\end{array}$} \\
\hline$\left[\mathrm{X}-[74]_{4}-\mathrm{Y}+\mathrm{H}\right]^{+}$ & $\mathrm{C}_{23} \mathrm{H}_{43} \mathrm{O}_{14}$ & 543.2647 & -1.513 & -2.7852 \\
\hline$\left[\mathrm{X}-[74]_{4}-\mathrm{Y}+\mathrm{Na}\right]^{+}$ & $\mathrm{C}_{21} \mathrm{H}_{44} \mathrm{O}_{14} \mathrm{Na}^{+}$ & 543.2623 & 0.8921 & 1.6422 \\
\hline \multicolumn{5}{|l|}{$\begin{array}{c}559.23724 \\
\text { Type (b) parent ion }\end{array}$} \\
\hline$\left.[\mathrm{X}-74]_{4}-\mathrm{Y}+\mathrm{K}\right]^{+}$ & $\mathbf{C}_{21} \mathbf{H}_{44} \mathrm{O}_{14} \mathrm{~K}^{+}$ & 559.2362 & 0.9739 & 1.7415 \\
\hline$\left[\mathrm{X}-[74]_{4}-\mathrm{Y}(\mathrm{O})+\mathrm{Na}\right]^{+}$ & $\mathrm{C}_{21} \mathrm{H}_{44} \mathrm{O}_{15} \mathrm{Na}^{+}$ & 559.2572 & -20.0024 & -35.7673 \\
\hline$\left[\mathrm{X}-[74]_{4}-\mathrm{Y}(\mathrm{O})+\mathrm{H}\right]^{+}$ & $\mathrm{C}_{23} \mathrm{H}_{43} \mathrm{O}_{15}$ & 559.2596 & -22.4077 & -40.0683 \\
\hline \multicolumn{5}{|l|}{$\begin{array}{l}\mathbf{5 2 7 . 2 8 8 9 6} \\
\text { parent ion with } \mathrm{Li}^{+} \\
\text {exchange }\end{array}$} \\
\hline$\left[\mathrm{X}-[\mathbf{7 4}]_{4}-\mathrm{Y}+\mathbf{L i}\right]^{+}$ & $\mathrm{C}_{21} \mathbf{H}_{44} \mathbf{O}_{14} \mathbf{L i}^{+}$ & 527.2885 & 0.3973 & 0.7535 \\
\hline
\end{tabular}

The much smaller number of fragmentation pathways observed in the present work therefore indicates that a much smaller variety of isomers exists for these oligomer parent ions. The reason of this might be the larger size of the oligomer chain units, which are of mass $74\left(\mathrm{C}_{3} \mathrm{H}_{6} \mathrm{O}_{2}\right.$ for EBE, trans-3-hexene and 2,3-dimethyl-2-butene) and mass $88\left(\mathrm{C}_{4} \mathrm{H}_{8} \mathrm{O}_{2}\right.$ for trans-4-octene $)$ in the present work compared to mass $46\left(\mathrm{CH}_{2} \mathrm{O}_{2}\right.$ for AVE) and mass $60\left(\mathrm{C}_{2} \mathrm{H}_{4} \mathrm{O}_{2}\right.$ for EPE) in our previous study (Sadezky et al., 2006). With increasing size, the chain units eventually become more sterically hindered, an effect that might exclude the formation of some isomers and moreover reduce the total degree of oligomerization (Sect. 3.3.1).

Interestingly, MS/MS spectra of type (a) oligomers formed from 2,3,-dimethyl-2-butene show at least four different fragmentation pathways (Fig. 4c), while those of type (a) 


\title{
$\left[\mathrm{X}-[\mathrm{CI}]_{2}-\mathrm{Y}+\mathrm{Na}\right]^{+}$Parention
}

\author{
Ethyl vinyl ether $\left(\mathrm{R}^{`}=\mathrm{H}\right): \quad \mathrm{C}_{7} \mathrm{H}_{16} \mathrm{O}_{10} \mathrm{Na}^{+}(283)^{*}$ \\ Ethyl propenyl ether $\left(\mathrm{R}^{`}=\mathrm{CH} 3\right): \quad \mathrm{C}_{11} \mathrm{H}_{24} \mathrm{O}_{10} \mathrm{Na}^{+}(339)^{*}$ \\ Ethyl butenyl ether $\left(\mathrm{R}^{\star}=\mathrm{C} 2 \mathrm{H} 5\right): \quad \mathrm{C}_{15} \mathrm{H}_{32} \mathrm{O}_{10} \mathrm{Na}^{+}(395)$
}

\begin{abstract}
Initial neutral loss $\mathrm{X}: \mathrm{C}_{4} \mathrm{H}_{8} \mathrm{O}_{3}+2 \times \mathrm{R}^{6}$
Ethyl vinyl ether $\left(\mathrm{R}^{`}=\mathrm{H}\right): \quad \mathrm{C}_{4} \mathrm{H}_{10} \mathrm{O}_{3}(106)$

Ethyl propenyl ether $\left(\mathrm{R}^{\mathrm{c}}=\mathrm{CH}_{3}\right): \mathrm{C}_{6} \mathrm{H}_{14} \mathrm{O}_{3}(134)$

Ethyl butenyl ether $\left(\mathrm{R}^{\mathrm{c}}=\mathrm{C}_{2} \mathrm{H}_{5}\right): \mathrm{C}_{8} \mathrm{H}_{18} \mathrm{O}_{3}(162)$
\end{abstract}

Initial neutral loss $\mathrm{Y}: \mathrm{CH}_{2} \mathrm{O}_{3}+2 \times \mathrm{R}^{6}$

Ethyl vinyl ether $\left(\mathrm{R}^{`}=\mathrm{H}\right): \quad \mathrm{CH}_{4} \mathrm{O}_{3} \quad$ (64)

Ethyl propenyl ether $\left(\mathrm{R}^{\star}=\mathrm{CH}_{3}\right): \mathrm{C}_{3} \mathrm{H}_{8} \mathrm{O}_{3}$ (92)

Ethyl butenyl ether $\left(\mathrm{R}^{`}=\mathrm{C}_{2} \mathrm{H}_{5}\right): \mathrm{C}_{5} \mathrm{H}_{12} \mathrm{O}_{3}(120)$

$$
\begin{array}{ccc}
\text { Fragment ion } & {\left[\mathbf{Y}-[\mathbf{C I}]_{2}+\mathbf{N a}\right]^{+} \quad\left[\mathbf{X}-[\mathbf{C I}]_{2}+\mathbf{N a}\right]^{+}} & \text {Fragment ion } \\
\mathrm{C}_{3} \mathrm{H}_{6} \mathrm{O}_{7} \mathrm{Na}^{+}(177) & \text { Ethyl vinyl ether }\left(\mathrm{R}^{`}=\mathrm{H}\right): & \mathrm{C}_{6} \mathrm{H}_{12} \mathrm{O}_{7} \mathrm{Na}^{+}(219) \\
\mathrm{C}_{5} \mathrm{H}_{10} \mathrm{O}_{7} \mathrm{Na}^{+}(205) & \text { Ethyl propenyl ether }\left(\mathrm{R}^{`}=\mathrm{CH}_{3}\right): & \mathrm{C}_{8} \mathrm{H}_{16} \mathrm{O}_{7} \mathrm{Na}^{+}(247) \\
\mathrm{C}_{7} \mathrm{H}_{14} \mathrm{O}_{7} \mathrm{Na}^{+}(233) & \text { Ethyl butenyl ether }\left(\mathrm{R}^{`}=\mathrm{C}_{2} \mathrm{H}_{5}\right) & \mathrm{C}_{10} \mathrm{H}_{20} \mathrm{O}_{7} \mathrm{Na}^{+}(275)
\end{array}
$$

Loss of neutral chain carrier [CI]:

Ethyl vinyl ether $\left(\mathrm{R}^{`}=\mathrm{H}\right): \quad \mathrm{CH}_{2} \mathrm{O}_{2} \quad(46)$

Ethyl propenyl ether $\left(\mathrm{R}^{`}=\mathrm{CH}_{3}\right): \mathrm{C}_{2} \mathrm{H}_{4} \mathrm{O}_{2}$ (60)

Ethyl butenyl ether $\left(\mathrm{R}^{\mathrm{c}}=\mathrm{C}_{2} \mathrm{H}_{5}\right): \mathrm{C}_{3} \mathrm{H}_{6} \mathrm{O}_{2}$ (74)
Loss of neutral chain carrier $[\mathrm{CI}]$ :

Ethyl vinyl ether $\left(\mathrm{R}^{\natural}=\mathrm{H}\right): \quad \mathrm{CH}_{2} \mathrm{O}_{2} \quad(46)$

Ethyl propenyl ether $\left(\mathrm{R}^{`}=\mathrm{CH}_{3}\right): \mathrm{C}_{2} \mathrm{H}_{4} \mathrm{O}_{2}$ (60)

Ethyl butenyl ether $\left(\mathrm{R}^{`}=\mathrm{C}_{2} \mathrm{H}_{5}\right): \mathrm{C}_{3} \mathrm{H}_{6} \mathrm{O}_{2}$ (74)

$$
\begin{array}{ccc}
\text { Fragment ion } & \left.\mathbf{Y}-[\mathbf{C I}]_{\mathbf{1}}+\mathbf{N a}\right]^{+} \quad\left[\mathbf{X}-[\mathbf{C I}]_{\mathbf{1}}+\mathbf{N a}\right]^{+} & \text {Fragment ion } \\
& \text { Ethyl vinyl ether }\left(\mathrm{R}^{`}=\mathrm{H}\right): & \mathrm{C}_{5} \mathrm{H}_{10} \mathrm{O}_{5} \mathrm{Na}^{+}(173) \\
\mathrm{C}_{2} \mathrm{H}_{4} \mathrm{O}_{5} \mathrm{Na}^{+}(131) & \text { Ethyl propenyl ether }\left(\mathrm{R}^{`}=\mathrm{CH}_{3}\right): & \mathrm{C}_{6} \mathrm{H}_{12} \mathrm{O}_{5} \mathrm{Na}^{+}(187) \\
\mathrm{C}_{3} \mathrm{H}_{6} \mathrm{O}_{5} \mathrm{Na}^{+}(145) & \text { Ethyl butenyl ether }\left(\mathrm{R}^{`}=\mathrm{C}_{2} \mathrm{H}_{5}\right) & \mathrm{C}_{7} \mathrm{H}_{14} \mathrm{O}_{5} \mathrm{Na}^{+}(201) \\
\mathrm{C}_{4} \mathrm{H}_{8} \mathrm{O}_{5} \mathrm{Na}^{+}(159) &
\end{array}
$$

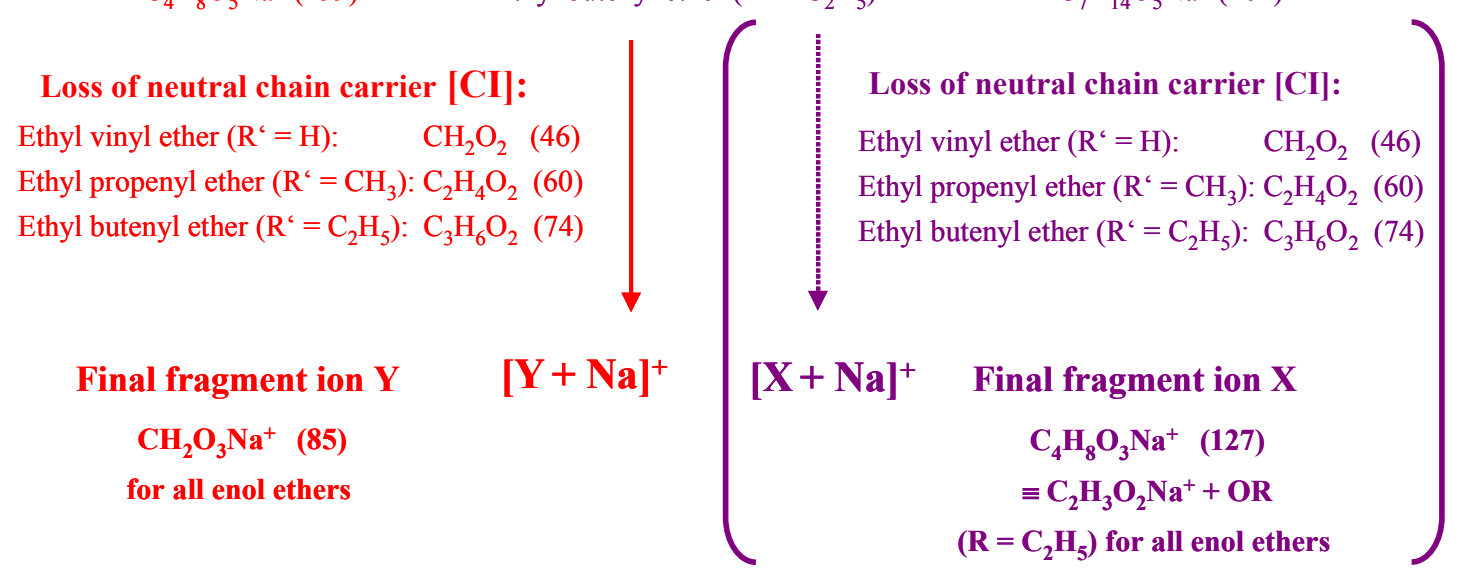

* Oligomers studied in our previous work (Sadezky et al., 2006).

Fig. 5. Schematic structure and main fragmentation pathways of type (a) oligomers formed during gas-phase ozonolysis of enol ethers ( $\mathrm{n}=2$ ). 


\section{$\left[\mathrm{X}-[\mathrm{CI}]_{2}-\mathrm{Y}+\mathrm{Na}\right]^{+}$Parention}

$$
\begin{array}{r}
\text { trans-3-hexene }\left(\mathrm{R}^{`}=\mathrm{C}_{2} \mathrm{H}_{5}\right) \text { and 2,3-dimethyl-2-butene : } \mathrm{C}_{15} \mathrm{H}_{32} \mathrm{O}_{9} \mathrm{Na}^{+}(379) \\
\text { trans-4-octene }\left(\mathrm{R}^{`}=\mathrm{C}_{3} \mathrm{H}_{7}\right): \mathrm{C}_{20} \mathrm{H}_{42} \mathrm{O}_{9} \mathrm{Na}^{+} \text {(449) }
\end{array}
$$

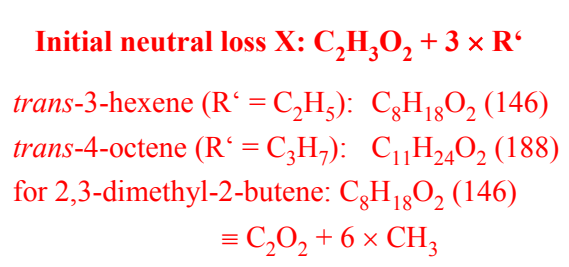

Fragment ion

$$
\begin{aligned}
& \mathrm{C}_{7} \mathrm{H}_{14} \mathrm{O}_{7} \mathrm{Na}^{+}(233) \text { trans-3-hexene }\left(\mathrm{R}^{\star}=\mathrm{C}_{2} \mathrm{H}_{5}\right) \text { and 2,3-dimethyl-2-butene } \mathrm{C}_{10} \mathrm{H}_{20} \mathrm{O}_{6} \mathrm{Na}^{+}(259) \\
& \mathrm{C}_{9} \mathrm{H}_{18} \mathrm{O}_{7} \mathrm{Na}^{+}(261) \quad \text { trans-4-octene }\left(\mathrm{R}^{`}=\mathrm{C}_{3} \mathrm{H}_{7}\right) \quad \mathrm{C}_{13} \mathrm{H}_{26} \mathrm{O}_{6} \mathrm{Na}^{+}(301)
\end{aligned}
$$
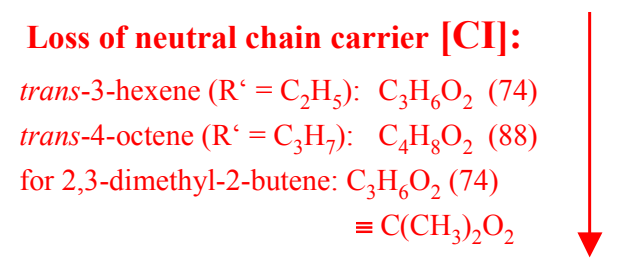

Loss of neutral chain carrier $[\mathrm{CI}]$ : trans-3-hexene $\left(\mathrm{R}^{`}=\mathrm{C}_{2} \mathrm{H}_{5}\right): \mathrm{C}_{3} \mathrm{H}_{6} \mathrm{O}_{2} \quad(74)$ trans-4-octene $\left(\mathrm{R}^{`}=\mathrm{C}_{3} \mathrm{H}_{7}\right): \quad \mathrm{C}_{4} \mathrm{H}_{8} \mathrm{O}_{2}$ (88)

\begin{tabular}{|c|c|}
\hline $\begin{array}{l}\text { Loss of neutral chain carrier [CI]: } \\
\text { trans-3-hexene }\left(\mathrm{R}^{`}=\mathrm{C}_{2} \mathrm{H}_{5}\right): \mathrm{C}_{3} \mathrm{H}_{6} \mathrm{O}_{2}(74) \\
\text { trans-4-octene }\left(\mathrm{R}^{`}=\mathrm{C}_{3} \mathrm{H}_{7}\right): \mathrm{C}_{4} \mathrm{H}_{8} \mathrm{O}_{2}(88) \\
\text { for 2,3-dimethyl-2-butene: } \mathrm{C}_{3} \mathrm{H}_{6} \mathrm{O}_{2}(74) \\
\qquad \mathrm{C}\left(\mathrm{CH}_{3}\right)_{2} \mathrm{O}_{2}\end{array}$ & $\begin{array}{l}\text { Loss of neutral chain carrier }[\mathrm{CI}]: \\
\text { trans-3-hexene }\left(\mathrm{R}^{`}=\mathrm{C}_{2} \mathrm{H}_{5}\right): \mathrm{C}_{3} \mathrm{H}_{6} \mathrm{O}_{2}(74) \\
\text { trans-4-octene }\left(\mathrm{R}^{`}=\mathrm{C}_{3} \mathrm{H}_{7}\right): \mathrm{C}_{4} \mathrm{H}_{8} \mathrm{O}_{2}(88) \\
\text { for 2,3-dimethyl-2-butene: } \mathrm{C}_{3} \mathrm{H}_{6} \mathrm{O}_{2}(74) \\
\equiv \mathrm{C}\left(\mathrm{CH}_{3}\right)_{2} \mathrm{O}_{2}\end{array}$ \\
\hline $\begin{array}{l}\text { Final fragment ion } \mathrm{Y} \\
\mathrm{CH}_{2} \mathrm{O}_{3} \mathrm{Na}^{+} \text {(85) } \\
\text { for all alkenes }\end{array}$ & $\begin{array}{c}{\left[\mathbf{X}+\mathbf{N a}^{+} \text {Final fragment ion } \mathbf{X} \text { (hypothetic): }\right.} \\
\qquad \mathbf{C}_{2} \mathrm{H}_{3} \mathrm{O}_{2} \mathrm{Na}^{+}+\mathbf{R}^{6} \\
\text { trans-3-hexene }\left(\mathrm{R}^{\natural}=\mathrm{C}_{2} \mathrm{H}_{5}\right): \mathrm{C}_{4} \mathrm{H}_{8} \mathrm{O}_{2} \mathrm{Na}^{+}(111) \\
\text { trans-4-octene }\left(\mathrm{R}^{\natural}=\mathrm{C}_{3} \mathrm{H}_{7}\right): \mathrm{C}_{5} \mathrm{H}_{10} \mathrm{O}_{2} \mathrm{Na}^{+}(125) \\
\text { for 2,3-dimethyl-2-butene: } \mathrm{C}_{4} \mathrm{H}_{8} \mathrm{O}_{2} \mathrm{Na}^{+}(111) \\
\equiv \mathrm{C}_{2} \mathrm{H}_{2} \mathrm{O}_{2} \mathrm{Na}^{+}+2 \times \mathrm{CH}_{3}\end{array}$ \\
\hline
\end{tabular}
for 2,3-dimethyl-2-butene: $\mathrm{C}_{3} \mathrm{H}_{6} \mathrm{O}_{2}$ (74) $\equiv \mathrm{C}\left(\mathrm{CH}_{3}\right)_{2} \mathrm{O}_{2}$

$$
\begin{aligned}
& \text { Fragment ion } \quad\left[\mathrm{Y}-[\mathrm{CI}]_{1}+\mathrm{Na}\right]^{+} \quad\left[\mathrm{X}-[\mathrm{CI}]_{1}+\mathrm{Na}\right]^{+} \quad \text { Fragment ion } \\
& \mathrm{C}_{4} \mathrm{H}_{8} \mathrm{O}_{5} \mathrm{Na}^{+}(159) \text { trans-3-hexene }\left(\mathrm{R}^{\star}=\mathrm{C}_{2} \mathrm{H}_{5}\right) \text { and 2,3-dimethyl-2-butene } \mathrm{C}_{7} \mathrm{H}_{14} \mathrm{O}_{4} \mathrm{Na}^{+} \text {(185) } \\
& \mathrm{C}_{5} \mathrm{H}_{10} \mathrm{O}_{5} \mathrm{Na}^{+}(173) \quad \text { trans-4-octene }\left(\mathrm{R}^{`}=\mathrm{C}_{3} \mathrm{H}_{7}\right) \quad \mathrm{C}_{9} \mathrm{H}_{18} \mathrm{O}_{4} \mathrm{Na}^{+}(213)
\end{aligned}
$$

Fig. 6. Schematic structure and main fragmentation pathways of type (a) oligomers formed during gas-phase ozonolysis of symmetric alkenes $(n=2)$.

oligomers from both EBE and trans-3-hexene (Fig. 4c) contain only two fragmentation pathways, marked in red and violet colours. However, the chain units of oligomers from all three compounds are of similar mass 74 and chemical composition $\mathrm{C}_{3} \mathrm{H}_{6} \mathrm{O}_{2}$. A main difference between the compounds is in the structures of their $\mathrm{CI}$ : 2,3-dimethyl-2-butene leads to formation of the iso- $\mathrm{C}_{3}-\mathrm{CI}\left(\left(\mathrm{CH}_{3}\right)_{2} \mathrm{COO}\right)$ (Fig. $4 \mathrm{a}$ and $\mathrm{b}$ ), while the major $\mathrm{CI}$ produced by both $\mathrm{EBE}$ and trans3-hexene is the $\mathrm{C}_{3}-\mathrm{CI}\left(\mathrm{C}_{2} \mathrm{H}_{5} \mathrm{CHOO}\right)$. When we assume that the oligomer chain units $74\left(\mathrm{C}_{3} \mathrm{H}_{6} \mathrm{O}_{2}\right)$ from EBE and trans3-hexene and those from 2,3-dimethyl-2-butene are isomers in the same way as the respective CI formed during the 
ozonolysis reaction, then the chain unit that is substituted, like the iso- $\mathrm{C}_{3}$ - $\mathrm{CI}$, by two $\mathrm{CH}_{3}$ groups is expected to be more compact and therefore less sterically hindered than the chain unit that is substituted, like the $\mathrm{C}_{3}-\mathrm{CI}$, by a linear alkylic chain $\mathrm{R}^{\prime}=\mathrm{C}_{2} \mathrm{H}_{5}$.

Therefore, oligomers with chain units of mass 74 substituted corresponding to the iso- $\mathrm{C}_{3}-\mathrm{CI}$ might be able to form a wider variety of isomers than those with chain units of similar mass 74 that are substituted corresponding to the $\mathrm{C}_{3}-\mathrm{CI}$. For example, the fragmentation pathway marked in dark green colour (Fig. 4c), which generally terminates on fragment ions of $m / z 99$, is observed for the type (a) oligomer ions formed from 2,3-dimethyl-2-butene (iso- $\mathrm{C}_{3}$-CI, $\left(\mathrm{CH}_{3}\right)_{2} \mathrm{COO}$ ) (Fig. $4 \mathrm{c}$ ), but not for those from EBE and trans-3-hexene $\left(\mathrm{C}_{3}-\mathrm{CI}, \mathrm{C}_{2} \mathrm{H}_{5} \mathrm{CHOO}\right)$ (Figs. 4a and $\mathrm{b}$ ). Furthermore, an analogous fragmentation pathway is observed for type (a) oligomers formed from AVE $\left(\mathrm{C}_{1}-\mathrm{CI}, \mathrm{CH}_{2} \mathrm{OO}\right)$ and EPE $\left(\mathrm{C}_{2}-\mathrm{CI}, \mathrm{CH}_{3} \mathrm{CHOO}\right)$ (Sadezky et al., 2006), but not for those from trans-4-octene ( $\mathrm{C}_{4}$-CI, $\mathrm{C}_{3} \mathrm{H}_{7} \mathrm{CHOO}$ ) (Fig. 4d). Assuming that the oligomer chain units are generally substituted in a similar way as the respective major CI, chain units from EBE, trans-3-hexene and trans-4-octene supposedly comprise a linear alkyl substituent $\mathrm{R}^{\prime}=\mathrm{C}_{2} \mathrm{H}_{5}$ (EBE and trans-3-hexene) or $\mathrm{R}^{\prime}=\mathrm{C}_{3} \mathrm{H}_{7}$ (trans-4octene). Chain units from 2,3-dimethyl-2-butene, AVE and EPE, however, carry only $\mathrm{CH}_{3}$ substituents (2,3-dimethyl2-butene and EPE) or are not at all substituted (AVE). The dark green-coloured fragmentation pathway might thus originate from an isomer of the pseudomolecular ion, which is formed only for small chain units similar to the iso- $\mathrm{C}_{3}$-CI or less bulky $\left(\mathrm{C}_{1}-\mathrm{CI}, \mathrm{C}_{2}-\mathrm{CI}\right)$, but might not be stable for sterical reasons for chain units comprising a linear alkyl substituent with two or more $\mathrm{CH}_{2}$ groups $\left(\mathrm{C}_{3}-\mathrm{CI}, \mathrm{C}_{4}-\mathrm{CI}\right)$.

\subsubsection{Oligoperoxidic structure and role of CI for oligomer} formation

These results first of all corroborate the decisive role of the Criegee Intermediates in the formation of oligomers, which was already suggested in our previous study (Sadezky et al., 2006). Indeed, the linking chain units of the different oligomers repeatedly have the same elementary compositions as the Criegee Intermediates CI (see Sect. 3.3.4.): $\mathrm{CH}_{2} \mathrm{O}_{2}\left(=\mathrm{CH}_{2} \mathrm{OO}\right.$ for $\mathrm{C}_{1}$-CI) of mass 46 (AVE), $\mathrm{C}_{2} \mathrm{H}_{4} \mathrm{O}_{2}$ $\left(=\mathrm{CH}_{3} \mathrm{CHOO}\right.$ for $\mathrm{C}_{2}$-CI) of mass $60(\mathrm{EPE}), \mathrm{C}_{3} \mathrm{H}_{6} \mathrm{O}_{2}$ (= $\mathrm{C}_{2} \mathrm{H}_{5} \mathrm{CHOO}$ for $\mathrm{C}_{3}-\mathrm{CI}$ or $\left(\mathrm{CH}_{3}\right)_{2} \mathrm{COO}$ for iso- $\left.\mathrm{C}_{3}-\mathrm{CI}\right)$ of mass $74\left(\mathrm{C}_{3}\right.$-CI: EBE and trans-3-hexene; iso- $\mathrm{C}_{3}-\mathrm{CI}$ : 2,3dimethyl-2-butene $)$ and $\mathrm{C}_{4} \mathrm{H}_{8} \mathrm{O}_{2}\left(=\mathrm{C}_{3} \mathrm{H}_{7} \mathrm{CHOO}\right.$ for $\mathrm{C}_{4}$-CI $)$ of mass 88 (trans-4-octene). In our previous study (Sadezky et al., 2006), we suggested the basic structure of an oligoperoxide for the oligomers identified from ozonolysis of the enol ethers AVE and EPE. We extend this suggestion now to the oligomers formed from the diverse unsaturated compounds studied in the present work. Figure 7 a presents the CI-like peroxidic oligomer chain units incorporated into the schematical oligomer structure $\mathrm{X}-[\mathrm{CI}]_{n}-\mathrm{Y}$ (Sect. 3.3.4.). Accurate mass measurements by ESI(+)/FTICR in our present work, leading to definitive elemental compositions for parent ions, fragment ions, and fragmented neutrals, now allow the identification of the oligomer starting and end groups $\mathrm{X}$ and $\mathrm{Y}$. Structures for $\mathrm{X}$ and $\mathrm{Y}$ in their roles as initially fragmented neutrals and final fragment ions are given together with a structure of the complete oligomer molecule in Figs. $7 \mathrm{~b}$ and c. The sum formulas of the parent ions necessarily lead to linear, saturated oligomer molecules. While the chemical compositions of the chain units " $\mathrm{CI}$ " and the end group "Y" correspond to those of the respective CI, the starting group " $\mathrm{X}$ " obviously consists of a molecule of the initial alkene or enol ether (Fig. 7c). Fragmentation mechanisms for the oligomer molecules given in Fig. 7b, which are in agreement with the observations from the MS/MS experiments described in Sect. 3.3.4., are exemplarily shown in Figs. $7 \mathrm{~d}$ and e for the oligomer parent ion 379 formed from trans-3-hexene.

Oligomers with suggested similar structures are known so far only from liquid-phase ozonolysis reactions (Barton et al., 2005, 2004; Lockley et al., 2001; and references therein). Barton et al. (2004) identified by ESI/MS oligoperoxides with $\mathrm{m} / \mathrm{z}$ up to $900 \mathrm{u}$ as reaction products from liquid-phase ozonolysis of 2,3-dimethyl-2-butene ("tetramethyl ethylene" TME) in pentane as a nonparticipating solvent at $-60^{\circ} \mathrm{C}$. The peroxidic chain link of the mass peaks was of mass 74 and thus corresponded to the $\mathrm{CI}$ formed during ozonolysis of 2,3dimethyl-2-butene, referred to as acetone carbonyl oxide by the authors and as iso- $\mathrm{C}_{3}-\mathrm{CI}\left(\mathrm{CH}_{3}\right)_{2} \mathrm{COO}$ in this work. The authors observed up to 12 chain units for different oligoperoxides. These observations are in excellent agreement with our results for ozonolysis reactions of enol ethers and small alkenes in the gas phase described in the present work and in our previous study (Sadezky et al., 2006). By similar experimental methods, Barton et al. (2005) characterized oligoperoxides formed from the liquid-phase ozonolysis of 3-methyl2-pentene, which consisted of units of the major CI, referred to as butanone carbonyl oxide $\left(\mathrm{C}_{4}-\mathrm{CI}, \mathrm{C}_{3} \mathrm{H}_{7} \mathrm{CHOO}\right.$, mass 88), randomly copolymerized with units of the corresponding primary carbonyl compound, acetaldehyde (mass 44). The observations of oligomeric peroxides composed of CI-like chain units are again in very good agreement with our studies and with Barton et al. (2004). However, a random incorporation of the corresponding primary aldehydes into those oligomer chains, as was observed by Barton et al. (2005), could not be confirmed in our experiments.

For gas-phase ozonolysis, various mechanisms involving secondary reactions of Criegee Intermediates have been discussed in the literature as formation pathways of major SOA constituents. Unimolecular decomposition of Criegee Intermediates via the "hydroperoxide" and the "hot acid" channel has been suggested as an important pathway to form low-volatile carboxylic acids, diacids, and peroxidic compounds, such as diacylperoxides, peracids and other 
<smiles>[R]C(OOC([Y])([Y])C)C([X])(C)C</smiles>

with

$\mathrm{R}^{\prime}=\mathrm{H} \quad\left(\mathrm{C}_{1}\right.$-CI, mass 46) for $\mathrm{AVE}\left(\mathrm{ROCH}=\mathrm{CH}_{2}\right)$,

$\mathrm{R}^{\prime}=\mathrm{CH}_{3} \quad\left(\mathrm{C}_{2}\right.$-CI, mass 60) for $\mathrm{EPE}\left(\mathrm{C}_{2} \mathrm{H}_{5} \mathrm{OCH}=\mathrm{CHCH}_{3}\right)$

$\mathbf{R}^{\prime}=\mathrm{C}_{2} \mathrm{H}_{5}\left(\mathrm{C}_{3}\right.$-CI, mass 74$)$ for $\mathrm{EBE}\left(\mathrm{C}_{2} \mathrm{H}_{5} \mathrm{OCH}=\mathrm{CHC}_{2} \mathrm{H}_{5}\right)$

and trans-3-hexene $\left(\mathrm{C}_{2} \mathrm{H}_{5} \mathrm{CH}=\mathrm{CHC}_{2} \mathrm{H}_{5}\right)$

$\mathbf{R}^{\prime}=\mathrm{C}_{3} \mathrm{H}_{7}\left(\mathrm{C}_{4}-\mathrm{CI}\right.$, mass 88$)$ for trans-4-octene

$\left(\mathrm{C}_{3} \mathrm{H}_{7} \mathrm{CH}=\mathrm{CHC}_{3} \mathrm{H}_{7}\right)$

(iso- $\mathrm{C}_{3}$-CI, mass 74 ) for 2,3-dimethyl-2-butene

(a)<smiles>[X]C(C)(C)OOC([Y])(C)C</smiles><smiles>CC(C)(OO)OOC(C)(C)OOC(C)(C)OOC(C)(C)C(C)(C)O</smiles><smiles>[R]C([R])OOC([R])([R])OOC([R])[C@H]([R])OOO</smiles><smiles>[R]OC(O)C([R])OOC([R])([R])OOC([R])([2H])OOC([R])([R])OO</smiles>

(b)<smiles>[R]OC([R])C([R])O</smiles>

final fragment ion

$$
[\mathbf{Y}+\mathbf{N a}]^{+}
$$

Violet-marked fragmentation pathway:<smiles>COOC(C)(C)OC</smiles>

$$
\mathbf{H}-\mathbf{O}-\mathbf{O}-\underset{\substack{\mid \\ \mathrm{R}^{\prime}}}{\mathbf{C}}-\mathbf{O}-\mathrm{R}^{\prime}
$$

(c) initially fragmented neutral $Y$
Initial alkene

2,3-Dimethyl-2-butene

trans-3-hexene,

trans-4-octene

Enol ethers AVE, EPE, EBE (AVE: $\mathbf{R}=\mathrm{C}_{2} \mathrm{H}_{5}, \mathrm{C}_{3} \mathrm{H}_{7}, \mathrm{C}_{4} \mathrm{H}_{8}$; EPE: $\mathbf{R}=\mathrm{C}_{2} \mathrm{H}_{5}$; EBE: $\mathbf{R}=\mathrm{C}_{2} \mathbf{H}_{5}$ )<smiles>[R]OC([R])C([R])O</smiles>

initially fragmented neutral $\mathrm{X}$
$-\mathrm{O}-\mathrm{C}-\mathrm{C}-\mathrm{O}-\mathrm{CH}_{3}$
$\mathrm{H}_{3} \mathrm{C} \mathrm{CH}_{3}$ 


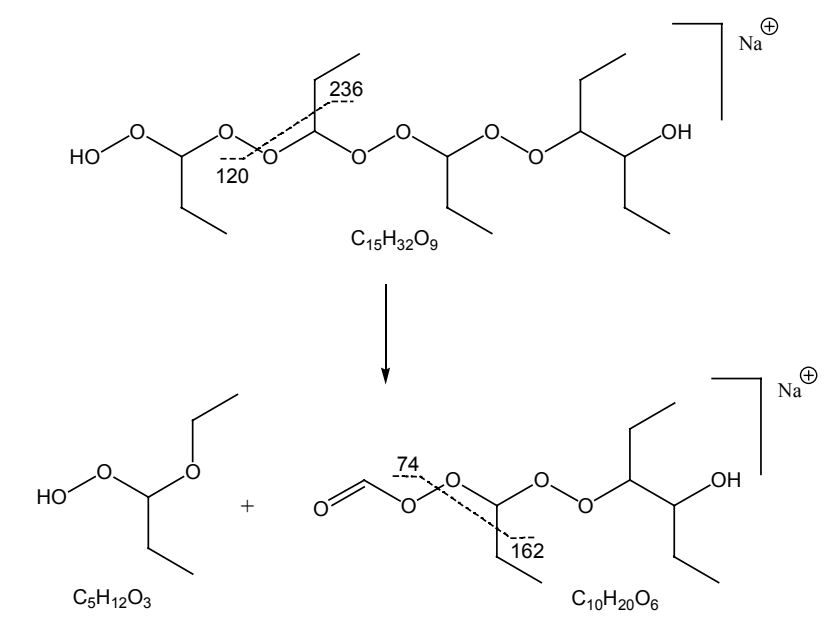

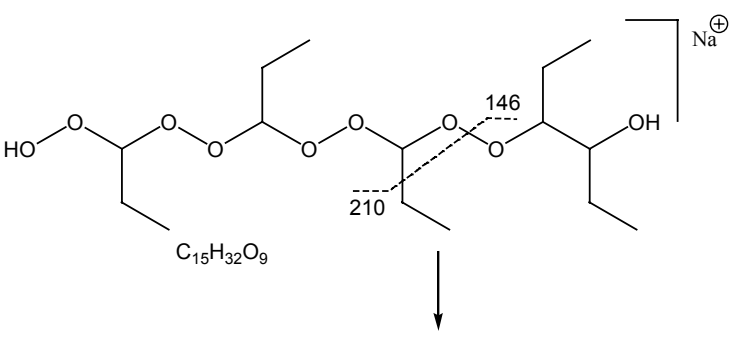

(d)

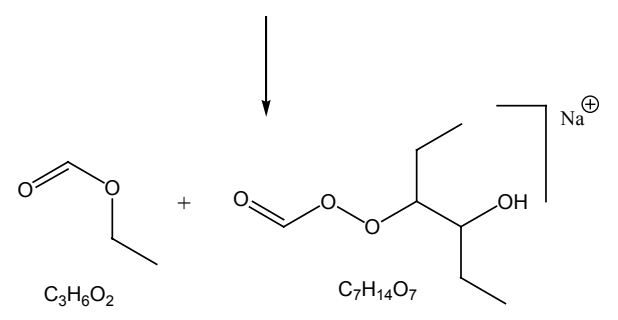

(e)<smiles>CCC(OOC(=O)OCC(C)C)OOC(CC)C(O)CC</smiles><smiles>CCOC(=O)OC=CC(CC)OO</smiles><smiles>CC(C)OCOOC(=O)OO</smiles>

Fig. 7. Oligoperoxidic structure suggested for the oligomers formed during gas-phase ozonolysis of enol ethers and alkenes (d) Fragmentation of the oligomer parent ion 379 formed during ozonolysis of trans-3-hexene: violet-marked fragmentation pathway (e) Fragmentation of the oligomer parent ion 379 formed during ozonolysis of trans-3-hexene: red-marked fragmentation pathway.

multifunctional hydroperoxides, during reactions with ozone of cyclic monoterpenes and cycloalkenes consisting of at least six carbon atoms (Tolocka et al., 2006; Docherty et al., 2005; Keywood et al., 2004; Ziemann, 2002; Koch et al., 2000). Moreover, reactions of stabilized Criegee Intermediates lead to a wide variety of products containing peroxide moieties, several of which were identified in the past as SOA constituents from alkene ozonolysis. The most important reactions among them are those of the stabilized CI with carbonyl compounds to form secondary ozonides and with hydroxylic functionalities of carboxylic acids, alcohols and water to form $\alpha$-acyloxyalkyl hydroperoxides, $\alpha$-alkyloxyalkyl hydroperoxides and $\alpha$-hydroxyalkyl hydroperoxides, respectively. Such products were particularly identified in SOA from ozonolysis reactions of large linear alkenes, such as 1-tetradecene, oleic acid and methyl oleate (Zahardis and Petrucci, 2007, and references therein; Tobias et al., 2000; Tobias and Ziemann, 2000). The presence of secondary ozonides and $\alpha$-alkyloxyalkyl hydroperoxides has also been reported in SOA formed from cyclic monoterpenes and cy- cloalkenes containing six to ten carbon atoms (Tolocka et al., 2006; Ziemann, 2003). Some of the peroxidic products have been observed to undergo further association reactions with other molecules in order to form high-molecular weight compounds either in the liquid phase within the SOA particles or heterogeneously on the particle surface. Thus, hydroperoxides formed either by unimolecular decomposition of CI or by reactions of stabilized $\mathrm{CI}$ have been observed to react with a variety of aldehydes to form peroxyhemiacetals (Zahardis and Petrucci, 2007, and references therein; Docherty et al., 2005, and references therein). Moreover, peroxidic products in the oleic acid/ozone and cholesterol/ozone reaction systems might carry additional free hydroxyl, carbonyl, or carboxylic acid functionalities, which can further react with other stabilized Criegee Intermediates to form oligomeric compounds (Zahardis and Petrucci, 2007; Zahardis et al., 2006; Dreyfus et al., 2005).

However, none of the above-described mechanisms is consistent with the formation of oligomers with $\mathrm{m} / \mathrm{z}, 200$ to 800 and repeated CI-like chain units identified as main SOA 
constituents in our experiments. Key species of the mechanisms suggested to lead to SOA formation by unimolecular decomposition of CI are acyl radicals, whose structures are based on the original CI formed from cyclic alkenes and monoterpenes and therefore consist of at least five to six C atoms with additional carbonyl or hydroxy functionalities. These acyl radicals are first transformed into acylperoxy radicals by addition of $\mathrm{O}_{2}$, which then either react with $\mathrm{HO}_{2}$ and $\mathrm{RO}_{2}$ to form low-volatile acids, diacids, peracids and other peroxides (Docherty et al., 2005; Keywood et al., 2004) or cross-react to form diacylperoxides (Ziemann, 2002). However, for the small linear alkenes and enol ethers investigated in this work and in our previous study (Sadezky et al., 2006), the same mechanisms of unimolecular CI decomposition only lead to acyl radicals of the type R' $\mathrm{CO}$, with $\mathrm{R}^{\prime}=\mathrm{H}$, $\mathrm{CH}_{3}, \mathrm{C}_{2} \mathrm{H}_{5}$, or $\mathrm{C}_{3} \mathrm{H}_{7}$. By further reaction with $\mathrm{O}_{2}, \mathrm{HO}_{2}$ and $\mathrm{RO}_{2}$, the acyl radicals R'CO form mainly volatile products consisting of four or less $\mathrm{C}$ atoms or immediately decompose, while their recombination by cross-reaction (Ziemann, 2002) leads to dimers only and cannot explain the origin of the observed oligomeric chains.

Similarly, peroxidic SOA constituents formed by reactions of the stabilized CI, such as secondary ozonides, $\alpha$ acyloxyalkyl hydroperoxides and $\alpha$-alkyloxyalkyl hydroperoxides, involve CI that consist of nine, ten or 13 carbon atoms for the ozonolysis of linear alkenes such as oleic acid (Zahardis and Petrucci, 2007), methyl oleate (Mochida et al., 2006), and 1-tetradecene (Tobias et al., 2000; Tobias and Ziemann, 2000), and of six to ten carbon atoms for cyclic alkenes (Ziemann, 2003) and the monoterpene $\alpha$ pinene (Tolocka et al., 2006). By their secondary reactions, these stabilized CI often become associated to aldehydes or carboxylic acids of similar sizes, such as nonanoic acid (oleic acid/ozone system, Zahardis and Petrucci, 2007; Zahardis et al., 2006), tridecanal (1-tetradecene ozonolysis, Tobias et al., 2000), or pinonaldehyde ( $\alpha$-pinene ozonolysis, Tolocka et al., 2006), leading to large, low-volatile peroxidic compounds consisting of 18 and more carbon atoms. However, the $\mathrm{CI}$ formed from the small unsaturated compounds investigated in our present work and in our previous study (Sadezky et al., 2006) consist of one to four carbon atoms only. Known gas-phase reaction pathways following ozonolysis do not lead to larger carbonyl, carboxylic or hydroxylic products either. Therefore, analogous peroxidic products of reactions of the stabilized CI with aldehydes and carboxylic acids formed in the alkene/ozone reaction system are mainly expected to be volatile. Peroxyhemiacetals formed by subsequent reaction of these compounds with aldehydes within the same reaction system, as described by Zahardis and Petrucci (2007), and references therein, and by Docherty et al. (2005), and references therein, do not account for the observed oligomers with regular CI-like peroxidic chain units either. Moreover, oligomerization of these reaction products by mechanisms similar to those described for the oleic acid/ozone reaction by Zahardis and Petrucci (2007) and Zahardis et al. (2006)
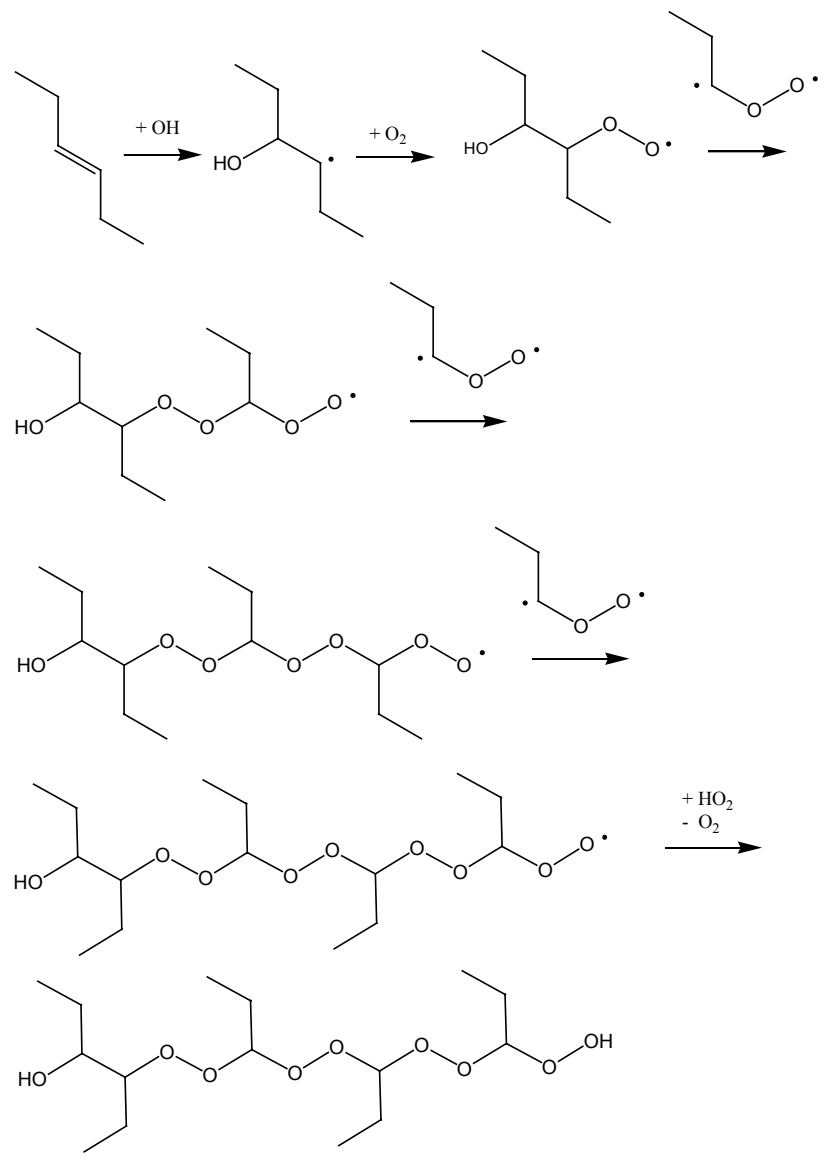

Fig. 8. Formation of the oligomer molecule representing the parent ion 379 during ozonolysis of trans-3-hexene: Oligomer formation by repeated addition of a stabilized CI to a peroxy radical.

should be very limited for the ozonolysis of the compounds studied in our work. These mechanisms require the presence of free carbonyl or hydroxylic functionalities on the peroxidic products, which might allow them to further react with other stabilized CI. However, the CI incorporated into the oligomeric molecules carry hydrogen atoms and alkyl groups, with $\mathrm{R}^{\prime}=\mathrm{H}, \mathrm{CH}_{3}, \mathrm{C}_{2} \mathrm{H}_{5}$, or $\mathrm{C}_{3} \mathrm{H}_{7}$. Given the linearity, small sizes and simple structures of the original unsaturated compounds, the main carbonyl, carboxylic and hydroxylic products formed in the reaction system also comprise a single functionality and a non-reactive group derived from R' (or from OR for the enol ethers) rather than being multifunctional. Therefore, oligomerization mechanisms based on the participation of additional reactive functional groups on R' (or OR) cannot explain the observed formation of oligomeric chains consisting of CI-like units in our present work.

Still there is mechanistic evidence that the chemistry of stabilized CI plays a decisive role in oligomer and SOA formation in our reaction system. CI formed from the ozonolysis of small simple alkenes in the gas phase and stabilized by collision with inert gas molecules have been shown to 


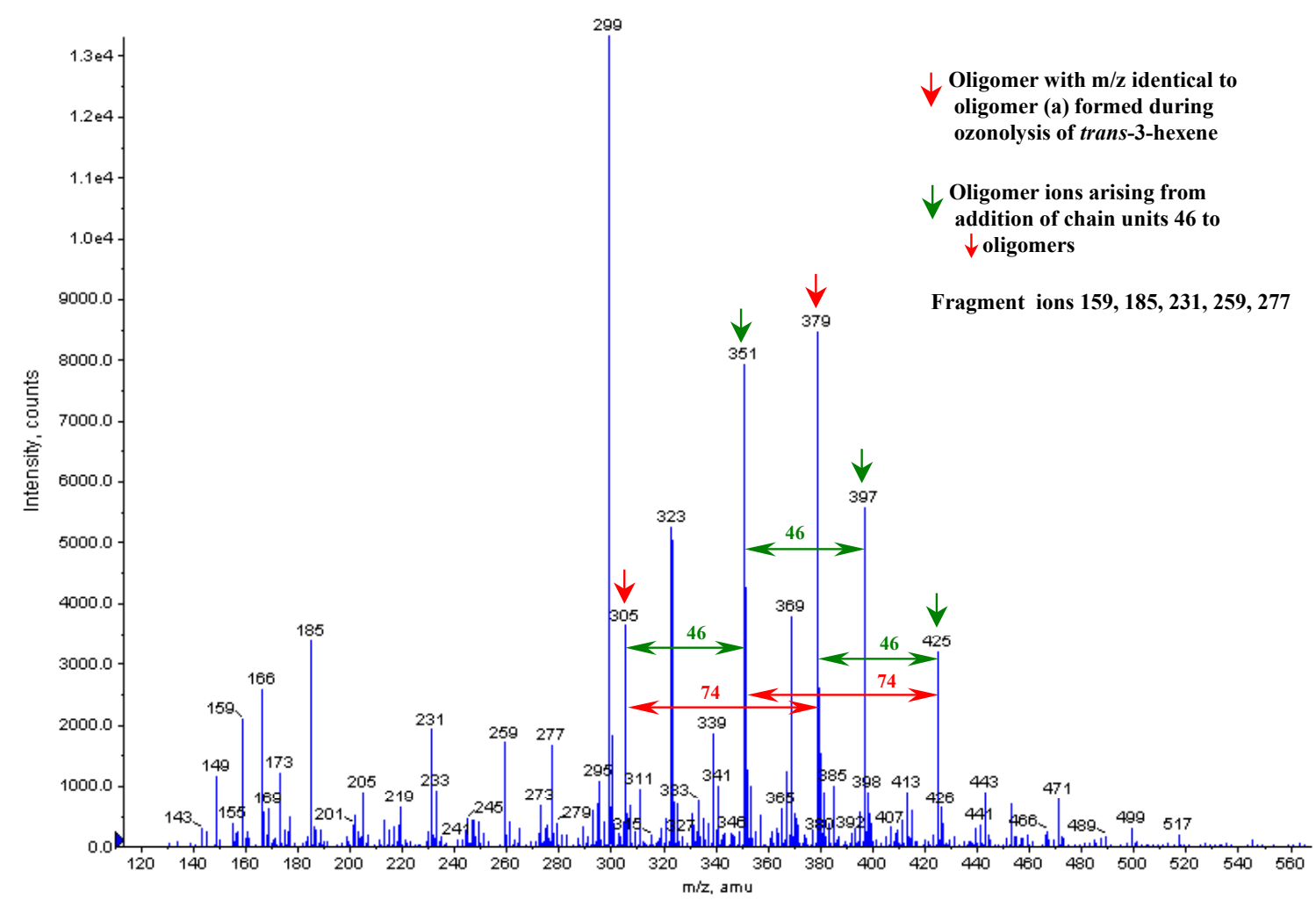

Fig. 9. ESI(+)/TOF MS mass spectrum of SOA formed during simultaneous gas phase ozonolysis of trans-3-hexene and EVE (initial mixing ratios: 8 ppm ozone, 8 ppm EVE, 12 ppm trans-3-hexene).

undergo a variety of reactions similar to those known for a long time from liquid-phase chemistry (Calvert et al., 2000, and references therein; Bunnelle, 1991). Reactions of the stabilized $\mathrm{C}_{1}$-CI and $\mathrm{C}_{2}$-CI have been thoroughly investigated for gas-phase ozonolysis of alkyl vinyl ethers (AVE) and ethyl propenyl ether (EPE) (Sadezky, 2005), ethene (Neeb et al., 1998, 1997), 2-butene (Horie et al., 1997) and propene (Neeb et al., 1996). A variety of peroxidic products analogous to those described above for larger linear alkenes were identified in these studies: thus, the stabilized $\mathrm{C}_{1}-\mathrm{CI}$ and $\mathrm{C}_{2}$ $\mathrm{CI}$ react with formaldehyde and acetaldehyde to form secondary ozonides and with the hydroxylic functionalities of water and formic acid to produce the hydroperoxides hydroxymethyl and hydroxyethyl hydroperoxide, as well as hydroperoxymethyl and hydroperoxyethyl formate, respectively. All these products are however highly volatile due to their low molecular weights and were identified only in the gas phase of the alkene/ozone reaction systems. We reported in our previous studies (Sadezky et al., 2006; Sadezky, 2005) that SOA yields from ozonolysis of ethyl vinyl ether (EVE) and ethyl propenyl ether (EPE) were drastically reduced, eventually suppressed, in the presence of an excess of gaseous $\mathrm{HCOOH}$. Simultaneously, oligomers were not detected onto the filter samples taken from these experiments (Sadezky et al., 2006; Sadezky, 2005). SOA formation was also shown to be strongly reduced in the presence of water vapour (Sadezky, 2005). $\mathrm{HCOOH}$, and to a lesser extent $\mathrm{H}_{2} \mathrm{O}$, are known to act as efficient scavengers for stabilized CI through the above-mentioned formation of hydroperoxy formates and hydroxy hydroperoxides. Consequently, the key reaction mechanisms leading to SOA and oligomer formation are in direct concurrence with the known reactions of the stabilized CI with $\mathrm{HCOOH}$ or $\mathrm{H}_{2} \mathrm{O}$ to form lowmolecular, volatile hydroperoxides. The observations point towards a direct implication of stabilized $\mathrm{CI}$ in the SOA and oligomer formation.

Therefore, we suggested in our previous study (Sadezky et al., 2006) that oligoperoxide formation is another, so far unknown gas-phase reaction of stabilized CI, which contributes to SOA formation. In our present work, we show that the observed formation of oligomers consisting of repeated CIlike chain units as main SOA constituents is not limited to enol ethers, but occurs in an analogous way for short-chain hydrocarbon alkenes.

To our knowledge, besides our previous study by Sadezky et al. (2006), formation of stable reaction products containing several linked CI-like units has not been reported previously for gas-phase ozonolysis. So far, such reactions have been observed for alkene-ozone reactions in the liquid phase only. Thus, recombination of two CI leading to the 


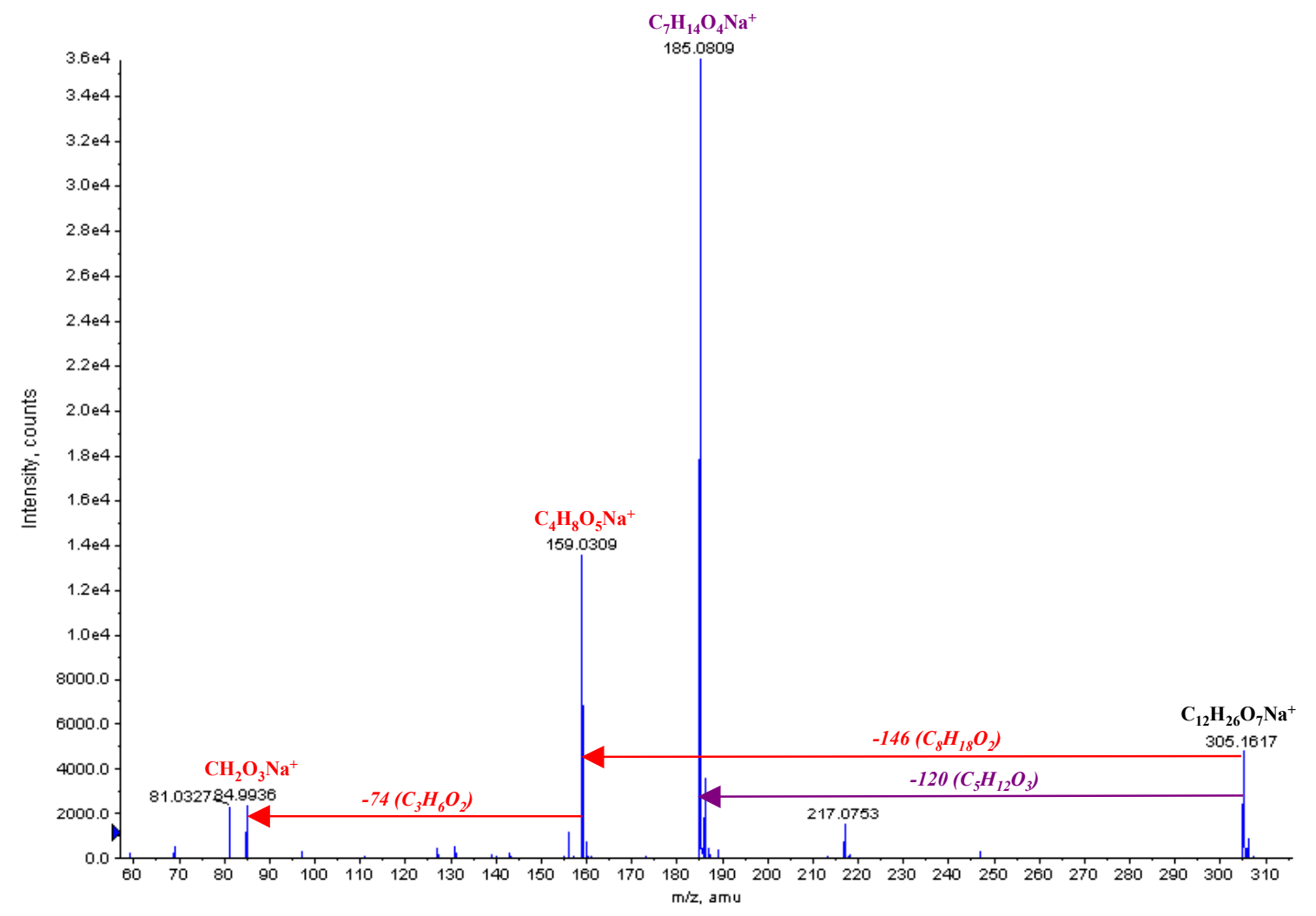

Fig. 10a. SOA formed during simultaneous gas phase ozonolysis of trans-3-hexene and EVE (initial mixing ratios: 8 ppm ozone, 8 ppm EVE, 12 ppm trans-3-hexene): ESI(+)/TOF MS/MS spectrum of the parent ion 305.

formation of cyclic geminal diperoxides (1,2,4,5-tetroxanes) was described as a minor reaction of stabilized CI during the ozonolysis of oleic acid (Zahardis and Petrucci, 2007; Reynolds et al., 2006; Zahardis et al., 2005). Oleic acidozone reactions in these studies take place in the condensed phase either in bulk solution with high reactant concentrations (Reynolds et al., 2006) or in liquid submicron aerosol droplets after diffusion of ozone into the particles (Zahardis and Petrucci, 2007; Zahardis et al., 2005). Moreover, 1,2,4,5tetroxanes are known as common crystalline byproducts of many bulk liquid-phase ozonolysis reactions (Bunnelle, 1991). Formation of linear CI dimers in the liquid phase is mentioned by March (1992), these compounds are however reported to be unstable and to directly decompose into two carbonyl compounds and $\mathrm{O}_{2}$. Tolocka et al. (2006) take into consideration a cyclic or linear dimer of two stabilized $\mathrm{CI}$ with an added $\mathrm{H}_{2} \mathrm{O}$, which then undergoes elimination of $\mathrm{H}_{2} \mathrm{O}_{2}$ either in the condensed particle phase or during the ionization process, for an unknown product observed in the mass spectra of SOA from gas-phase ozonolysis of $\alpha$ pinene. The authors suggest that the linear dimer molecule, if formed, might be capped by the added $\mathrm{H}_{2} \mathrm{O}$.

Linear oligomerization of $\mathrm{CI}$ leading to stable longchain oligoperoxides was so far only reported by Bar- ton et al. (2005) and Barton et al. (2004) for liquidphase ozonolysis of the hydrocarbon alkenes 2,3-dimethyl-2butene $\left(\left(\mathrm{CH}_{3}\right)_{2} \mathrm{C}=\mathrm{C}\left(\mathrm{CH}_{3}\right)_{2}\right), 3$-methyl-2-pentene, and trans2-hexene. As mentioned before, oligoperoxides identified as reaction products of the ozonolysis of 2,3-dimethyl-2-butene in the liquid phase by Barton et al. (2004) and in the gas phase in our present work show the same repetitive chain link of mass 74, which corresponds to the only Criegee Intermediate $\left(\mathrm{CH}_{3}\right)_{2} \mathrm{COO}$ (iso- $\left.\mathrm{C}_{3}-\mathrm{CI}\right)$ formed by this alkene. Oligoperoxides identified by Barton et al. (2005) and Barton et al. (2004) are mainly cyclic hexamers or pentamers, with minor products consisting of linear chains endcapped by $-\mathrm{OOH}$ or $-\mathrm{OH}$ groups. Moreover, these oligomeric products were found by Barton et al. (2004) to be thermally stable when extracted and refluxed in methanol for a few hours, a behaviour that agrees with their observed stability in methanol used as solvent for the filter extraction in our work. Furthermore, Barton et al. (2004) observed a strong competition among the described formation of oligoperoxides consisting of CI-like units and well known liquid-phase reactions of the CI with compounds carrying hydroxylic functionalities to form small hydroperoxides (see above; Bunnelle, 1991). The authors reported oligoperoxide formation during liquid-phase ozonolysis of 2,3-dimethyl-2-butene to 


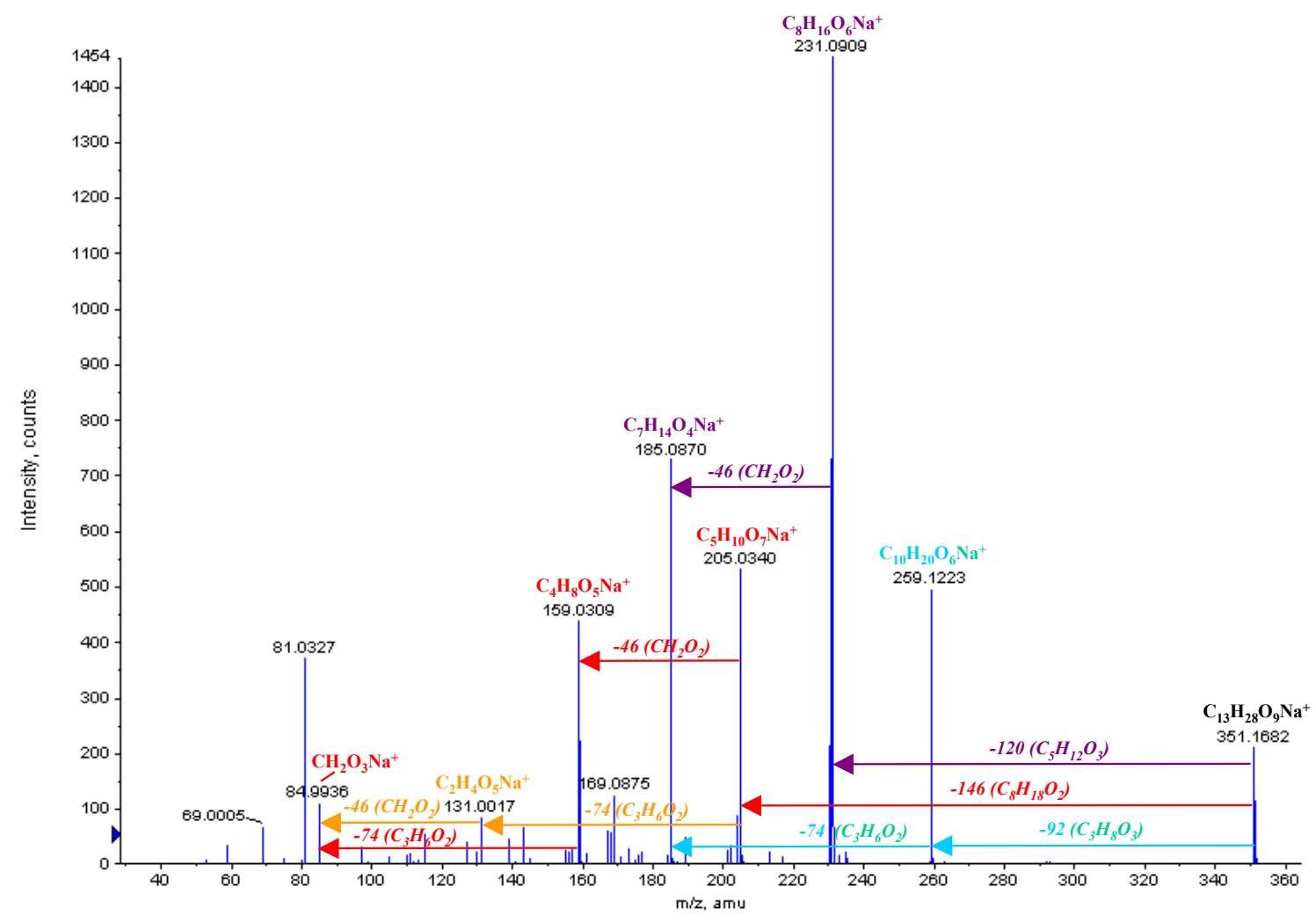

Fig. 10b. SOA formed during simultaneous gas phase ozonolysis of trans-3-hexene and EVE (initial mixing ratios: 8 ppm ozone, 8 ppm EVE, 12 ppm trans-3-hexene): ESI(+)/TOF MS/MS spectrum of the parent ion 351.

(b)

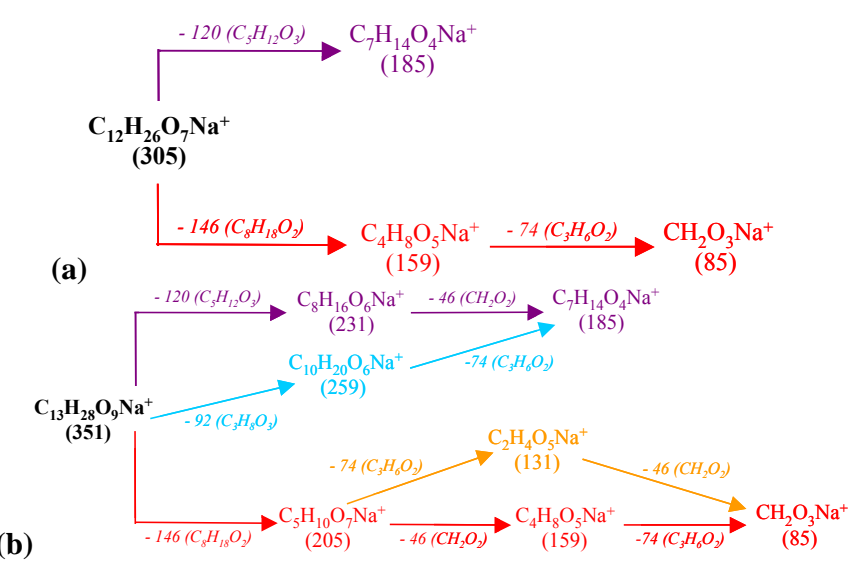

Fig. 11. Simultaneous gas phase ozonolysis of trans-3-hexene and EVE: Fragmentations of oligomer parent ions. (a) Main fragmentation pathways of the parent ion 305 (marked by a red arrow in Fig. 9) containing a single chain unit 74. (b) Main fragmentation pathways of the parent ion 351 (marked by a green arrow in Fig. 9) showing co-oligomerization of a chain unit 74 and a chain unit 46 . take place only in non-prononated solvents, such as pentane, while in methanol, the corresponding hydroperoxide, 2-methoxy-2-propyl hydroperoxide, was formed instead through reaction of the $\mathrm{CI},\left(\mathrm{CH}_{3}\right)_{2} \mathrm{COO}$ (iso- $\left.\mathrm{C}_{3}-\mathrm{CI}\right)$, with $\mathrm{MeOH}$. These observations of liquid-phase chemistry are in analogy to the suppression of SOA and oligomer formation during gas-phase enol ether ozonolysis in the presence of excess $\mathrm{HCOOH}$ or $\mathrm{H}_{2} \mathrm{O}$, as described in our previous work (Sadezky et al., 2006). The mechanistic analogies indicate that oligoperoxide formation takes place in similar ways in the liquid phase and in the gas phase, thus also confirming our suggestion by Sadezky et al. (2006) that the stabilized form of CI might be involved in the gas-phase reaction.

Addition of a CI to the double bond of the initial alkene, leading to formation of an 1,2-dioxolane, represents another reaction pathway of CI known from liquid-phase alkene ozonolysis (Bunnelle, 1991), in particular for vinyl ethers (Keul et al., 1985). A similar mechanism as a minor reaction pathway of stabilized CI has been attributed to products identified in the oleic acid/ozone and methyl oleate/ozone reaction systems (Mochida et al., 2006; Zahardis et al., 2006). Decomposition of the 1,2-dioxolane then leads to an aldehyde derived from the CI and a ketone representing the oxygenated initial alkene. For the small unsaturated ethers and 
alkenes studied in our work, these products are expected to be volatile, and consequently, this reaction pathway is not expected to contribute to SOA formation.

As mentioned in Sects. 3.2 and 3.3.1 of the present work, a comparison of the SOA mass and oligomer chain lengths obtained from ozonolysis of trans-3-hexene and EBE on the one hand, and 2,3-dimethyl-2-butene on the other hand, points towards a key role of stabilized $\mathrm{CI}$ in the SOA formation as well. The very low stabilization rate of the iso- $\mathrm{C}_{3}-$ $\mathrm{CI}\left(\left(\mathrm{CH}_{3}\right)_{2} \mathrm{COO}\right)$, which is less than $1 \%$ in the gas phase, correlates with much lower SOA mass and lower degrees of oligomerization from 2,3-dimethyl-2-butene in comparison with those from EBE and trans-3-hexene, which involve the isomer $\mathrm{C}_{3}-\mathrm{CI}\left(\mathrm{C}_{2} \mathrm{H}_{5} \mathrm{CHOO}\right)$ with stabilization rates between $20 \%$ and $40 \%$ (Kroll et al., 2002; Rickard et al., 1999).

However, the influence of excess cyclohexane added as $\mathrm{OH}$ radical scavenger on SOA mass described in Sect. 3.2 indicates also a contribution of radical chemistry to SOA formation, in addition to the chemistry of stabilized CI. The increase of SOA mass for the symmetric hydrocarbon alkenes trans-3-hexene and 2,3-dimethyl-2-butene in the presence of excess cyclohexane observed in our present work agrees with similar tendencies of formed SOA mass from $\beta$-pinene reported by Docherty and Ziemann (2003). Small vinyl ethers investigated in our previous work (Sadezky et al., 2006) and cyclohexene studied by Keywood et al. (2004), however, follow the opposite trend. Keywood et al. (2004) and Docherty and Ziemann (2003) explain the influence of cyclohexane as an $\mathrm{OH}$ radical scavenger by a decrease of the ratio [hydroperoxy radicals]/[organic peroxy radicals] in the reaction system, which, according to Keywood et al. (2004), especially affects the production pathways and chemistry of acyl radicals considered as key species in the formation of low-volatile compounds during cyclohexene and $\beta$-pinene ozonolysis. However, for the alkenes and enol ethers studied in our present and previous work (Sadezky et al., 2006), acyl radicals are not expected to contribute to the formation of high-molecular oligomers by any of their reaction pathways known so far, as discussed before in this section.

The observations in the present work and in our previous study (Sadezky et al., 2006) cannot be explained by any classical reaction mechanisms established so far and must involve some new chemistry. The analogous structures and elemental compositions of oligomers originating from the different alkenes and enol ethers point towards a common oligomer formation mechanism in the gas phase. The oligomer structure (Fig. 7b) resembles to those identified from liquid-phase ozonolysis by Barton et al. (2004) and Barton et al. (2005), which are either linear with -OOH or $-\mathrm{OH}$ on both oligomer endings or cyclic without any fragments accounting for other than the repeated chain units. In contrast to the structures described by Barton et al. (2004) and Barton et al. (2005), however, the oligomers identified in our present work do not exclusively consist of CI-like chain units and $-\mathrm{OH}$ and $-\mathrm{OOH}$ groups as chain endings, as the starting group $\mathrm{X}$ obviously comprises a molecule of the initial alkene or enol ether (Fig. 7c).

The obvious key role of stabilized CI in SOA and oligomer formation, in combination with the observed influence of cyclohexane as $\mathrm{OH}$ radical scavenger on SOA yields, points towards a mechanism based on so far unknown CI-radical reactions. We suggest the following formation mechanism displayed in Figure 8, which involves the repeated reaction of peroxy radicals with stabilized CI as oligomer formation process. The reactions starts with the addition of an $\mathrm{OH}$ radical - ubiquitous in any gas-phase alkene ozonolysis reactions - to the double bond of the initial alkene or enol ether. The peroxy radical formed by this reaction then adds to a stabilized CI, thus forming a larger peroxy radical, which then adds to another stabilized CI. The peroxy radical-CI addition is repeated until the oligomerization is ended by reaction of the oligoperoxy radical with $\mathrm{HO}_{2}$. Figure 8 exemplarily shows the formation of the oligomer molecule representing the oligomer parent ion 379 during gas-phase ozonolysis of trans-3-hexene. To our knowledge, a similar addition reaction of a peroxy radical and a stabilized CI in the gas phase has not yet been described in the literature.

\subsection{Copolymerization of chain units from different ozonol- ysis reactions}

In order to investigate the role of the $\mathrm{CI}$ in relation to the role of the initial unsaturated compounds in the formation of oligomers, simultaneous gas-phase ozonolysis of trans-3hexene and EVE was performed in the atmospheric simulation chamber. The MS spectrum of the SOA collected during this experiment is shown in Fig. 9.

Several of the most intense ion peaks are identified as oligomer ions consisting of CI-like chain units. These ion peaks are marked by red and green arrows in Fig. 9. Oligomer ions marked by red arrows are of $m / z$ similar to those of oligomer (a) ions formed during ozonolysis of trans3-hexene solely (Fig. 2b and Table 2). According to our results presented in the Sect. 3.3, these ions might therefore comprise only chain units of mass $74\left(\mathrm{C}_{3} \mathrm{H}_{6} \mathrm{O}_{2}\right)$, with $\mathrm{n}=1$ and $n=2$ for the two most intense ions 305 and 379 in Fig. 9. Oligomer ions marked by green arrows are deduced from ions marked by red arrows by addition of multiples of $\Delta \mathrm{m} / \mathrm{z}$ 46. Thus, these ions eventually contain combinations of both chain units $74\left(\mathrm{C}_{3} \mathrm{H}_{6} \mathrm{O}_{2}\right)$ and $46\left(\mathrm{CH}_{2} \mathrm{O}_{2}\right)$. The most intense ions of this type are of $m / z 351(\mathrm{~m} / \mathrm{z}, 351=\mathrm{m} / \mathrm{z} 305+\Delta \mathrm{m} / \mathrm{z}$ 46), $m / z 397(m / z, 397=m / z \quad 305+2 \times \Delta m / z \quad 46)$, and $m / z 425$ $(m / z$ 425 $=m / z$ 379+ $m / z$ 46) (Fig. 9). Some ions between $\mathrm{m} / z \quad 150$ and 300 are identified from MS/MS experiments as fragment ions of higher parent ions and are listed separately in Fig. 9.

MS/MS spectra of the pseudomolecular ions 305 (marked by a red arrow in Fig. 9) and 351 (marked by a green arrow in Fig. 9) are exemplarily given in Fig. 10a and b, and the observed main fragmentation pathways of these two parent 
ions are schematically displayed in Figs. 11a and b. The MS/MS spectrum of the parent ion 305 (Figs. 10a and 11a) confirms that its structure is indeed similar to those of the type (a) oligomer ions formed during gas-phase ozonolysis of trans-3-hexene solely, which are described in Sect. 3.3 of this work. Its fragmentation pathways are identical to those of its higher homologue 379 observed from ozonolysis of trans-3hexene solely (Fig. 4a), and show the presence of one chain unit $74\left(\mathrm{C}_{3} \mathrm{H}_{6} \mathrm{O}_{2}\right)$, as expected (Fig. $2 \mathrm{~b}$ and Table 2).

The MS/MS spectrum of the parent ion 351 (Figs. 10b and 11b) reproduces the fragmentation pathways observed for the parent ion 305 (Figs. 10a and 11a), but includes an additional loss of a neutral of mass 46 . This result shows that the parent ion 351, and more generally all pseudomolecular ions marked by green arrows in Fig. 9, correspond to ions initially formed from ozonolysis of trans-3-hexene (marked by red arrows in Fig. 9) that contain additional chain units of mass 46.

The formation of such ions signifies that copolymerization of the two CI-like chain units $74\left(\mathrm{C}_{3} \mathrm{H}_{6} \mathrm{O}_{2}, \mathrm{C}_{3}\right.$-CI from trans-3-hexene) and $46\left(\mathrm{CH}_{2} \mathrm{O}_{2}, \mathrm{C}_{1}\right.$-CI from EVE) takes place. The two chain units arise from $\mathrm{CI}$ that are simultaneously present in the reaction system, but are formed independently during gas-phase ozonolysis of trans-3-hexene and EVE. The observed copolymerization of the two chain units under these experimental conditions indicates that oligomer formation might be based on reactions of the free CI itself after complete dissociation of the primary ozonide.

Copolymerization of CI-like chain units formed from different alkenes was also observed by Barton et al. (2005) for the simultaneous ozonolysis of 2,3-dimethyl-2-butene and 3methyl-2-pentene in the liquid phase. The authors identified a variety of oligomeric molecules, which follow similar structural principles as those obtained by separate ozonolysis of each alkene (see Sect. 3.3.6.), but contain a mixture of the chain units formed by both unsaturated compounds, that is, acetone carbonyl oxide (iso- $\mathrm{C}_{3}-\mathrm{CI},\left(\mathrm{CH}_{3}\right)_{2} \mathrm{COO}$ ) from 2,3-dimethyl-2-butene, and butanone carbonyl oxide $\left(\mathrm{C}_{4}\right.$ - $\mathrm{CI}$, $\mathrm{C}_{3} \mathrm{H}_{7} \mathrm{CHOO}$ ) and acetaldehyde from 3-methyl-2-pentene.

\section{Conclusions}

In the present work, we investigate secondary organic aerosol (SOA) formation during gas phase ozonolysis of an enol ether, ethyl butenyl ether (EBE), and three symmetric alkenes, trans-3-hexene, trans-4-octene, and 2,3-dimethyl2-butene. Chemical analysis of the formed SOA is performed employing the ESI(+)/TOF MS and MS/MS, and the accurate ESI(+)/FTICR MS and MS/MS technique. These techniques allow to identify and thoroughly characterize oligomeric products in the mass range 200 to $800 \mathrm{u}$ as main constituents of the SOA for all alkenes and the enol ether studied.
Similar oligomers in SOA formed by gas phase ozonolysis of small unsaturated compounds have been identified for the first time for a series of small alkyl vinyl ethers (AVE) and ethyl propenyl ether (EPE) in our previous study (Sadezky et al., 2006). The results of our present work corroborate our findings of Sadezky et al. (2006), in particular the essential role of Criegee Intermediates (CI), initially formed in the gas-phase, in oligomer and SOA formation: oligomer chain units are shown to systematically have the same chemical composition as the respective main Criegee Intermediate (CI) formed by the gas-phase ozonolysis reaction. Fragmentation spectra (MS/MS) of oligomer pseudomolecular ions and the elemental compositions of parent ions, fragment ions and fragmented neutrals determined by $\operatorname{ESI}(+) / F T I C R$ allow to derive detailed structures for the oligomer molecules. These molecular structures are analogous among all oligomers formed from ozonolysis of different alkenes and enol ethers, and therefore indicate a common formation mechanism.

We suggested in our previous study (Sadezky et al., 2006) that $\mathrm{CI}$ in their stabilized form undergo oligomerization in the gas-phase according to a new, so far unknown reaction mechanism that leads to the formation of oligoperoxidic chains. In our present work, we show that our observations by Sadezky et al. (2006) are not limited to enol ethers, but analogously apply to a variety of short-chain hydrocarbon alkenes. Based on the molecular structures attributed to the oligomers in our work, we suggest that their formation occurs by a new gas-phase reaction mechanism, which has not been described in the literature so far: the repeated addition of stabilized CI to organic peroxy radicals. For the oligomers identified in our work, oligomerization might start with a large organic peroxy radical formed through addition of an $\mathrm{OH}$ radical to the original alkene or enol ether. In the light of these results, we propose oligoperoxide formation as a new, general reaction pathway of stabilized CI in the gas phase.

Moreover, we report an example for copolymerization of different CI independently produced during simultaneous gas-phase ozonolysis of two different unsaturated compounds, leading to the formation of oligomers with mixed CI-like chain units. These observations further point towards a direct participation of free $\mathrm{CI}$ in the oligomerization mechanism, which is independent of their formation process from the original unsaturated compound.

The smallest unsaturated organic compound shown to produce SOA during its gas-phase ozonolysis under atmospheric conditions is methyl vinyl ether (MVE) with three carbon atoms (Klotz et al., 2004). Before, it was widely accepted in the literature, that seven or more $\mathrm{C}$ atoms are required from non-cyclic unsaturated hydrocarbons, six for cyclic unsaturated species to initiate SOA formation from ozonolysis (Seinfeld and Pankow, 2003). The classical reaction pathways of gas-phase ozonolysis established for such large compounds, which lead to low-volatile products identified 
as SOA constituents, however, cannot explain SOA formation from small and structurally simple unsaturated reactants, such as MVE.

While Klotz et al. (2004) could not give any clues about the chemical composition and formation mechanism of the SOA formed from ozonolysis of methyl vinyl ether (MVE), the oligomeric compounds newly discovered and characterized in our previous work (Sadezky et al., 2006) as reaction products of gas-phase ozonolysis of several similar enol ethers containing five to seven carbon atoms, provided a sound explanation. By the identification of analogous oligomeric SOA constituents for the compounds studied in our present work, we show that formation of such oligomers occurs for a wider range of small oxygenated as well as hydrocarbon alkenes.

The high-molecular oligoperoxides formed by the new mechanism in the gas phase might then initiate nucleation, and thus lead to the observed formation of new SOA particles. We therefore suggest that the reported oligoperoxide formation involving the reaction of stabilized $\mathrm{CI}$ and peroxy radicals represents an alternative way to SOA formation especially for gas-phase ozonolysis of unsaturated compounds with few carbon atoms and simple structures.

According to Klotz et al. (2004), new SOA particle formation from methyl vinyl ether (MVE) occurs only during its gas-phase ozonolysis, but not by its reactions with $\mathrm{OH}$ or $\mathrm{NO}_{3}$ radicals, the two other major pathways of atmospheric degradation. This observation further supports the key role of the CI in SOA formation as an intermediate species specific to ozonolysis. In the troposphere, stabilized CI are expected to mainly react with water vapour, a reaction that has been shown to be in direct concurrence with oligomer and new SOA particle formation during the ozonolysis of enol ethers (Sadezky et al., 2006; Sadezky, 2005). The relevance of the described oligoperoxide formation for SOA formation in the atmosphere has therefore to be further investigated.

Acknowledgements. The study was financially supported by the European Science Foundation (ESF) through a grant for a researcher's visit within the INTROP exchange program.

We would like to thank Referee 1 for suggesting new elemental compositions based on $\mathrm{Na}^{+}$adducts for the oligomer parent and fragment ions in his review. Our experiments carried out with the FTICR MS instrument at the University of Giessen have finally proven the correctness of these $\mathrm{Na}^{+}$adducts.

Edited by: T. Hoffmann

\section{References}

Altieri, K. E., Carlton, A. G., Lim, H.-J., Turpin, B. J., and Seitzinger, S. P.: Evidence for oligomer formation in clouds: Reactions of isoprene oxidation products, Environ. Sci. Technol., 40, 4956-4960, 2006.
Barton, M., Ebdon, J. R., Foster, A. B., and Rimmer, S.: Ozonolysis of tetramethylethylene: Characterization of cyclic and openchain oligoperoxidic products, J. Org. Chem., 69, 6967-6973, 2004.

Barton, M., Ebdon, J. R., Foster, A. B., and Rimmer, S.: Complete ozonolysis of alkyl substituted ethenes at $-60^{\circ} \mathrm{C}$ : Distributions of ozonide and oligomeric products, Org. Biomol. Chem., 3, 13231329, 2005.

Bunnelle, W. H.: Preparation, properties, and reactions of carbonyl oxides, Chem. Rev., 91, 335-362, 1991.

Calvert J. G., Atkinson R., Kerr J. A., Madronich S., Moortgat G. K., Wallington T. J., and Yarwood G.: The mechanisms of atmospheric oxidation of the alkenes, Oxford University Press, 2000.

Chen, R., Tseng, A. M., Uhing, M., and Li, L.: Application of an integrated Matrix-Assisted Laser Desorption/Ionization Time-ofFlight, Electrospray Ionization Mass Spectrometry and Tandem Mass Spectrometry approach to characterizing complex polyol mixtures, J. Am. Soc. Mass Spectrom., 12, 55-60, 2001.

Docherty, K. S. and Ziemann, P. J.: Effects of stabilized Criegee Intermediate and $\mathrm{OH}$ radical scavengers on aerosol formation from reactions of $\beta$-pinene with $\mathrm{O}_{3}$, Aerosol Sci. Technol., 37, 877891, 2003.

Docherty, K. S., Wu, W., Lim, Y. B., and Ziemann, P. J.: Contributions of organic peroxides to secondary aerosol formed from reactions of monoterpenes with $\mathrm{O}_{3}$, Environ. Sci. Technol., 39, 4049-4059, 2005.

Dreyfus, M. A., Tolocka, M. P., Dodds, S. M., Dykins, J., and Johnston, M. V.: Cholesterol ozonolysis: Kinetics, mechanism and oligomer products, J. Phys. Chem. A, 109, 6242-6248, 2005.

Finlayson, B. J., Pitts, J. N., and Akimoto, H.: Production of vibrationnally excited $\mathrm{OH}$ in chemiluminescent ozone-olefin reactions, Chem. Phys. Lett., 12, 495-498, 1972.

Fuzzi, S., Andreae, M. O., Huebert, B. J., Kulmala, M., Bond, T. C., Boy, M., Doherty, S. J., Guenther, A., Kanakidou, M., Kawamura, K., Kerminen, V.-M., Lohmann, U., Russell, L. M., and Pöschl, U.: Critical assessment of the current state of scientific knowledge, terminology, and research needs concerning the role of organic aerosols in the atmosphere, climate, and global change, Atmos. Chem. Phys., 6, 2017-2038, 2006, http://www.atmos-chem-phys.net/6/2017/2006/.

Gao, S., Nga, L. N., Keywood, M., Varutbangkul, V., Bahreini, R., Nenes, A., He, J., Yoo, K. Y., Beauchamp, J. L., Hodyss, R. P., Flagan, R. C., and Seinfeld, J. H.: Particle phase acidity and oligomer formation in secondary organic aerosol, Environ. Sci. Technol., 38, 6582-6589, 2004.

Gross, D. S., Gälli, M. E., Kalberer, M., Prevot, A. S. H., Dommen, J., Alfarra, M. R., Duplissy, J., Gaeggeler, K., Gascho, A., Metzger, A., and Baltensperger, U.: Real-time measurement of oligomeric species in secondary organic aerosol with the aerosol time-of-flight mass spectrometer, Anal. Chem., 78, 2130-2137, 2006.

Guzman, M. I., Colussi, A. J., and Hoffmann, M. R.: Photoinduced oligomerization of aqueous pyruvic acid, J. Phys. Chem. A, 110, 3619-3626, 2006.

Hamilton, J. F., Lewis, A. C., Reynolds, J. C., Carpenter, L. J., and Lubben, A.: Investigating the composition of organic aerosol resulting from cyclohexene ozonolysis: Low molecular weight and heterogeneous reactions products, Atmos. Chem. Phys., 6, 49734984, 2006, 
http://www.atmos-chem-phys.net/6/4973/2006/.

Horie, O., Neeb, P., and Moortgat, G. K.: The reactions of the criegee-intermediate $\mathrm{CH}_{3} \mathrm{CHOO}$ in the gas-phase ozonolysis of 2-butene isomers, Int. J. Chem. Kin., 29, 461-468, 1997.

Kalberer, M., Paulsen, D., Sax, M., Steinbacher, M., Dommen, J., Prevot, A. S. H., Fisseha, R., Weingartner, E., Frankevich, V., Zenobi, R., and Baltensperger, U.: Identification of polymers as major components of atmospheric organic aerosols, Science, 303, 1659-1662, 2004.

Kanakidou, M., Seinfeld, J. H., Pandis, S. N., Barnes, I., Dentener, F. J., Facchini, M. C., van Dingenen, R., Ervens, B., Nenes, A., Nielsen, C. J., Swietlicki, E., Putaud, J. P., Balkanski, Y., Fuzzi, S., Hjorth, J., Moortgat, G. K., Winterhalter, R., Myhre, C. E. L., Tsigaridis, K., Vignati, E., Stephanou, E. G., and Wilson, J.: Organic aerosol and global climate modelling: A review, Atmos. Chem. Phys., 5, 1053-1123, 2005,

http://www.atmos-chem-phys.net/5/1053/2005/.

Keul, H., Choi, H. S., and Kuczkowski, R. L.: Ozonolysis of enol ethers. Formation of 3-alkoxy-1,2-dioxolanes by concerted addition of a carbonyl oxide to an enol ether, J. Org. Chem., 50, 3365-3371, 1985.

Keywood, M. D., Kroll, J. H., Varutbangkul, V., Bahreini, R., Flagan, R. C., and Seinfeld, J. H.: Secondary organic aerosol formation from cyclohexene ozonolysis: Effect of $\mathrm{OH}$ scavenger and the role of radical chemistry, Environ. Sci. Technol., 38, 33433350, 2004.

Klotz, B., Barnes, I., and Imamura, T.: Product study of the gasphase reactions of $\mathrm{O}_{3}, \mathrm{OH}$ and $\mathrm{NO}_{3}$ radicals with methyl vinyl ether, Phys. Chem. Chem. Phys., 6, 1725-1734, 2004.

Koch, S., Winterhalter, R., Uherek, E., Kolloff, A., Neeb, P., and Moortgat, G. K.: Formation of new particles in the gas-phase ozonolysis of monoterpenes, Atmos. Environ., 34, 4031-4042, 2000.

Kroll, J. H., Donahue, N. M., Cee, V. J., Demerjian, K. L., and Anderson, J. G.: Gas-phase ozonolysis of alkenes: Formation of OH from anti carbonyl oxides, J. Am. Chem. Soc., 124, 85188519, 2002.

Lockley, J. E., Ebdon, J. R., Rimmer, S., and Tabner, B. J.: Polymerization of methyl methacrylate initiated by ozonates of tetramethylethene, Polymer, 42, 1797-1807, 2001.

March, J.: Advanced organic chemistry: reactions, mechanisms, and structure (fourth edition), John Wiley \& Sons, Inc., 1992.

Mochida, M., Katrib, Y., Jayne, J. T., Worsnop, D. R., and Martin, S. T.: The relative importance of competing pathways for the formation of high-molecular-weight peroxides in the ozonolysis of organic aerosol particles, Atmos. Chem. Phys., 6, 4851-4866, 2006 , http://www.atmos-chem-phys.net/6/4851/2006/.

Murphy, S. M., Sorooshian, A., Kroll, J. H., Ng, N. L., Chabra, P., Tong, C., Surratt, J. D., Knipping, E., Flagan, R. C., and Seinfeld, J. H.: Secondary aerosol formation from atmospheric reactions of aliphatic amines, Atmos. Chem. Phys., 7, 2313-2337, 2007, http://www.atmos-chem-phys.net/7/2313/2007/.

Neeb, P., Horie, O., and Moortgat, G. K.: Formation of secondary ozonides in the gas-phase ozonolysis of simple alkenes, Tetrahedron Lett., 37, 9297-9300, 1996.

Neeb, P., Sauer, F., Horie, O., and Moortgat, G. K.: Formation of hydroxymethyl hydroperoxide and formic acid in alkene ozonolysis in the presence of water vapour, Atmos. Environ., 31, 1417-
1423, 1997.

Neeb, P., Horie, O., and Moortgat, G. K.: The ethene-ozone reaction in the gas phase, J. Phys. Chem. A, 102, 6778-6785, 1998.

Pöschl, U.: Atmospheric aerosols: Composition, transformation, climate and health effects, Angew. Chem. Int. Ed., 44, 7520 7540, 2005.

Reinhardt, A., Emmenegger, C., Gerrits, B., Panse, C., Dommen, J., Baltensperger, U., Zenobi, R., and Kalberer, M.: Ultrahigh mass resolution and accurate mass measurements as a tool to characterize oligomers in secondary organic aerosols, Anal. Chem., 79, 4074-4082, 2007.

Reynolds, J. C., Last, D. J., McGillen, M., Nijs, A., Horn, A. B., Percival, C., Carpenter, L. J., and Lewis, A. C.: Structural analysis of oligomeric molecules formed from the reaction products of oleic acid ozonolysis, Environ. Sci. Technol., 40, 6674-6681, 2006.

Rickard, A. R., Johnson, D., McGill, C. D., and Marston, G.: OH yields in the gas-phase reactions of ozone with alkenes, J. Phys. Chem. A, 103, 7656-7664, 1999.

Römpp, A., Taban, I. M., Mihalca, R., Duursma, M. C, Mize, T. H., McDonnell, L. A., and Heeren, R. M. A., Examples of Fourier transform ion cyclotron resonance mass spectrometry developments: from ion physics to remote access biochemical mass spectrometry, Eur. J. Mass. Spectrom., 11, 443-456, 2005.

Sadezky A.: Ozonolyse d'éthers insaturés: Etudes des mécanismes en phase gazeuse et de la formation d'aérosol organique secondaire, PhD Thesis, University of Orleans, 2005.

Sadezky, A., Chaimbault, P., Mellouki, A., Römpp, A., Winterhalter, R., Moortgat, G. K., and Le Bras, G.: Formation of secondary organic aerosol and oligomers from the ozonolysis of enol ethers, Atmos. Chem. Phys., 6, 5009-5024, 2006, http://www.atmos-chem-phys.net/6/5009/2006/.

Seinfeld J. H. and Pandis S. N., Atmospheric chemistry and physics: From air pollution to climate change, John Wiley \& Sons Inc., New York, p. 738, 1998.

Seinfeld, J. H. and Pankow, J. F.: Organic atmospheric particular material, Annu. Rev. Phys. Chem., 54, 121-140, 2003.

Surratt, J. D., Murphy, S. M., Kroll, J. H., Nga, L. N., Hildebrandt, L., Sorooshian, A., Szmigielski, R., Vermeylen, R., Maenhaut, W., Claeys, M., Flagan, R. C., and Seinfeld, J. H.: Chemical composition of secondary organic aerosol formed from the photooxidation of isoprene, J. Phys. Chem. A, 110, 9665-9690, 2006.

Tobias, H. J., Docherty, K. S., Beving, D. E., and Ziemann, P. J.: Effect of relative humidity on the chemical composition of secondary organic aerosol formed from reactions of 1-tetradecene and $\mathrm{O}_{3}$, Environ. Sci. Technol., 34, 2116-2125, 2000.

Tobias, H. J. and Ziemann, P. J.: Thermal desorption mass spectrometric analysis of organic aerosol from reactions of 1tetradecene and $\mathrm{O}_{3}$ in the presence of alcohols and carboxylic acids, Environ. Sci. Technol., 34, 2105-2115, 2000.

Tolocka, M. P., Jang, M., Ginter, J. M., Cox, F. J., Kamens, R. M., and Johnston, M. V.: Formation of oligomers in secondary organic aerosol, Environ. Sci. Technol., 38, 1428-1434, 2004.

Tolocka, M. P., Heaton, K. J., Dreyfus, M. A., Wang, S., Zordan, C. A., Saul, T. D., and Johnston, M. V.: Chemistry of particle inception and growth during $\alpha$-pinene ozonolysis, Environ. Sci. Technol., 40, 1843-1848, 2006.

Zahardis, J., LaFranchi, B. W., and Petrucci, G. A.: Photoelec- 
tron resonance capture ionization-aerosol mass spectrometry of the ozonolysis products of oleic acid particles: Direct measure of higher molecular weight oxygenates, J. Geophys. Res., 110, D08307, doi:10.1029/2004JD005336, 2005.

Zahardis, J., LaFranchi, B. W., and Petrucci, G. A.: Direct observation of polymerization in the oleic acid-ozone heterogeneous reaction system by photoelectron resonance capture ionization aerosol mass spectrometry, Atmos. Environ., 40, 1661-1670, 2006.

Zahardis, J. and Petrucci, G. A.: The oleic acid-ozone heterogeneous reaction system: Products, kinetics, secondary chemistry, and atmospheric implications of a model system - a review, Atmos. Chem. Phys., 7, 1237-1274, 2007,

http://www.atmos-chem-phys.net/7/1237/2007/.
Ziemann, P. J.: Evidence for low-volatility diacyl peroxides as a nucleating agent and major component of aerosol formed from reactions of $\mathrm{O}_{3}$ with cyclohexene and homologous compounds, J. Phys. Chem. A, 106, 4390-4402, 2002.

Ziemann, P. J.: Formation of alkoxyhydroperoxy aldehydes and cyclic peroxyhemiacetals from reactions of cyclic alkenes with $\mathrm{O}_{3}$ in the presence of alcohols, J. Phys. Chem. A, 107, 20482060, 2003. 